\title{
"A descriptive study of New Zealand midwives' primary care management of iron status in pregnancy and the postpartum period"
}

\author{
by \\ Esther Calje \\ A thesis submitted to the Victoria University of Wellington \\ in fulfilment of the requirements for the degree of \\ Master of Midwifery
}

VICTORIA UNIVERSITY OF WELLINGTON

2016 
This page is intentionally left blank

Page ii 


\section{Abstract}

Background: Globally there is no consensus on haemoglobin $(\mathrm{Hb})$ parameters that define maternal anaemia. Therefore it is difficult to distinguish physiological anaemia of pregnancy from anaemia associated with pathology. Low maternal iron status is associated with adverse outcomes, although the evidence is difficult to interpret. Non-anaemic iron deficiency requires prevention and treatment, before end stage iron deficiency anaemia. Increases in serum ferritin (SF) secondary to inflammation, gives misleading results of iron stores if not tested with C-reactive protein (CRP). Given the complexities, how do Lead Maternity Carer (LMC) midwives in New Zealand manage anaemia and iron deficiency, without a clinical guideline?

Methods: In this descriptive study, quantitative data was retrospectively collected from September-December 2013, from LMC midwives ( $n=21)$ and women ( $n=189$ ), in one New Zealand area. Main outcomes assessed were women's iron status. Anaemia was defined as $\mathrm{Hb}<110 \mathrm{~g} / \mathrm{L}$ in the first trimester, $<105 \mathrm{~g} / \mathrm{L}$ in subsequent trimesters, and $<100 \mathrm{~g} / \mathrm{L}$ postnatally. Iron deficiency was defined as SF $<20 \mu \mathrm{g} / \mathrm{L}$, if $\mathrm{CRP}<5 \mathrm{mg} / \mathrm{L}$. A secondary analysis of iron status and body mass index (BMI) was undertaken.

Results: Of the 186 women who had $\mathrm{Hb}$ testing at booking, $46 \%$ did not have ferritin tested concurrently. Of the 385 ferritin tests undertaken, $86 \%$ were not tested with CRP. Despite midwives prescribing iron for $48.7 \%$, and recommending iron for $16.9 \%$ of second trimester women, $47.1 \%$ had low iron status before birth. Only $22.8 \%$ had $\mathrm{Hb}$ testing postpartum, including $65.1 \%$ (of 38 ) with blood loss $>500 \mathrm{mls}$. Results of a secondary analysis showed a significant difference $(p=.05)$ between third trimester ferritin levels in women with BMI $\geq 25$ (Md SF $14 \mu \mathrm{g} / \mathrm{L}$ ) and BMI $<25$ (Md SF $18 \mu \mathrm{g} / \mathrm{L}$ ).

Conclusions: Inconsistent testing of ferritin made it difficult to assess maternal iron status, especially without concurrent testing of CRP. Midwives may not understand and recognise the progression from iron sufficiency to end-stage iron deficiency anaemia. Even without further research this small study may indicate the need for improved education for midwives, and a clinical guideline. More complex studies on the prevalence in New Zealand, BMI and iron status, and maternal outcomes especially in the postpartum period, are warranted. 


\section{Table of Contents}

ABSTRACT ................................................................................................................ III

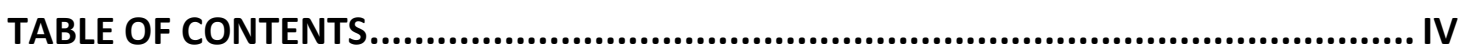

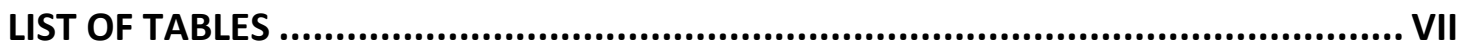

GLOSSARY OF TERMS .............................................................................. VII

CHAPTER ONE: INTRODUCTION AND BACKGROUND ............................................. 1

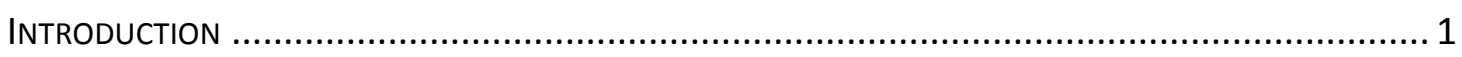

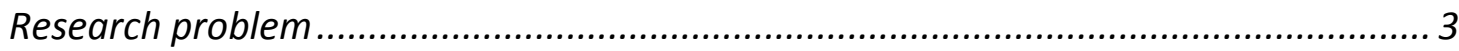

The research question, aims and objectives........................................................ 4

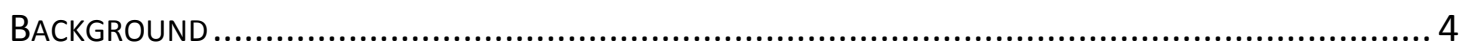

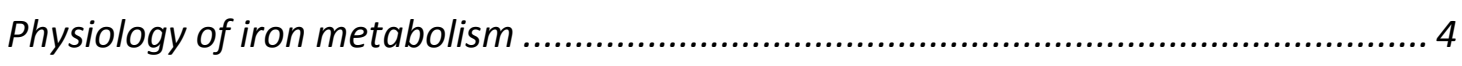

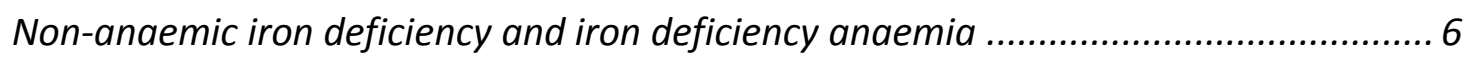

Iron requirements in pregnancy and postpartum .................................................... 7

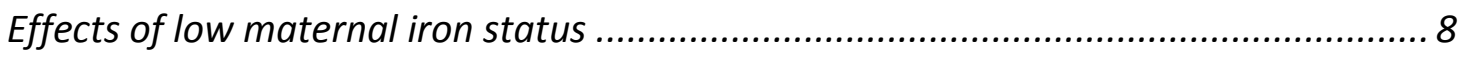

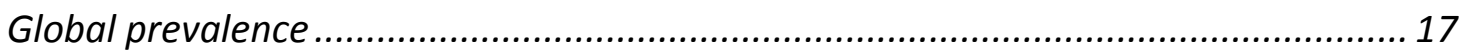

Maternal anaemia and iron deficiency in New Zealand .......................................... 18

Evidence based midwifery, midwifery research, midwifery guideline development ... 20

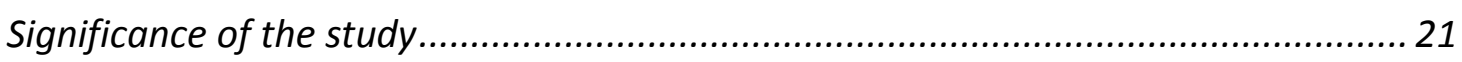

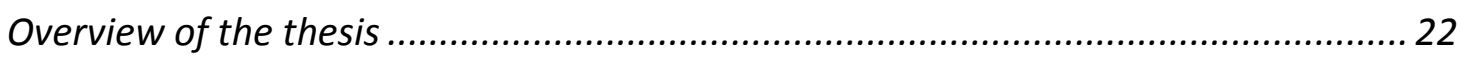

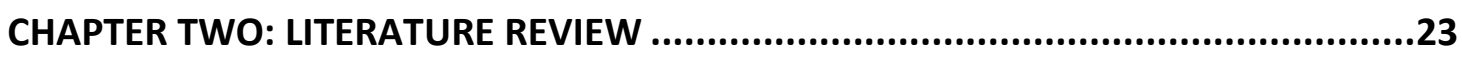

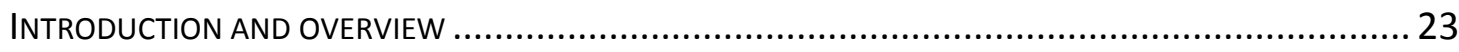

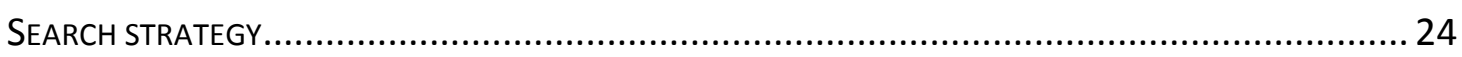

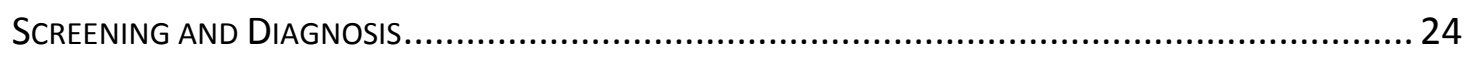

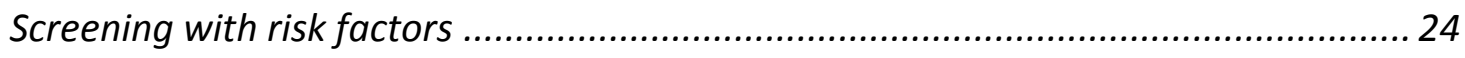

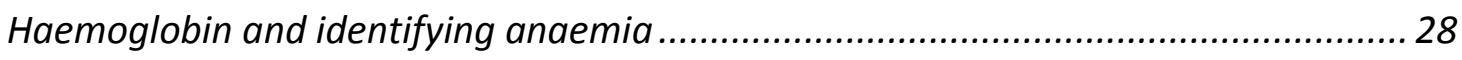

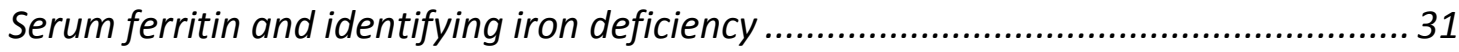

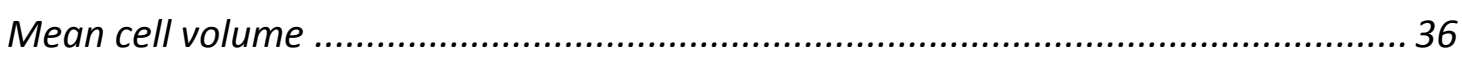

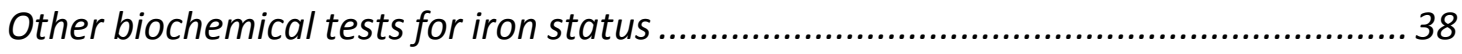

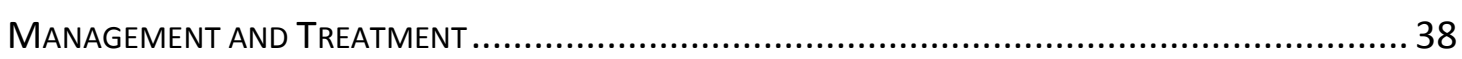

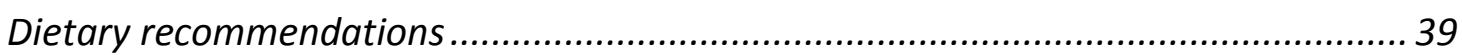

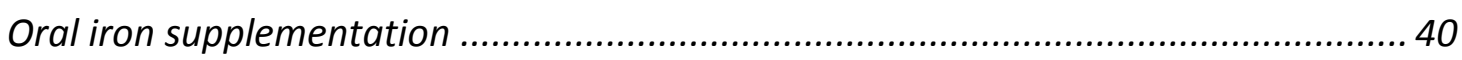

Postpartum anaemia, blood transfusion and intravenous iron .................................... 43

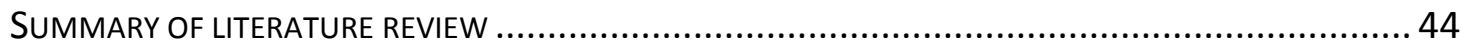

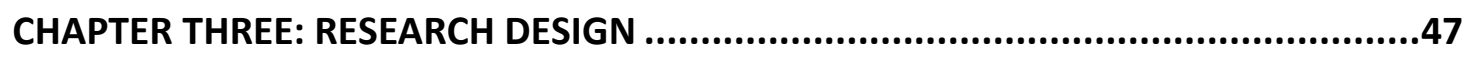

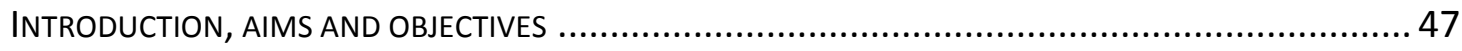

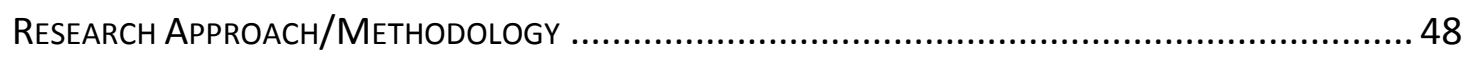

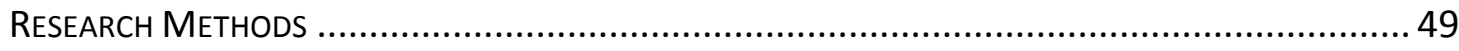


Setting.

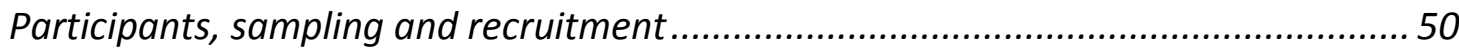

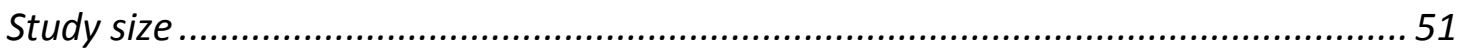

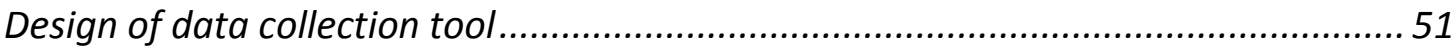

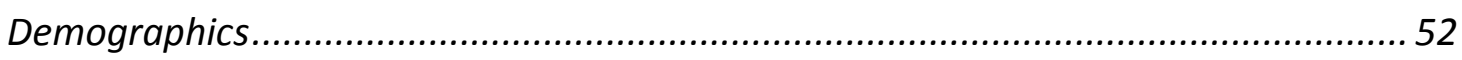

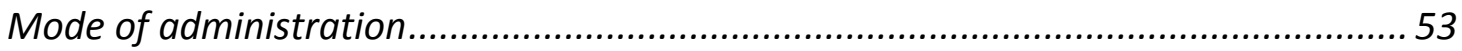

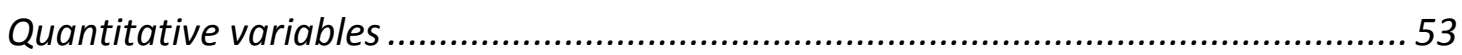

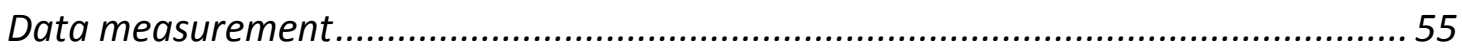

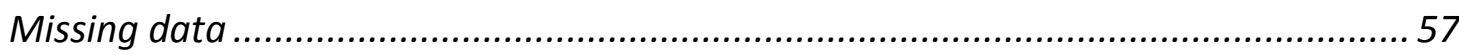

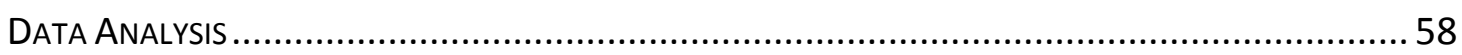

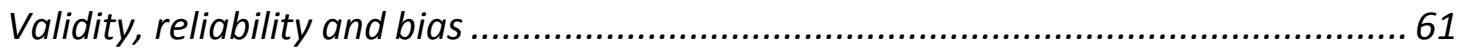

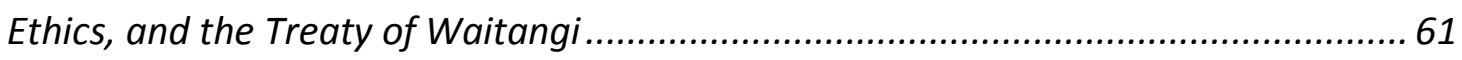

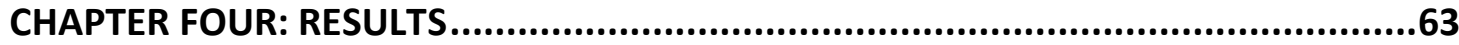

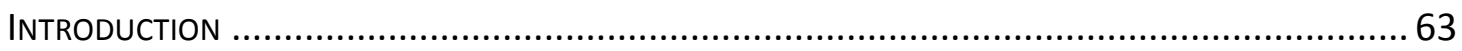

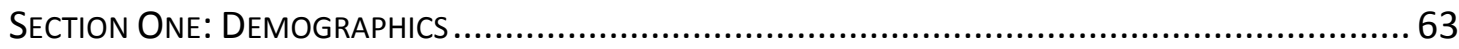

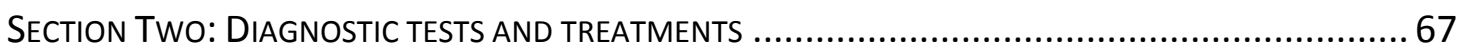

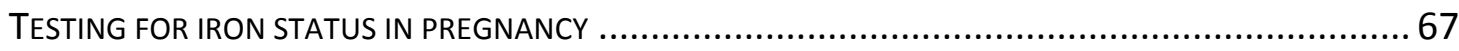

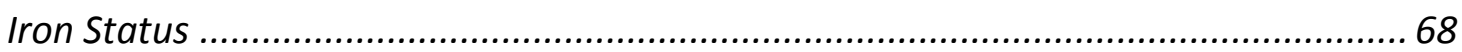

ANTENATAL PREVENTION AND TREATMENT OF ANAEMIA AND IRON DEFICIENCY .......................... 71

Midwives' years in practice, caseloads and testing for iron deficiency in pregnancy.. 76

Midwives' years in practice, caseloads and iron supplementation in pregnancy........ 80

Postpartum management of anaemia ........................................................... 84

Midwives' years in practice, caseloads and management of postnatal iron status .... 87

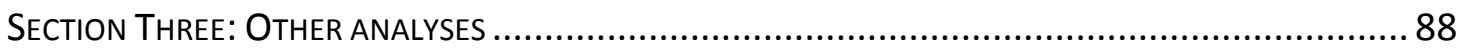

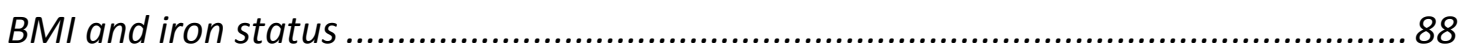

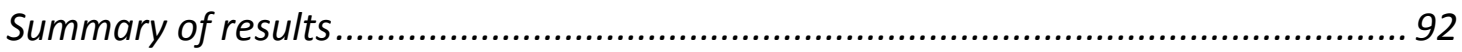

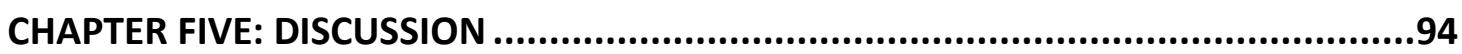

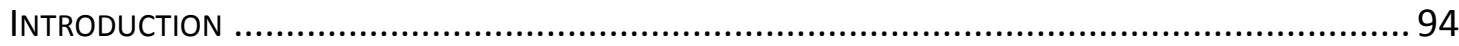

CONSISTENCIES AND INCONSISTENCIES WHEN TESTING FOR IRON STATUS ...................................... 95

LIMITED TESTING AND UNDERSTANDING OF C-REACTIVE PROTEIN ............................................ 97

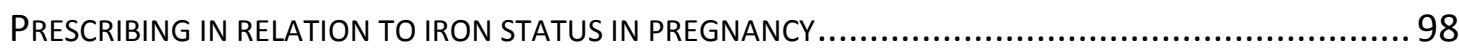

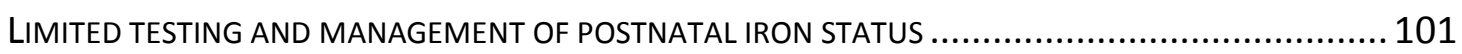

BMI, UNCONFIRMED IRON SUFFICIENCY, AND SUBSEQUENT LOW IRON STATUS .......................... 103

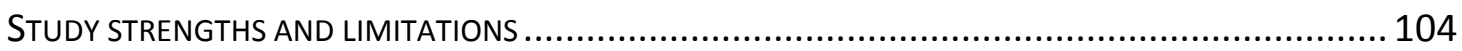

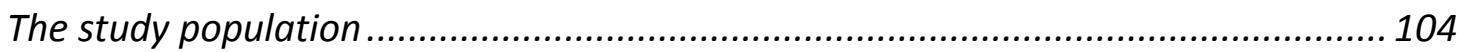

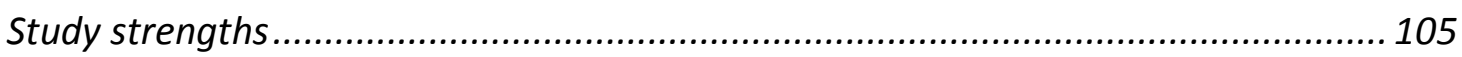

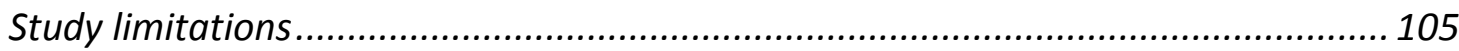

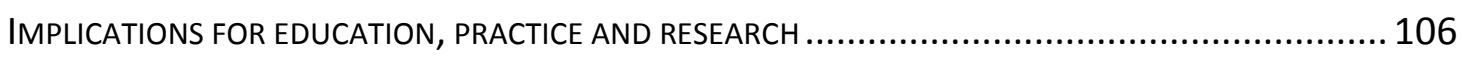

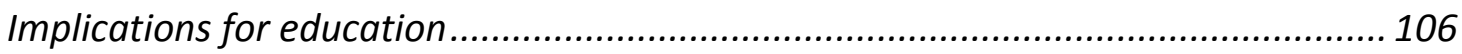

Implications for primary care midwifery practice ................................................ 107 


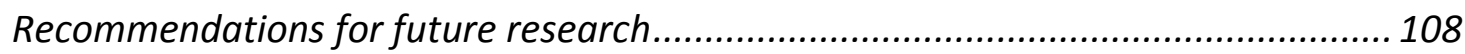

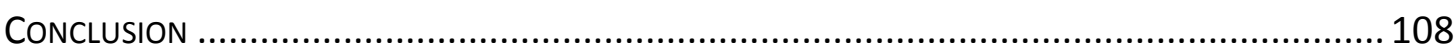

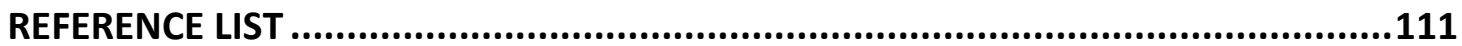

LIST OF APPENDICES ..................................................................................123

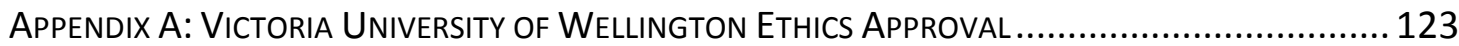

Appendix B: District Health Board Ethics Approval................................................... 123

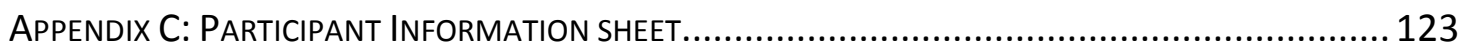

APPENDIX D: LMC MIDWIVES ANTENATAL DECISION TREE: SERUM FERRITIN TESTED IN THE FIRST

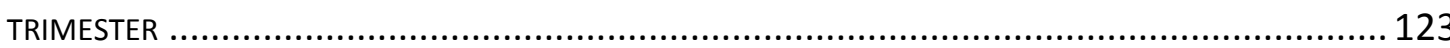

APPENDIX E: LMC MIDWIVES ANTENATAL DECISION TREE: SERUM FERRITIN NOT TESTED IN THE FIRST

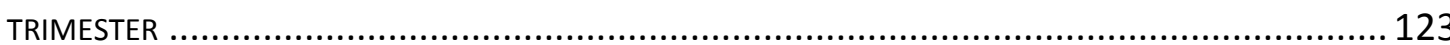

APPENDIX F: LMC MIDWIVES POSTPARTUM DECISION TREE .............................................. 123 


\section{List of Tables}

Table 1: Comparison of guidelines, recommendations, and definitions of anaemia and iron deficiency in pregnancy and postpartum

Table 2*: Overview of interpreting laboratory blood test results to assess iron status

Table 3: Characteristics of Lead Maternity Carer Midwife participants compared with those with a practicing certificate in 2012

Table 4: Characteristics of women in study, compared to birthing population of

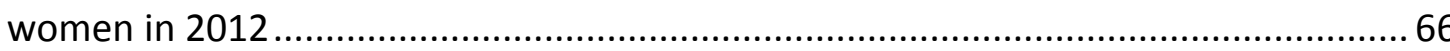

Table 5: Testing for iron status in pregnancy by trimester. .....................................6 67

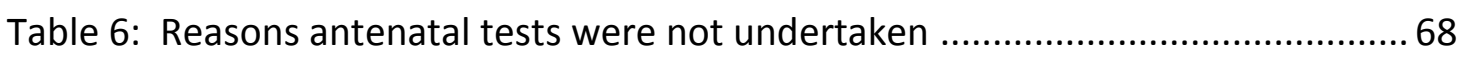

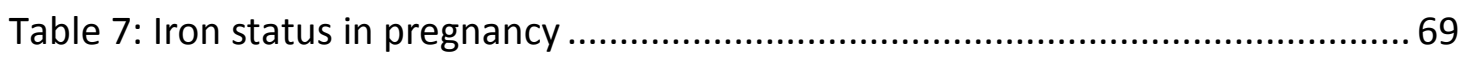

Table 8: Laboratory type and analyses of serum ferritin and C-reactive protein (CRP)

Table 9: Antenatal prevention and treatment of anaemia and iron deficiency 72

Table 10: Comparison of antenatal haemoglobin and serum ferritin when dietary advice offered, over the counter iron recommended or prescribed.....

Table 11: Main documented approach to management of iron status in pregnancy 74

Table 12: Midwives' years in practice and ferritin testing ......................................... 77

Table 13: Midwives' years in practice (regrouped) and ferritin testing....................... 78

Table 14: Midwives' annual caseloads and ferritin testing ........................................ 79

Table 15: Midwives' annual caseload (regrouped) and ferritin testing ...................... 80

Table 16: Midwives' years in practice and management of antenatal iron status...... 81

Table 17: Midwives' years in practice (regrouped) and oral iron prescriptions .......... 82

Table 18: Midwives' annual caseloads and management of antenatal iron status..... 83

Table 19: Midwives' caseload (regrouped) and oral iron prescriptions

Table 20: Late pregnancy iron status, peri-partum blood loss, and management of postnatal anaemia

Table 21: Midwives' years in practice and postpartum management of iron status .. 87

Table 22: Midwives' caseloads and postpartum management of iron status

Table 23: Comparison of Body Mass Index (BMI)* and subsequent iron status of women with serum ferritin $<20 \mu \mathrm{g} / \mathrm{L},<30 \mu \mathrm{g} / \mathrm{L}$, and $<50 \mu \mathrm{g} / \mathrm{L} \mathrm{uncorrected}^{\S}$ for inflammation (no CRP) in the first trimester. 


\section{Glossary of terms}

Absent iron stores: very low or absent iron stores, insufficient for erythropoeisis, i.e. $\mathrm{SF}<12 \mu \mathrm{g} / \mathrm{L}$.

Anaemia: Low haemoglobin levels (defined as: first trimester $\mathrm{Hb}<110 \mathrm{~g} / \mathrm{L}$, second trimester $\mathrm{Hb}<105 \mathrm{~g} / \mathrm{L}$, third trimester $\mathrm{Hb}<105 \mathrm{~g} / \mathrm{L}$, early postpartum $\mathrm{Hb}<100 \mathrm{~g} / \mathrm{L}$ ).

Anaemia of chronic disease (ACD), or anaemia of inflammation: A type of functional iron deficiency where, due to the presence of inflammation, hepcidin decreases iron uptake in the gut and limits the amount of iron available in the body for erythropoeisis.

Body Mass Index (BMI): a measure of body fat based on weight and height in $\mathrm{kg} / \mathrm{m}^{2}$.

Complete blood count (CBC): single test which in New Zealand includes haemoglobin count, white cell count, and RBC indices i.e. $\mathrm{MCV}, \mathrm{MCH}$, and Hct.

C-reactive protein (CRP): acute phase protein and measure of inflammation if CRP $>5 \mathrm{mg} / \mathrm{L}$.

Erythropoeisis: production of red blood cells, in the bone marrow of adults.

Haematocrit (Hct): the number of RBCs packed by centrifuge in a given volume of blood.

Haemoglobin $(\mathbf{H b})$ : the iron containing protein in RBCs that binds to oxygen, for oxygen transport to the tissues.

Haemoglobinopathy (HbP): general term for haemoglobin abnormalities i.e. sickle cell disease and thalassaemia.

Hepcidin: liver hormone and master regulator of iron metabolism.

Iron deficiency (ID): low iron stores (defined as: SF $<20 \mu \mathrm{g} / \mathrm{L}$, or $\mathrm{SF}<50 \mu \mathrm{g} / \mathrm{L}$ if CRP $>5 \mathrm{mg} / \mathrm{L}$ ).

Iron deficiency anaemia (IDA): low iron stores and anaemia.

Iron sufficiency: non-anaemic and non-iron deficient.

KNOV: The Royal Dutch Organisation of Midwives.

Lead Maternity Carer (LMC): primary maternity care provider, chosen by the woman, to provide continuity of care from early pregnancy until 6 weeks after the birth.

Low birth weight (LBW): neonates weighing less than 2500 gms.

Mean cell volume (MCV): size of the red blood cells.

Mean cell haemoglobin ( $\mathrm{MCH})$ : average weight or mass of haemoglobin.

Non-anaemic iron deficiency (NAID): normal haemoglobin, and low or absent iron stores (SF $<20 \mu \mathrm{g} / \mathrm{L}$, or SF $<50 \mu \mathrm{g} / \mathrm{L}$ if CRP $>5 \mathrm{mg} / \mathrm{L}$ ).

Over the counter oral iron (OTC): includes liquid/tablet iron supplements, multivitamins and minerals, and herbal preparations.

Red blood cells (RBCs): or erythrocytes carry oxygen, nutrients and wastes to and from the tissues. 
Serum ferritin (SF): a multifunctional acute-phase protein that measures iron stores, and inflammation.

Sickle cell disease: genetic blood disorder resulting in abnormally shaped red blood cells.

Small for gestational age (SGA): neonate weighing less than the $10^{\text {th }}$ percentile.

Thalassaemia: genetic blood disorder, resulting in mild or severe microcytic anaemia, and possible iron overload. 
This page is intentionally left blank 


\section{Chapter One: Introduction and Background}

\section{Introduction}

There are no national guidelines In New Zealand for the diagnosis and treatment of maternal anaemia, non-anaemic iron deficiency (NAID) and iron deficiency anaemia (IDA). So how do New Zealand midwives, the main providers of primary maternity care, manage low maternal iron status in pregnancy and the postpartum period? This thesis reports on a study that describes a snapshot of New Zealand Lead Maternity Carer (LMC) midwives current practice in the diagnosis and treatment of maternal anaemia and iron deficiency, as little is known about actual practice in this clinical area. The research design used was a retrospective descriptive study, utilising quantitative data on midwives' practice, and haematological and clinical outcomes of women in their care. In addition to contributing to a body of knowledge about maternal anaemia and iron deficiency, from a unique New Zealand midwifery perspective, the main objective of this study was to clarify whether there is a need for a midwifery, or multi-disciplinary guideline, to inform practice and improve care of mothers and babies.

New Zealand's maternity care system is recognised internationally as a unique model that promotes normal birth, by promoting primary midwifery care (Grigg \& Tracy, 2013). The model is based on the partnership between the woman and the midwife. The midwife provides primary care as an autonomous practitioner within her scope of professional practice (Guilliland \& Pairman, 1995). Under section 88 of the New Zealand Public Health and Disability Act 2007 (Ministry of Health (MOH), 2007) women can choose a midwife, general practitioner doctor, or obstetric specialist as their LMC to provide care throughout pregnancy, birth and the postnatal period. In 2012 the majority of women (88.8\%) registered with midwives as their LMCs (MOH, 2015).

The midwifery profession in New Zealand draws on the theory of evidence-based practice as the framework that guides practice. One of the challenges of the theoretical perspective of evidence based practice is closing the gaps between 
knowledge, education and practice (Spiby \& Munro, 2010). However the evidence around maternal anaemia and iron deficiency is surprisingly complicated and contentious.

As primary maternity care providers, New Zealand LMC midwives provide continuity of care from early in pregnancy, to up to six weeks postpartum. LMC midwives assess women's iron status throughout pregnancy, give dietary advice, and prescribe or recommend oral iron treatment options, if indicated. But there are difficulties in diagnosing anaemia and iron deficiency as internationally there is no clear consensus regarding diagnostic criteria. This makes it problematic for midwives to distinguish normal physiological anaemia of pregnancy from anaemia requiring treatment, or anaemia associated with underlying pathology.

Globally, poor maternal iron status has been associated with increased mortality, morbidity and adverse outcomes for mothers, babies and infants. These adverse outcomes are controversial and challenging to evaluate because of the multi-factorial nature of anaemia, and the heterogeneity of studies that make it difficult to pool data for meta-analyses (National Blood Authority (NBA), 2015). There is clear evidence however, that maternal anaemia is associated with a high utilisation of hospital resources and a nine-fold increase in blood transfusion (James et al., 2008). But the overarching question of whether there is evidence that iron supplementation improves outcomes for women and babies remains difficult to elucidate (and beyond the scope of this study), and requires more research (Barroso et al., 2011; Crowther, 2010; Jans, 2012; Wiegerinck \& Mole, 2012).

Although the current study focuses on primary midwifery care, medical research and scientific data have provided most of the evidence on anaemia and iron deficiency. Therefore, the background and literature review are informed by a wide range of disciplines as well as midwifery, including: obstetrics, pharmacology, haematology, neonatology, paediatrics, pathology, nutrition, public health and epidemiology.

To provide a context for this study, the background includes overviews on global prevalence, iron metabolism, and the effects of low maternal iron status. This background is detailed because of the complexity of the essential role of iron; an 
element that is fundamental to life, that affects the development and functioning of every bodily system. It is therefore important to have some understanding of why, and to what extent low maternal iron status is a problem, if we are to diagnose and treat anaemia and iron deficiency. These overviews include what is known about maternal anaemia and iron deficiency in New Zealand, from an evidence-based midwifery perspective.

\section{Research problem}

On the surface, maternal anaemia is "seemingly straightforward", but there are large gaps between evidence and practice (Amelink-Verburg, Herschderfer, Offerhaus \& Buitendijk, 2010, p. 28), and the clinical issues are complex. This study began with the idea of exploring the overarching question of how do midwives in New Zealand distinguish normal physiological anaemia of pregnancy from anaemia requiring treatment, or anaemia associated with pathology? A clear definition of anaemia is fundamental in making this distinction. However the boundaries between physiological and pathological anaemia in pregnancy are not well understood or defined. The Royal Dutch Organisation of Midwives (KNOV) sought to address these issues with the introduction in 2000 of a primary care evidence-based midwifery guideline on anaemia for low risk women (Amelink-Verburg et al., 2010). This guideline is particularly relevant to this study, given the similarities between the New Zealand and the Dutch models of maternity care.

The rationale for the KNOV anaemia guideline was therefore partly motivated by the fact that "there is no global consensus on the definition of anaemia and $\mathrm{Hb}$ cut-off points vary" (Amelink-Verburg et al., 2010, p. 27). The World Health Organisation's (WHO) 1968 definition of anaemia in pregnancy as a haemoglobin ( $\mathrm{Hb})$ of less than $110 \mathrm{~g} / \mathrm{L}$ is the most often cited, although considered statistically flawed (McMahon, 2010) as it does not distinguish differences between races (Pasricha, Drakesmith, Black, Hipgrave \& Biggs, 2013). This limits the applicability of the WHO anaemia definition to the Australasian population (NBA, 2015). 


\section{The research question, aims and objectives}

Without clinical guidance it is unclear how New Zealand primary care midwives actually manage maternal iron status in practice. Therefore the study's research question was: "what is LMC midwives' practice around management of women's $\mathrm{Hb}<110 \mathrm{~g} / \mathrm{L}$ and/or serum ferritin $<20 \mathrm{mcg} / \mathrm{L}$, during pregnancy and postpartum?"

The overall aim of the research was to ascertain whether there may be a need for a consensus statement or guideline for New Zealand midwives, in the diagnosis and treatment of maternal anaemia, NAID and IDA. As well as beginning to address the lack of New Zealand research on maternal iron status, the specific study objectives were:

- To ascertain levels of consistency of New Zealand LMC midwives' testing and diagnosis of maternal anaemia and iron deficiency.

- To describe New Zealand LMC midwives' practice around recommending or prescribing iron supplementation in relation to iron status and gestation.

The exploratory nature of this study contributes to the small body of global midwifery research on maternal iron status, from a unique New Zealand midwifery perspective based on continuity of care (Grigg \& Tracy, 2013).

\section{Background}

\section{Physiology of iron metabolism}

An overview of iron metabolism is an important background to this study. In addition to the traditional understanding of iron metabolism, new knowledge has deepened our understanding of the complexities of how iron is absorbed and used in the body, especially in the presence of inflammation. Understanding the physiology of iron is fundamental if midwives are to accurately diagnose and treat anaemia and iron deficiency, and recognise the factors that affect iron status in pregnancy and postpartum. 
It is well known that the primary function of iron is the synthesis of haemoglobin for transport of oxygen to all the tissues in the body. Iron is also absolutely essential for all cell growth and body systems (Barut \& Harma, 2009), including neural and cognitive development and function in the young and adult brain (Bodnar, Cogswell \& McDonald, 2005; Morton et al., 2014). Iron is also a component of certain enzymes needed for catecholamine neurotransmitter function, and for the production of adenosine tri-phosphate for cell respiration and energy (Jordan, 2010).

Dietary iron is absorbed and eliminated by mucosal cells in the gut wall and transported to plasma where it is bound to the transport protein transferrin. Dietary sources of non-haem ferric iron (found in grains, fruits and vegetables), are converted to ferrous iron, as only ferrous and haem iron are available for absorption (Elias, 2007; Milman, 2006). Haem iron is found in fish, meats and poultry. Iron absorption is physiologically promoted by depleted or absent iron stores, increased erythropoiesis during pregnancy, and by blood loss around the time of birth (Milman 2006). Erythropoiesis is the production of red blood cells (RBCs) in the bone marrow (Rosto, 2009), and is totally dependent on iron.

In the last decade, knowledge of iron metabolism has significantly changed with the discovery of the liver hormone hepcidin; as the master regulator of systemic bioavailabilty of iron in humans (Koenig, Tussing-Humphreys, Day, Cadwell \& Nemeth, 2014). In the presence of acute or chronic infection or inflammation, hepcidin regulates body iron by decreasing iron uptake in the gut, as well as decreasing availability of iron in the body for erythropoiesis (Koenig et al., 2014; Wang, Knovich, Coffman, Torti \& Torti, 2010). This defence mechanism is presumed to have developed to restrict iron's availability for pathogens and micro-organisms to grow (Friedman et al., 2012; Wang et al., 2010).

Approximately $70 \%$ of the body's iron is in haemoglobin, the oxygen carrying substance on RBCs (Rosto, 2009); $3 \%$ is in myoglobin an intramuscular oxygen store (Jordan, 2010). The remainder of iron is predominantly stored within ferritin, in the reticuloendothelial tissue cells in the bone marrow, the liver, spleen and gut (Koenig et al., 2014). This intracellular iron is stored as an iron core within the hollow, 
spherical glycoprotein ferritin molecules (WHO, 2011), that protect the cells from the toxicity of free iron (Milman, 2006). A single iron core within a ferritin molecule may contain up to $4000-4500$ iron atoms (WHO, 2011). When body iron reserves are small, the iron is present in ferritin. With larger iron reserves, ferritin is condensed to haemosiderin which can be visualised in bone marrow biopsy (Wang et al., 2010).

\section{Non-anaemic iron deficiency and iron deficiency anaemia}

Iron deficiency is on the spectrum ranging from iron sufficiency to iron deficiency anaemia (Pavord et al., 2012). From normal body iron stores (iron sufficiency), depletion progresses to deficient, then absent iron stores. An absence of iron stores for erythropoiesis forces haemoglobin (functional iron) to be used up for the limited production of red blood cells, resulting in IDA. Iron deficiency anaemia is therefore, a depletion or absence of iron stores with a low $\mathrm{Hb}$. The decrease in $\mathrm{Hb}$ is preceded by depletion of iron stores, and is the end stage, and most severe form of iron deficiency (Pavord et al., 2012).

In general, anaemia can result from decreased production of RBCs, increased destruction of RBCs, or blood loss (Smith, 2010). During pregnancy, iron deficiency is the most common cause of anaemia (Haider et al., 2013; Pasricha, 2012). However anaemia, NAID and IDA are often multi-factorial and may be difficult to diagnose due to co-existing conditions such as: infections, inflammation, parasitic diseases (e.g. malaria and hookworm), micronutrient deficiencies (e.g. folic acid and vitamin B12), inherited haemoglobinopathies (e.g. thalassaemia and sickle cell disease), gastrointestinal and menstrual blood loss in premenopausal women (Goonewardene, Shehata \& Hamad, 2012; Pasricha et al., 2010). Because of the decreased bioavailability and sequestering of iron, secondary to acute or chronic infections or inflammation, anaemia of inflammation is now recognised as the second most prevalent cause of anaemia, after iron deficiency (Friedman et al, 2012).

Diagnoses of anaemia and IDA are further complicated by the normal physiological changes of pregnancy and haematological values (Jordan, 2010). A greater increase in plasma volume $(40-50 \%)$ compared to the red cell mass increase $(\leq 30 \%)$ results in normal physiological haemodilution and anaemia of pregnancy (Baddock, 2015). 
Normal physiological haemodilution of pregnancy reduces blood viscosity, thereby increasing placental and fetal perfusion and oxygenation, whilst also minimising the risks of stasis and thrombosis (Walsh et al., 2011; Ziaei, Norrozi, Faghihzadeh \& Jafarbegloo, 2007).

Frye (2007) states the normal haemoglobin drop in pregnancy of $20 \mathrm{~g} / \mathrm{L}$ by $28-30$ weeks gestation is an excellent indicator of expanded blood volume, although this drop is not quantified so precisely elsewhere in the literature. Conversely, extreme haemo-concentration with $\mathrm{Hb}>145 \mathrm{~g} / \mathrm{L}$ in early pregnancy, or $\mathrm{Hb}>132 \mathrm{~g} / \mathrm{L}$ mid pregnancy may herald fetal growth restriction, or even demise (Rasmussen, Bergsjo, Jacobsen, Harem \& Bakketeig, 2005; Ziaei et al., 2007). There is considerable individual variation in the degree of haemodilution, with the nadir of haemoglobin estimated to be between 24-28 (Graves \& Barger, 2001) or 24-32 weeks gestation (Milman, 2006).

\section{Iron requirements in pregnancy and postpartum}

Pregnancy, birth and lactation dramatically increase the demand for iron due to the increased demands of the fetoplacental unit and increased maternal red cell mass (Bhandall \& Russell, 2006). Estimates of the total demand throughout pregnancy range from 800-1000mg (Barut \& Harma, 2009) to 1200mg (McMahon, 2010). Requirements for absorbed iron increase through pregnancy from $0.8 \mathrm{mg} /$ day in the first trimester to $7.5 \mathrm{mg} /$ day in the third trimester, an average requirement of $4.4 \mathrm{mg} /$ day (Milman, 2006).

Although iron demands increase, iron absorption also increases from 30\% (James, Steer, Weiner \& Gonik, 2006) to 70 \% (Jordan, 2010), in response to decreasing iron stores. Women with ample iron reserves have less of an increase in iron absorption (Milman 2006). However, few women enter conception with sufficient iron stores to meet the extra iron demands of pregnancy (McMahon, 2010).

The growing fetus receives iron even when the mother is iron deficient (Barut \& Harma, 2009). Fetal iron demands are greatest in the third trimester (McMahon, 2010), when there is a transfer of iron from the mother's iron stores to her baby to 
establish good neonatal iron stores (Monti, 2004). There is strong evidence that delayed cord clamping at birth, also improves neonatal iron status (Andersson, Hellstrom-Westas, Andersson, \& Domellof, 2011).

Blood loss at delivery further exacerbates the demand for iron. Barut and Harma (2009) estimate that $7 \%$ of vaginal deliveries have an estimated blood loss (EBL) of $\geq 1000 \mathrm{mls}$, with $23 \%$ of caesareans associated with an EBL of $1000-1500 \mathrm{ml}$. In the study area, the District Health Board 2014 statistics are lower with 5.9\% of vaginal births, and $9.0 \%$ of caesareans associated with EBL $\geq 1000 \mathrm{mls}$.

In the postpartum period, plasma volume decreases, primarily via diuresis. In the first two months postpartum, a significant amount of iron is returned to body stores from the erythron mass (McMahon, 2010). For postpartum women, breastfeeding removes about $1 \mathrm{gm}$ of iron per day, but this iron demand is partly mitigated by lactational amenorrhoea (Pasricha et al., 2010). These processes result in a substantial rise in haemoglobin levels over this time (James et al., 2006; Friedman et al., 2012).

\section{Effects of low maternal iron status}

Anecdotally, and in the literature, some midwives debate the evidence of adverse effects of low iron status on pregnancy and postpartum, and the benefits of iron supplementation (Amelink-Verburg et al., 2010; Jans, 2012; Graves \& Barger, 2001; Grigg, 2015). Some New Zealand midwives may therefore, be less pro-active in their approach to preventing or managing anaemia, and iron deficiency in pregnancy. Evidence does indicate that the effects of iron deficiency, even without anaemia, causes tissue enzyme malfunction and functional impairment (WHO, 2001). This brings in to focus NAID as an important clinical issue requiring prevention and treatment in pregnancy and postpartum (Goonewardene et al., 2012; Grigg, 2015; Pavord et al., 2012).

A recent UK study (Daru et al., 2015) examined the views and opinions of 148 midwives, obstetricians, anaesthetists and haematologists, on NAID in pregnancy. The study found that all clinicians were interested in testing for NAID as a target 
condition, if proven to be effective at improving maternal and neonatal outcomes. Daru et al.'s (2015) finding highlights an underlying question posed in this study: if it is important to diagnose and treat anaemia and iron deficiency in pregnancy, why is the evidence so difficult to decipher?

At a population and individual level, the causes of anaemia and iron deficiency are often multi-factorial, and associated with other pregnancy risks such as poor nutrition and low socio-economic status (Pasricha et al., 2013; Pavord et al., 2012). It is difficult to clearly establish adverse outcomes related to low iron status due to the heterogeneity of clinical trials on iron interventions. The ranges of the variables studied in clinical trials are heterogenous and very wide, i.e: different haemoglobin and serum ferritin parameters, interventions including different doses and routes of administration, populations, study sizes and outcomes (NBA, 2015). The heterogeneity of randomised clinical trials (RCTs) has, therefore, made the outcomes difficult to pool in meta-analyses such as the Cochrane Collaboration (Dodd, Dare \& Middleton, 2009; Reveiz, Gyte, Cuervo, 2007).

A Cochrane review (Dodd et al., 2009) is also critical of the over-emphasis on haematological indices in studies on maternal iron status, rather than clinical or maternal outcomes. This over-emphasis has resulted in a substantial body of evidence on the positive effects of iron therapy on the so called soft values (i.e. laboratory values), whilst the evidence of effects on hard values, or clinical outcomes is much smaller (Milman, 2012a). The discussion below is an overview of the evidence of specific risks associated with maternal anaemia and iron deficiency. As Pasricha (2012) succinctly says "it is important not to confuse no evidence of an effect, with evidence of no effect" (p.143).

\section{Quality of life, fatigue, cognition and postnatal depression}

Iron deficiency impacts directly on cognitive function in the adult and infant brain (Bodnar et al., 2005; Morton et al., 2014). Reduced iron in the brain alters iron containing enzymes, neurotransmitter function, cellular and oxidation processes (Beard et al., 2005), infant brain development (Morton et al., 2014), and thyroid hormone metabolism (Bodnar et al., 2005). Anaemia and iron deficiency are 
therefore physiologic factors that are associated with maternal depression; contributing to fatigue, apathy and inability to concentrate (Corwin, Murray-Kolb, \& Beard, 2003).

There are strong recommendations in the literature for good quality research on low maternal iron status, psychological functioning and quality of life (QOL), (Allen, 2000; Barroso et al., 2011; Dodd et al., 2009; James et al., 2008; Makrides, Crowther, Gibson \& Skeaff, 2003; Milman, 2012b). However, very few studies have been undertaken. Many psychosocial factors influence maternal depression, including child care stress, infant temperament, low self esteem and poor social support (Corwin et al., 2003; Waldie et al., 2015). The lack of research may reflect the difficulties of analysing subjective and multidimensional risk factors, variables and outcomes, as well as the sensitivity of tools such as the Edinburgh Postnatal Depression Score (EPDS) and SF26 to measure QOL (Ross et al., 2003).

A recent study of 5664 pregnant women in New Zealand, found that one in eight (11.9\%) women were depressed during pregnancy, with EPDS scores $>12$ (Waldie et al., 2015). These women were also more likely to eat poorly and smoke (Waldie et al., 2015). In comparison, the prevalence of minor postnatal depression (PND) in the USA is estimated at 19\%, and major PND at $12 \%$ (Corwin et al., 2003). The New Zealand Perinatal Maternal Mortality Review Committee Report (PMMRC, 2015) found that maternal suicide is the most common indirect cause of maternal mortality in New Zealand, with 21 women taking their lives during pregnancy and postpartum, from 2006-2013. Investigating this has become a priority for the PMMRC (2015). There is no prevalence data on maternal anaemia and iron deficiency in New Zealand (Morton et al., 2014). However, there may be an un-studied association between the high rates of depression, maternal suicide, and poor iron status in New Zealand.

A study of 81 poor South African mothers demonstrated a significant association between postpartum IDA, depression and stress with the association more evident at nine months than ten weeks postpartum (Beard et al., 2005). This suggested a cumulative effect of both iron deficiency and environmental factors such as fatigue, poverty and hunger. There was a $25 \%$ improvement in depression and stress scales in 
the women who received $125 \mathrm{mg}$ iron/day, despite ongoing environmental stresses (Beard et al., 2005).

As part of the same larger study, Perez at al. (2005) found that at ten weeks postpartum, anaemic mothers were less responsive and more controlling of their infants. At nine months postpartum, mothers with IDA were significantly less engaged in goal setting and more negative towards their babies. In contrast, the anaemic mothers who received $125 \mathrm{mg}$ iron/day were more like the non-anaemic women in terms of being positive and responsive towards their infants at nine months. Infants of the mothers with IDA scored worse on developmental tests at ten weeks and nine months of age. Thus the negative cumulative effect of postpartum IDA on maternal-infant interactions was significantly exacerbated by poverty (Perez et al., 2005).

Beard et al. (2005) and Perez et al., (2005) questioned whether delayed infant development was also related to infants' iron deficiency, secondary to poor maternal iron status in pregnancy. Although this question was beyond the scope of Beard et al. (2005) and Perez et al. (2005), their results suggested that low maternal iron status contributed to both environmental and biological factors that negatively affects infant development.

\section{Anaemia, iron deficiency and breastfeeding}

Anaemic mothers with postpartum symptoms of depression and/or fatigue may miss or misinterpret their newborn infant's cues from very early on (Corwin et al., 2003). Interpretation of infants feeding cues is essential for the establishment of breastfeeding. The association between low maternal iron status and missing infants' cues may therefore, have adverse affects on lactation and breastfeeding in multiple ways. A small Canadian study of 85 mothers, found that women with a low haemoglobin $(<95 \mathrm{~g} / \mathrm{L})$ on day two postpartum were significantly more likely to discontinue breastfeeding before four months of infants age $(P<0.02)$ than nonanaemic women (Rioux, Sovoie \& Allard, 2006).

The WHO recommends exclusive breastfeeding (EBF) for the first six months of life, to reduce infant mortality and improve recovery from common childhood illnesses. 
However, there are some concerns about prolonged EBF in developing countries with a high prevalence of maternal and infant anaemia. In their study of 183 infants, Meinzen-Derr et al. (2006) found that maternal anaemia is associated with a 3-fold increased risk of infant anaemia $(p=0.03)$. At nine months, a lower infant haemoglobin was associated with longer duration of EBF among anaemic mothers $(p=0.003)$. These findings warrant further research (Meinzen-Derr et al., 2006).

\section{Fetal and infant development}

Iron is essential for fetal brain development (Andersson et al., 2011), and to a large extent the iron status of a newborn depends on the iron status of the mother in pregnancy (Milman, 2012a). However the risk of iron deficiency is highest in the first 6-18 months of life (Pasricha, 2012). Anaemia and iron deficiency in infants and young children are associated with impaired motor development, long lasting behavioural and cognitive delays (Andersson et al., 2011).

In the fetus, most iron is transferred from the mother after 30 weeks gestation, which corresponds with peak maternal iron absorption (Allen, 2000). When maternal iron status is poor, there is an increase in the number of placental transferrin receptors to take up more iron. However, there is evidence that this system is insufficient to maintain iron transfer to the fetus when the mother is iron deficient (Allen, 2000). Recent evidence demonstrates that pregnant women with lower hepcidin levels (due to an absence of inflammation) transfer more iron to their fetus compared to mothers with detectable hepcidin levels (Koenig et al., 2014). These mechanisms for maternal-fetal iron transfer are complex.

A review prior to the discovery of hepcidin in 2000 , that did not analyse ferritin levels, found no significant association between maternal haemoglobin at or near term, and haemoglobin concentration in cord blood, except for rare cases of severe maternal anaemia (Allen, 2000). This was also a result of a New Zealand study (Emery \& Barry, 2004) comparing the haemoglobin concentration in cord blood of non-Maori $(n=93)$ and Maori participants $(n=31) \quad(p=0.95)$. However Maori mothers had significantly lower (undefined) haemoglobin levels $(p=0.002)$, but not ferritin levels $(p=0.02)$, than non-Maori mothers (Emery \& Barry, 2004). Emery and Barry (2004) did 
not account for the effect of increased maternal serum ferritin levels in the presence of inflammation.

Morton et al. (2014) studied maternal and perinatal predictors of newborn iron status, as part of the Growing up in New Zealand (GUiNZ) study. The authors found that the mean umbilical cord haemoglobin $(n=131)$ was highest in neonates of European mothers (164 g/L), compared to Pacific neonates (150 g/L) ( $p=0.05)$. Seven per cent of all the newborns had iron deficiency, $2 \%$ were anaemic, and none had IDA. Cord blood samples with evidence of inflammation $(n=5, C R P>5 \mathrm{mg} / \mathrm{L}$ or serum ferritin $>370 \mu \mathrm{g} / \mathrm{L}$ ) were excluded from the study. The mean BMI of the women in the study was higher (26.9) compared to the mean (25.4) in the cohort of 6822 women in the GUiNZ study. Although Morton et al. (2014) state that there is a cumulative adverse effect on newborn iron status with multiple maternal co-morbitities, especially obesity and diabetes, the extent of this association is unclear and warrants further research. This study does provide an indication of the prevalence of neonatal iron deficiency in New Zealand.

\section{Low iron status, birth weight and pre-term birth.}

The associations between low iron status, prematurity and neonatal birth-weight are often discussed in the literature. Although normal physiological haemodilution of pregnancy optimises placental perfusion, severe anaemia and low iron status, in the first trimester especially, results in fetal growth restriction (Graves \& Barger, 2001; Walsh et al., 2011). The benefits of early recognition of poor iron status, and early prevention or treatment are generally recommended. Iron supplementation started early in pregnancy has the best effect on the length of gestation, birth weight and the development of the fetus (Milman, 2012b; Pena-Rosas, De-Regil, Dowswell \& Viteri, 2012). However, causal relationships of clinical outcomes related to a low haemoglobin have not been clearly established (Jans, 2012; Rasmussen, 2001). Metaanalyses of RCTs show there is a general paucity of studies reporting clinical outcomes, and interpretation of those studies is limited by the heterogeneity in design, intervention, setting and outcome measurements (Dodd et al, 2009; Reveiz et al., 2007). 
Most studies on outcomes associated with iron status are observational, and more controlled experiments are required (Rasmussen, 2001). However because it would be unethical not to treat anaemic women, it is difficult to conduct prospective randomised trials to examine the efficacy of iron supplementation (Allen, 2000). A meta-analysis of both observational studies and randomised trials, with a different methodological approach to Cochrane Collaboration methods, found a strong association between anaemia and a higher risk of low birth weight (LBW) (RR 0.81, Cl 0.71 to 0.93 ), especially when diagnosed in the first and second trimester (OR $1.29, \mathrm{Cl}$ 1.09 to 1.53 ) (Haider et al., 2013).

Some studies from developed and developing countries have demonstrated an association between iron status, prematurity and birth-weight. An often cited, randomised trial of 4,926 pregnant Nepalese women, who received daily supplements of $60 \mathrm{mg}$ of ferrous iron and folic acid from 11 weeks, resulted in a significant $16 \%(\mathrm{RR}=0.84, \mathrm{Cl} 0.72$ to 0.99$)$ reduction in the prevalence of LBW neonates (Christian et al., 2003). Follow-up of 3761 of the children in the Nepalese trial demonstrated that at seven years the children's development had improved, and the mortality rate was $31 \%$ less compared to children of women not supplemented with iron and folic acid antenatally (Christian et al., 2009).

Another often cited study in the United States of America (USA) of 513 low income women demonstrated that a daily supplement of $65 \mathrm{mg}$ ferrous iron decreased the frequency of LBW ( $4 \%$ vs. $17 \%, p=0.003$ ) and prematurity ( $3 \%$ vs. $10 \%, p=0.017$ ) compared to the placebo group (Cogswell, Parvanta, Ickes, Yip \& Brittenham, 2003). Furthermore, a large Chinese study of 5828 women also demonstrated that antenatal supplementation with iron, significantly decreased the risk of early preterm birth (PTB <34 weeks) ( $p=0.031$ ), and early neonatal mortality by 54\% (RR $0.46, \mathrm{Cl} 0.21$ 0.98) compared to the non-iron supplemented group (Zeng et al., 2008).

Although the optimal range for haemoglobin has not been established (NBA, 2015) it appears to fit a U-shaped curve (Pena-Rosas et al., 2012). There is evidence that high haemoglobin levels in pregnancy, defined variously as an $\mathrm{Hb}>130 \mathrm{~g} / \mathrm{L}$ at sea level (Pena-Rosas et al., 2012), >132 g/L (Ziaei et al., 2007), or >145g/L (Milman, 2006), are 
associated with adverse outcomes, especially maternal hypertension, low birth weight and premature births.

An Iranian study of 727 pregnant women with high haemoglobin levels ( $\mathrm{Hb}>132 \mathrm{~g} / \mathrm{L}$ ) in the second trimester, surprisingly gained ethics approval to test the outcome of supplementing the case group with $50 \mathrm{mg}$ of ferrous iron throughout the rest of pregnancy (Ziaei et al., 2007). Results showed that the small for gestational age (SGA i.e. < 10th percentile) birth rate, and number of women with hypertensive disorders increased significantly in the case group ( $p=0.035$ and $p=0.05$ respectively). The physiological explanation for these results was iron-induced macrocytosis, increasing blood viscosity to a point that utero-placental blood flow was impaired, placental perfusion decreased, with an increased risk of placental infarction (Ziaei et al., 2007). The authors of this study concluded that routine iron supplementation of nonanaemic women is not rational and may be harmful.

\section{Maternal mortality and morbidity associated with anaemia}

The primary function of iron in the body is the formation of haemoglobin in red blood cells, for delivery of oxygen to the tissues. But at what point is oxygen delivery to the tissues compromised by low haemoglobin, in the context of normal physiological haemodilution of pregnancy? Whilst some midwives (Graves \& Barger, 2001) are critical of the medical community for pathologising lower haemoglobins in pregnancy, they acknowledge the difficulty of trying to assess the lower threshold beyond which adequate oxygen delivery to cardiac tissues is compromised. Similarly, Jans (2012) says the risk of an anaemic woman being predisposed to circulatory problems following a postpartum haemorrhage is theoretical, and circulatory problems can only be expected when $\mathrm{Hb}<40-50 \mathrm{~g} / \mathrm{L}$.

From a medical perspective, a $\mathrm{Hb}<70 \mathrm{~g} / \mathrm{L}$ requires urgent medical treatment (Goonewardene et al., 2012), and may warrant a blood transfusion (NBA, 2015). An $\mathrm{Hb}<40 \mathrm{~g} / \mathrm{L}$ is an emergency with the risk of congestive heart failure, sepsis or death (Goonewardene et al., 2012). Pavord et al. (2012) say little is known about the $\mathrm{Hb}$ threshold under which mortality increases, although this may be as high as $89 \mathrm{~g} / \mathrm{L}$, 
which was associated with a doubling of the risk of maternal death in a 1958 British study (Brabin, Hakimi \& Pelletier, 2001).

Postpartum haemorrhage (PPH) is a leading cause of global maternal mortality, especially in developing countries where the risk of dying in pregnancy and childbirth is 50-100 times greater than for women in developed countries (Brabin et al., 2001). Worldwide, almost 600,000 women die each year as a result of complications relating to pregnancy and birth (Brabin et al., 2001). Postpartum anaemia is closely linked to anaemia in pregnancy, and aggravated by blood loss (Milman, 2011). However there are many causes of anaemia (e.g. nutrient deficiencies, malaria, haemoglobinopathies, and haemolytic anaemias) that contribute to the overall pathology of anaemia, in addition to blood loss (Brabin et al., 2001; Goonewardene et al., 2012; Pasricha, 2012). For these reasons, the reduction in prevalence of maternal anaemia has been the focus of global public health strategies such as the Safe Motherhood initiative (Brabin et al., 2001).

In New Zealand, $3.4 \%$ of the maternal mortality rate is related to PPH (Perinatal Maternal Mortality Review Committee (PMMRC), 2015). From 2006-2013, three women died in New Zealand due to blood loss. Excessive blood loss (>1999mls) is the leading cause of severe acute maternal morbidity (SAMM) in New Zealand, accounting for $44.9 \%$ (44 of 98) of SAMM intensive care admissions or 'near misses', from 2011-2012 (Lawton et al., 2014). Almost half of these $(n=20)$ were found to be preventable due to factors such as clinician delay, or failure to diagnose significant blood loss. Third trimester anaemia is not stated as a preventable factor in Lawton et al.'s (2014) report, although anaemia is recognised as a risk factor for lowered tolerance to blood loss (NBA, 2015; Milman, 2012b).

The associations between maternal anaemia, mortality, morbidity and the use of blood transfusions are not well researched by intervention studies (NBA, 2015), because of ethical and logistical reasons (Brabin et al., 2001). In observational studies, anaemia as 'all cause' for mortality or morbidity is difficult to establish due to the multi-factorial nature of anaemia (Allen, 2000; Goonewardene et al., 2012). For 
example, anaemia poses other risks such as increased risk of infection or sepsis, which further contribute to morbidity and mortality (Brabin et al., 2001).

\section{Global prevalence}

Anaemia is defined by the $\mathrm{WHO}$ as a severe health problem if the prevalence exceeds $40 \%$, a moderate problem if prevalence is $20-39.9 \%$, and a mild problem if the prevalence is $5-19.9 \%$ (Pasricha, 2012). It is challenging to extrapolate the prevalence of anaemia, from the prevalence of iron deficiency (Goonewardene et al., 2012; Haider et al., 2013). Previously, many agencies have considered anaemia and iron deficiency synonymously. But this is flawed as there are many other causes of anaemia other than iron deficiency, that contribute significantly to the overall burden of anaemia (Pasricha, 2012).

The multi-factorial nature of anaemia may partly explain the differences in estimates of global prevalence of anaemia and IDA. The WHO estimates the worldwide prevalence of anaemia in pregnant women is $41 \%$, compared to $6 \%$ pregnant women in the USA (Pasricha, 2012). One United Kingdom (UK) study found that $24.4 \%$ of women were anaemic at some stage antenatally (Barroso et al., 2011). Approximately $10 \%$ of women in the USA have postpartum anaemia (James et al., 2008), although Bhandal and Russell (2006) suggest higher rates of up to $30 \%$ in the UK; a prevalence rate also confirmed in Barroso et al.'s (2011) study. Comparison of prevalence data is also inherently complicated by the different diagnostic cut off values used for maternal anaemia and iron deficiency, by various agencies, researchers and reviewers.

The contribution of iron deficiency to the prevalence of anaemia also varies markedly in different populations (Pasricha, 2012). In recent UK Guidelines on the management of iron deficiency in pregnancy, it is estimated that $30-40 \%$ of pregnant women in the developed world have NAID (Pavord et al., 2012). A Dublin study on the occurrence of maternal NAID, reported one third of 492 pregnant women had low iron stores (defined as $\mathrm{SF}<20 \mu \mathrm{g} / \mathrm{L}$ ) at booking, increasing to $50 \%$ at 36 weeks gestation (Walsh et al., 2011). Milman et al. (2012a) compare a 25-30\% prevalence of IDA in pregnancy in prosperous Western societies, with a prevalence of $52 \%$ amongst pregnant women 
in developing countries. The distinction between developed and developing countries, when considering prevalence of anaemia, may be even less clear in countries with rapidly changing proportions of migrant populations. Major ethnic disparities exist for migrants in relation to access to health care, and health outcomes, including pregnancy outcomes (Jans, 2012). The extent to which this might also apply to the growing migrant population in New Zealand, is unknown.

Anaemia is nonetheless described as 'common' with a high, albeit inexact prevalence, based on surveillance data and results of RCTs (Makrides et al., 2003). However the commonness of anaemia and iron deficiency as complaints of pregnancy, are debated by some midwives as being elusive and overstated (Amelink-Verburg et al., 2010; Graves \& Barger, 2001).

With the prevalence of anaemia and iron deficiency difficult to ascertain, surrogate measures have been utilised to estimate prevalence in certain populations. For example, KNOV initially estimated the prevalence of anaemia for pregnant women in the Netherlands as indicated by a $72 \%$ use of iron medications; recognising a potential for over supplementation that inspired the formation of the anaemia guideline for midwives (Amelink-Verburg et al., 2010). A large USA study (James et al. 2008) based the prevalence of anaemia in 254,248 pregnant and postpartum women on pregnancy related hospital diagnosis codes on discharge, unverified by laboratory results. Nearly one in five women had a diagnosis of anaemia. Whilst the authors stated the actual prevalence may have been underestimated, the diagnosis of anaemia in hospitalized women was associated with "a 9-fold increase in blood transfusion ( $p<0.0001), 33 \%$ longer average length of stay $(p<0.0001)$, and $50 \%$ higher average total cost per hospitalisation ( $p<0.0001)$ "' (James et al. 2008, p.1279).

\section{Maternal anaemia and iron deficiency in New Zealand}

The increased hospital costs associated with a diagnosis of anaemia and obstetric bleeding may apply similarly to the New Zealand maternity health care setting. The NZ Maternity Clinical Indicators $(\mathrm{MOH}, 2011)$ report the rate of blood transfusions as an indicator for significant estimated blood loss across District Health Boards (DHB). In 2011, the national rate for blood transfusion was $1.6 \%$ for women giving birth 
vaginally, and $3.3 \%$ for women giving birth by Caesarean section $(\mathrm{MOH}, 2011)$. Although these rates give no real clue to the overall prevalence of anaemia, the rate of blood transfusion could be interpreted as a diagnosis by proxy, of clinically severe anaemia. The decision to transfuse blood is not only based on volume of blood loss, but also on a woman's haemodynamic stability, and iron status before and after birth (NBA, 2015).

To date, there is no published prevalence data for maternal anaemia or iron deficiency in the general Australasian populations (Pasricha, 2012). However one DHB has undertaken an audit of twelve months of laboratory results to estimate the prevalence of anaemia, NAID and IDA amongst the women birthing in the tertiary level hospital (R. Seigne, personal communication, February, 2014). Unpublished data from the 4726 women showed the rate of anaemia, NAID and IDA was $4.3 \%, 19.7 \%$ and $0.4 \%$ in the first trimester, and $19.7 \%, 54 \%$ and $13.4 \%$ (respectively) in the second trimester. The proportion of NAID and IDA was likely to be underestimated as only $40 \%$ of women had serum ferritin tested in the first trimester, and $85 \%$ in the second trimester.

Almost all women in New Zealand have their haemoglobin level checked, as part of the routine antenatal blood tests, which includes the complete blood count. In New Zealand the complete blood count automatically includes white cell count differentials, red cell indices (i.e. mean cell volume (MCV), mean cell haemoglobin $(\mathrm{MCH})$, haematocrit $(\mathrm{Hct}))$ and haemoglobin levels. This is usually requested by an LMC midwife, who provides primary maternity care for the majority (88.8\%) of New Zealand women (MOH 2012). However, general practitioner doctors also request the first antenatal bloods especially if women visit them to confirm pregnancy.

Many midwives also test antenatal serum ferritin to assess iron stores, although this is not done routinely. Oral iron is not prescribed routinely for pregnant women in New Zealand and Australia, but rather based on individual need (Gibbons \& Wratten, 2015). New Zealand midwives prescribe oral iron within their autonomous scope of practice. Anecdotally, there appears to be a variable range of midwifery practice 
around diagnoses, prevention and treatment of maternal anaemia and iron deficiency, in New Zealand.

\section{Evidence based midwifery, midwifery research, midwifery guideline development}

With a similar philosophy and level of autonomy comparable to New Zealand midwives, midwives in the Netherlands have formulated a guideline for the management of anaemia in pregnancy. No such guideline exists for New Zealand midwives. Internationally, KNOV are the only professional body of midwives to have a formal guideline on the management of maternal iron status.

Although midwives tend to support the position that anaemia of pregnancy is a normal physiological process, there is a shortfall of midwifery research and guidance on how to distinguish physiological anaemia of pregnancy, from anaemia requiring treatment. Amelink-Verburg et al. (2010) describe the evolving meaning of evidencebased midwifery as incorporating midwifery values with views of women, combined with evidence found in the scientific literature. However, the lack of midwifery research on maternal iron status raises questions, asked by Spiby and Munro (2010), of midwives' degree of engagement in the full cycle of research activity that generates the basis for evidence-based midwifery practice. This issue was echoed by midwifery leaders Dixon (2014) and Campbell (2013), who recently challenged New Zealand midwives to become fully engaged as primary researchers, rather than assistants, as a basis for midwifery guideline development.

Spiby and Munro (2010) also challenged the philosophical, midwifery concepts of supporting 'normality' by a conceptual shift of working towards achieving 'optimality', and utilising a wide range of literature and evidence from different sources. This multi-disciplinary argument could be applied to evidence on maternal iron status. Despite the abundance of scientific literature on anaemia and iron deficiency in pregnancy, so many questions remain. As Crowther (2010) asks "what can midwives add to this with their understanding and holistic approach to care?" (p. 49). As a midwifery researcher, my response to these questions and challenges is to design and undertake clinical research to begin to unravel some of the complexities surrounding maternal iron status in New Zealand. 


\section{Significance of the study}

The clinical issues around maternal anaemia and iron deficiency are immense, complex and contentious, especially amongst midwives. This is primarily because of the blurred line between normal physiological anaemia of pregnancy, and anaemia requiring treatment. Without a clear and current understanding of iron metabolism, it is not possible to accurately interpret laboratory tests, prescribe or recommend iron appropriately. Although anaemia is seen as common in pregnancy, the actual prevalence in New Zealand is unknown. It was necessary to explore the evidence on adverse outcomes associated with anaemia and iron deficiency in pregnancy and postpartum, as part of this study; to describe the extent to which low maternal iron status is problematic for mothers and their infants, despite the limited research in some areas, and heterogeneity of research in others. Without this background of explaining why low iron status is a problem, there is little value in focusing on diagnosis and management.

This study is significant because it describes how the participant midwives in this New Zealand study currently diagnose and manage anaemia and iron deficiency in pregnancy and postpartum, without clear clinical guidance. There are no studies in New Zealand or internationally, that have done this. Midwives in the Netherlands have led the way with anaemia research, particularly regarding haemoglobinopathies (Jans, 2012), and the development of an anaemia guideline in 2000 (Beentje \& Jans, 2011; Amelink-Verburg et al., 2010). The midwifery leaders in the Netherlands who developed the guideline remain sceptical that anaemia is a problem in terms of adverse outcomes (Amelink-Verburg et al., 2010; Jans, 2012), although a survey of Dutch midwives' opinions indicates that some disagree (Offerhaus, Fleuren \& Wensing, 2004).

Some midwives have published opinions in articles (Graves \& Barger, 2001), and books (Frye, 2007), and every midwifery text book has a section on maternal anaemia. Latterly these discussions have included iron deficiency, such as in the required reading for midwifery students in New Zealand by Pairman, Pincombe, Thorogood and Tracy (2015). Still, the diagnosis of anaemia and iron deficiency is 
unclear. This study starts to close the gap between evidence and practice, in the primary care management of maternal anaemia and iron deficiency, paving the way for more complex studies in New Zealand in the future.

\section{Overview of the thesis}

There are five chapters in this thesis that describe LMC midwives primary care management of iron status in pregnancy and postpartum. Chapter One has explained the research problem, question and aims. This includes background physiology of iron metabolism, effects of maternal anaemia and iron deficiency, global prevalence, and guideline development. In Chapter Two, the Literature Review explores the evidence around diagnosis and management of low iron status in pregnancy and postpartum, emphasising the recent focus in the literature on iron deficiency. Areas

of consensus are clarified, whilst discrepancies, controversies and gaps in the evidence, literature and practice are highlighted to specifically guide the design of this study. Chapter Three outlines the research design including justification and explanation of the descriptive methodology, and methods. Chapter Four presents the study results, including secondary analysis of the association between low iron status and body mass index. Chapter five discusses the results in relation to the literature, whilst exploring the implications of the study, areas of research, and the study's strengths and limitations. 


\section{Chapter Two: Literature Review}

\section{Introduction and overview}

Whilst Chapter one broadly explored the current understanding of the physiology and effects of anaemia and iron deficiency in pregnancy and postpartum, the literature review focuses on diagnosis and management. The international literature was reviewed to explore current knowledge and recommended practice in relation to diagnosis and treatment of low maternal iron status. This involved looking at global public health strategies, national guidelines and individual therapeutic approaches, from a primary midwifery care perspective.

Specifically, the literature was investigated to find out what guidance exists, and what evidence it is based on. As researcher, I have taken the position that low maternal iron status is problematic and associated with adverse maternal and infant outcomes, although the evidence is difficult to elucidate as discussed in Chapter One. Given the controversies and challenges around low maternal iron status, the literature was also investigated for studies that described how care providers actually manage this.

No observational or descriptive studies focusing on midwives' management of maternal anaemia and iron deficiency were found in the literature. However, one observational study, from a multi-disciplinary perspective was found: "Prevalence of maternal anaemia and its predictors: a multi-centre study" from the UK (Barroso et al., 2011). The aim of Barroso et al. (2011) was to observe current practice around identification and management of antenatal and postnatal anaemia. Their multicentre study of 2103 women also reported on the prevalence of anaemia. The outcome of my literature review informed the design of this study; to describe current practice around New Zealand LMC midwives diagnosis and management of anaemia and iron deficiency in pregnancy and postpartum, as little is known in this area. 


\section{Search strategy}

The literature search for this study was commenced in 2013, until completion in 2015. This included database searches on Pub Med, CINAHL (Cumulative Index to Nursing and Allied Health), Joanna Briggs Institute and the Cochrane Database of Systematic Reviews. Keywords were: anaemia, iron deficiency, pregnancy and postpartum. Maternity guidelines, reports from the Ministry of Health, textbooks, and references from published works were also searched. Although literature from the last ten years was preferred, there were some older often cited seminal references and reports, and several older but still very relevant articles.

\section{Screening and Diagnosis}

\section{Screening with risk factors}

Before testing or treatment is undertaken, women can be screened for risk factors associated with developing anaemia and iron deficiency in pregnancy. Many risk factors have been identified: multiple pregnancy (McMahon, 2010), increased multiparity (Barroso et al., 2011), short time interval between births (Allen, 2000; Barroso et al., 2011), teenage pregnancies (Alwan et al., 2011; Barroso et al., 2011; Brabin et al., 2001), vegan or poor diet (Jans, 2012), smoking (Rasmussen, Bergso, Jacobsen, Haram \& Bakketeig, 2005), high BMI (Friedman et al., 2012; Koenig et al., 2014), history of bleeding (James et al., 2008), low socio-economic status (Beard et al., 2005; Bodnar et al., 2005; Perez et al., 2005), non-white ethnicity (Barroso et al., 2011; James et al., 2008), haemoglobinopathies (Brabin et al., 2001; Jans, 2012), and chronic disease or infection (Koenig et al., 2014; Pasricha et al., 2013; Wang et al., 2010). Screening with risk factors for low maternal iron status can be undertaken at a population or individual level.

The concept of screening needs clarification. In 1968 the WHO defined screening as "the presumptive identification of unrecognized disease by the application of tests [or risk factors]...which can be applied rapidly to sort out apparently well persons who probably have a disease from those who probably do not" (p. 139), with a view 
to early detection of conditions that would benefit from early treatment or intervention.

The extent to which New Zealand midwives screen for low maternal iron status is unknown. Jans (2012), states that midwives generally take a more holistic approach to screening for anaemia, compared to a more medical technical approach. Some midwives may intuitively or knowingly screen women with risk factors, prior to testing or supplementation. Some midwives may screen for low iron status based on symptoms, or a combination of both. Crowther (2010) for example, encourages midwives to work with women on their iron status at each visit to genuinely find out how they are, and Frye (2007) discusses women's 'vitality gauge' as an indicator of anaemia, regardless of haemoglobin levels. Although fatigue is the most common symptom of anaemia and iron deficiency, symptoms are usually non-specific unless the anaemia is severe (Pavord et al., 2012).

In the literature review, only two guidelines were found that stated specific maternal risk factors as a screening tool for identifying women at higher risk of anaemia and iron deficiency in pregnancy. The KNOV 2000 guideline on anaemia (in Jans, 2012), and the UK guidelines on the management of iron deficiency in pregnancy (Pavord et al., 2012), both clearly identify risk factors that guide management for prevention of low maternal iron status. This includes additional testing for at risk women, and is summarised in Table 1, alongside other guidelines and recommendations. 
Table 1: Comparison of guidelines, recommendations, and definitions of anaemia and iron deficiency in pregnancy and postpartum

\begin{tabular}{|c|c|c|c|c|c|}
\hline Organisation & First trimester & Second trimester & Third trimester & Postpartum & General recommendations \\
\hline $\begin{array}{l}\text { Health Pathways } \\
\text { (2015) }\end{array}$ & $\begin{array}{l}\text { All women, test CBC*: } \\
\text { If } \mathrm{Hb}^{*}<110 \mathrm{~g} / \mathrm{L} \& \\
\mathrm{MCV}^{*}<80 \text {, test ferritin } \\
\text { ID*: SF* }<20 \mu \mathrm{g} / \mathrm{L}\end{array}$ & $\begin{array}{l}\text { Test CBC: if } \mathrm{Hb}<105 \\
\mathrm{~g} / \mathrm{L} \& \mathrm{MCV}<80 \text {, test } \\
\text { ferritin } \\
\text { ID: } \mathrm{SF}<20 \mu \mathrm{g} / \mathrm{L}\end{array}$ & $\begin{array}{l}\text { Test CBC: if } \mathrm{Hb}<105 \\
\mathrm{~g} / \mathrm{L} \& \mathrm{MCV}<80 \text {, test } \\
\text { ferritin } \\
\text { ID: } \mathrm{SF}<20 \mu \mathrm{g} / \mathrm{L}\end{array}$ & None stated & $\begin{array}{l}\text { - } \text { Mild (undefined) NAID*: } \\
\rightarrow \text { 65-200mg oral iron } \\
\text { - } \quad \text { Mod (undefined) NAID: } \\
\rightarrow 100-200 \mathrm{mg} \text { oral iron }\end{array}$ \\
\hline $\begin{array}{l}\text { New Zealand College } \\
\text { of Midwives (2005) }\end{array}$ & All women, test $C B C$ & None stated & Consider $\mathrm{CBC}$ & No parameters stated & None stated \\
\hline $\begin{array}{l}\text { NICE Guidelines } \\
(2014,2015)\end{array}$ & $\begin{array}{l}\text { Offered screening for } \\
\text { anaemia. If } \mathrm{Hb}<110 \\
\mathrm{~g} / \mathrm{L}, \text { investigate \& } \\
\text { consider iron } \\
\text { supplementation }\end{array}$ & $\begin{array}{l}\text { if } \mathrm{Hb}<105 \mathrm{~g} / \mathrm{L} \text { at } \\
28 \mathrm{wks} \text {, investigate } \& \\
\text { consider iron } \\
\text { supplementation }\end{array}$ & $\begin{array}{l}\text { No parameters } \\
\text { stated }\end{array}$ & $\begin{array}{l}\text { If woman persistently } \\
\text { fatigued, or if has had } \\
\text { PPH, check Hb. If low } \\
\text { treat according to } \\
\text { local policy }\end{array}$ & No routine supplementation \\
\hline RANZCOG (2013) & $\begin{array}{l}\text { All women, test } \mathrm{CBC} \text {. } \\
\text { Particular note of } \mathrm{MCV} \\
\text { as indicator of } \\
\text { underlying } \mathrm{HbP}^{*}\end{array}$ & $\begin{array}{l}\text { Test } \mathrm{Hb} \text { at } 28 \text { wks. } \\
\text { No parameters stated }\end{array}$ & $\begin{array}{l}\text { No parameters } \\
\text { stated }\end{array}$ & No parameters stated & None stated \\
\hline $\begin{array}{l}\text { Royal Netherlands } \\
\text { Organisation of } \\
\text { Midwives (KNOV in } \\
\text { Jans, 2012) }\end{array}$ & $\begin{array}{l}\text { All women, test CBC } \\
\mathrm{Hb}<114.5 \mathrm{~g} / \mathrm{L} \text { under } 13 \\
\text { wks }\end{array}$ & $\begin{array}{l}\text { Repeat CBC at } 20 \text { wks } \\
\text { for at risk groups } \$ \\
\mathrm{Hb}<110 \mathrm{~g} / \mathrm{L} \text { at } 14-17 \\
\text { wks } \\
\mathrm{Hb}<104.8 \mathrm{~g} / \mathrm{L} \text { at } 18-21 \\
\text { wks } \\
\mathrm{Hb}<101.6 \mathrm{~g} / \mathrm{L} \text { at } 22-37 \\
\text { wks }\end{array}$ & $\begin{array}{l}\mathrm{CBC} \text { for all women at } \\
30 \text { wks } \\
\mathrm{Hb}<101.6 \mathrm{~g} / \mathrm{L} \text { at } 22- \\
37 \text { wks } \\
\mathrm{Hb}<104.8 \mathrm{~g} / \mathrm{L} \text { after } 38 \\
\text { wks }\end{array}$ & $\begin{array}{l}\mathrm{Hb}<104.8 \mathrm{~g} / \mathrm{L} \text { at } 1-5 \\
\text { wks } \\
\mathrm{Hb}<116.1 \mathrm{~g} / \mathrm{L} \text { at } 6 \text { wks } \\
\text { All women: check } \\
\text { postpartum Hb at } 4-6 \\
\text { weeks } \\
\text { If } \mathrm{EBL}>1000 \text { mls: check } \\
\mathrm{Hb} \text { at 7-10 days, and } 6 \\
\text { weeks postpartum }\end{array}$ & $\begin{array}{l}\text { All women: } \\
\begin{array}{l}\text { - No ferritin testing } \\
\text { - Test MCV if Hb low: } \\
\text { If MCV } 80-100 \rightarrow \text { no } \\
\text { treatment } \\
\text { If MCV } 70-80 \rightarrow 200 \mathrm{mg} \\
\text { oral iron } \\
\text { If MCV <70 or } \geq 100 \rightarrow \\
\text { refer to GP } \\
\text { All women: check Hb 3-6 wks }\end{array}\end{array}$ \\
\hline
\end{tabular}




\begin{tabular}{|c|c|c|c|c|c|}
\hline Organisation & First trimester & Second trimester & Third trimester & Postpartum & General recommendations \\
\hline & & & & & after start of treatment \\
\hline $\begin{array}{l}\text { UK Guidelines } \\
\text { (Pavord et al., 2012) }\end{array}$ & $\begin{array}{l}\text { CBC for all women at } \\
\text { booking } \\
\mathrm{Hb}<110 \mathrm{~g} / \mathrm{L} \\
\text { ferritin testing for high } \\
\text { risk women only } \\
\mathrm{SF}<30 \mu \mathrm{g} / \mathrm{L}\end{array}$ & $\begin{array}{l}\text { CBC for all women at } \\
28 w k s \\
\mathrm{Hb}<105 \mathrm{~g} / \mathrm{L} \\
\mathrm{SF}<30 \mu \mathrm{g} / \mathrm{L}\end{array}$ & $\begin{array}{l}\mathrm{Hb}<105 \mathrm{~g} / \mathrm{L} \\
\mathrm{SF}<30 \mu \mathrm{g} / \mathrm{L}\end{array}$ & $\begin{array}{l}\text { Check } \mathrm{Hb} \text { if } \\
\mathrm{EBL}>500 \mathrm{mls} \text {, or } \\
\text { uncorrected anaemia } \\
\text { antenatally, or if } \\
\text { symptomatic } \\
\mathrm{Hb}<100 \mathrm{~g} / \mathrm{L}\end{array}$ & $\begin{array}{ll}\text { - } & \text { All women given dietary } \\
\text { advice } \\
\text { - } & \text { Routine supplementation } \\
\text { not recommended } \\
\text { - } & \text { NAID } \rightarrow 65 \mathrm{mg} \text { iron } \\
\text { - } & \text { IDA* } \rightarrow 100-200 \mathrm{mg} \text { iron }\end{array}$ \\
\hline $\begin{array}{l}\text { US Centre for } \\
\text { Disease Control } \\
\text { (1998) }\end{array}$ & $\begin{array}{l}\mathrm{Hb}<110 \mathrm{~g} / \mathrm{L} \text { at } 12 \mathrm{wks} \\
\mathrm{SF}<12 \mu \mathrm{g} / \mathrm{L}\end{array}$ & $\begin{array}{l}\mathrm{Hb}<105 \mathrm{~g} / \mathrm{L} \text { at } 24 \mathrm{wks} \\
\mathrm{SF}<12 \mu \mathrm{g} / \mathrm{L}\end{array}$ & $\begin{array}{l}\mathrm{Hb}<114 \mathrm{~g} / \mathrm{L} \text { at } 36 \text { wks } \\
\mathrm{SF}<12 \mu \mathrm{g} / \mathrm{L}\end{array}$ & $\begin{array}{l}\mathrm{Hb}<120 \mathrm{~g} / \mathrm{L} \text { at } 4-6 \\
\text { weeks. } \\
\text { Test } \mathrm{Hb} \& \mathrm{Hct} \text { if: } 3^{\text {rd }} \\
\text { trimester anaemia, } \\
\text { excessive blood loss, } \\
\text { or multiple births }\end{array}$ & $\begin{array}{l}\text { Routine } 30 \mathrm{mg} / \text { day oral iron } \\
\text { for all pregnant women }\end{array}$ \\
\hline $\begin{array}{l}\text { World Health } \\
\text { Organisation (1968) }\end{array}$ & $\begin{array}{l}\mathrm{Hb}<110 \mathrm{~g} / \mathrm{L} \\
\mathrm{SF}<15 \mu \mathrm{g} / \mathrm{L}\end{array}$ & $\begin{array}{l}\mathrm{Hb}<110 \mathrm{~g} / \mathrm{L} \\
\mathrm{SF}<15 \mu \mathrm{g} / \mathrm{L}\end{array}$ & $\begin{array}{l}\mathrm{Hb}<110 \mathrm{~g} / \mathrm{L} \\
\mathrm{SF}<15 \mu \mathrm{g} / \mathrm{L}\end{array}$ & $\mathrm{Hb}<100 \mathrm{~g} / \mathrm{L}$ & $\begin{array}{l}\text { - ferritin best measure of } \\
\text { iron stores } \\
\text { - ferritin not tested } \\
\text { routinely } \\
\text { - ferritin tested in at risk } \\
\text { populations }\end{array}$ \\
\hline
\end{tabular}

*Abbreviations: complete blood count (CBC); general practitioner (GP); haemoglobin (Hb); haemoglobinopathy (HbP); iron deficiency (ID); iron deficiency anaemia (IDA); mean cell volume (MCV); non-anaemic iron deficiency (NAID); serum ferritin (SF).

$\S$ KNOV risk factors: teenage pregnancies, pregnancies within 12 months of birth, poor nutrition, multiple pregnancy, haemoglobinopathies (e.g. thalassaemia).

ๆ UK Guideline risk factors: current or previous anaemia, teenage pregnancies, pregnancies within 12 months of birth, parity $\geq 3$, recent history of bleeding, high risk of bleeding, Jehovah's witnesses, haemoglobinopathies (e.g. thalassaemia). 
The KNOV and UK guidelines are clear and comprehensive, unlike other guidelines and recommendations. For example, recommendations in The New Zealand College of Midwives Handbook for Practice (NZCOM, 2005) are very limited. Also, there is no clear strategy for New Zealand midwives to identify risks factors for low maternal iron status, or how to manage them, despite some discussion on risk factors in the compulsory textbook Midwifery: preparation for practice (Hunter \& Gunn, 2015). Screening for risk factors of anaemia appears integral to the identification and management of maternal iron status. Yet, it is unknown whether or not New Zealand midwives are more pro-active in their management of women who have risk factors for anaemia and iron deficiency. Therefore demographic and clinical data on women's potential risk factors was collected for the study.

\section{Haemoglobin and identifying anaemia}

Internationally, there are few comprehensive guidelines on the management of maternal anaemia and iron deficiency (Table 1). A comparison of the different approaches and diagnostic parameters for anaemia highlights the major issues. Where guidelines do exist, most are short on detail. Most importantly, the diagnostic criteria differ significantly between guidelines.

Because of physiological haemodilution, pregnant women need different parameters to define normal haemoglobin values (Jans, 2012). However, the boundaries between physiological and pathological anaemia of pregnancy are not well understood or defined (Pena-Rosas \& Viteri, 2006). Consequently, there is no global consensus on the various cut-off points used to define anaemia (Amelink-Verburg et al., 2010), as illustrated in Table 1. The perception that healthy women with normal physiological anaemia of pregnancy were being over-diagnosed and over-treated for anaemia, motivated the Dutch midwives to develop their first evidence based guideline. This may be an important issue for New Zealand midwives too.

Statistically, anaemia is defined as a haemoglobin level less than two standard deviations below the mean, or $<5^{\text {th }}$ percentile, for a matched healthy population (Pavord et al., 2012). Without a large population study in New Zealand, normal and abnormal haemoglobin values are unknown here. The most often cited 1968 WHO 
definition of anaemia in pregnancy, as a haemoglobin concentration $<110 \mathrm{~g} / \mathrm{L}$ (Table 1), is considered by some to be arbitrarily chosen (Milman, 2006), statistically flawed due to population sampling errors (McMahon, 2010), and not applicable to the Australasian population (NBA, 2015). Nonetheless, the global WHO definition is recognised as necessary for comparisons of prevalence, and effects in different populations (Goonewardene et al., 2012).

The USA Centre for Disease Control (CDC, 1998) criteria for anaemia in pregnancy as $\mathrm{Hb}<105 \mathrm{~g} / \mathrm{L}$ (Table 1), is considered a reasonable alternative to the WHO definition, as it takes into account haemodilution of pregnancy (Paterson et al., 1994 ; Pavord et al., 2012). However Graves and Barger (2001) also question the validity of the CDC parameters, as they are based on aggregated data from four European studies of iron-supplemented women. Neither the WHO or CDC parameters distinguish cut-offs for race, although ranges of haemoglobin do vary by race, possibly because of ethnic differences in the prevalence of haemoglobinopathies (e.g. thalassaemia or sickle cell disease) (Pasricha et al., 2013). From their midwifery perspective, Graves and Barger (2001) suggest parameters for defining anaemia in normal healthy pregnant women may be much lower.

Dutch midwives based their 2000 anaemia guideline on gestation dependent reference values, stated in $\mathrm{mmol} / \mathrm{L}$ and converted to $\mathrm{g} / \mathrm{L}$ in Table 1 . The lowest KNOV parameter for defining anaemia is an $\mathrm{Hb}<101.6 \mathrm{~g} / \mathrm{L}$ at $22-37$ weeks gestation. These gestation specific criteria are based on two studies that Jans (2012) states are well known in the Netherlands. However, despite an extensive literature search, and direct email contact with S. Jans, and a Dutch Obstetrician, these studies were not available. KNOV's guideline may therefore be based on old or low quality evidence. Nonetheless, authors of the KNOV guideline consider it a small revolution, as the lower haemoglobin reference values are based on the $5^{\text {th }}$ percentile as the normal value (Beentje \& Jans, 2011), compared to other higher cut-off values such as the WHO definition (Amelink-Verburg et al., 2010).

Interestingly, a study of Dutch midwives' adherence to the KNOV guideline found that $31 \%$ of midwives considered the haemoglobin cut off values too low (Offerhaus 
et al., 2004). Critics of the KNOV guideline consider the lower haemoglobin cut off values leads to under-detection of IDA, and failure to detect anaemia sufficiently early enough in pregnancy (Jans, 2012). Twenty-one percent of Dutch midwives also consider the period between the KNOV recommendation of testing haemoglobin at twelve and thirty weeks gestation, for low risk women, as too long; further leading to under-detection of anaemia and iron deficiency, especially for immigrant women (Offerhaus et al., 2004).

Diagnostic parameters aside, a low haemoglobin concentration indicates anaemia but not the cause. The role of blood tests is to diagnose logically, beginning with the most common cause for abnormally low haemoglobin levels (iron deficiency), then explore more complex pathologies as the clinical picture fits (Crowther, 2010), e.g. folate or B12 deficiencies, haemoglobinopathies, chronic bleeding, infection or inflammation. Although haemoglobin is considered the simplest, least invasive test used to screen and diagnose anaemia (James et al., 2006), the low cost and ease of measuring haemoglobin concentration have also made it the most ubiquitous (Graves \& Barger, 2001).

Haemoglobin concentration is often used as a pseudo-marker for iron deficiency or iron status in pregnancy (Milman, 2006). However Walsh et al. (2011) demonstrated that as a single test, the WHO cut off of $\mathrm{Hb}<110 \mathrm{~g} / \mathrm{L}$ has a proven sensitivity of only $5 \%$ for iron deficiency (SF $<20 \mu \mathrm{g} / \mathrm{L}$ ), and only $8 \%$ for absent iron stores (SF $<12 \mu \mathrm{g} / \mathrm{L}$ ), effectively missing over $90 \%$ of absent iron stores. Haemoglobin alone is therefore a poor measure of iron status, as the $\mathrm{Hb}$ is the last red cell indice to drop before end stage iron deficiency anaemia (IDA) (Mei et al., 2005; Pasricha, 2012; Walsh et al., 2011).

In Ireland, Barrosso et al. (2011) observed that $88.7 \%$ of the 2103 women studied had their $\mathrm{Hb}$ tested as part of the CBC at booking. In total, $19.1 \%(n=402)$ of the women were anaemic at booking or in the second trimester. A significant number of these women remained anaemic in later pregnancy (30\%), and $24 \%$ had postnatal anaemia. A small proportion of the women in the study who were found to be anaemic in the first and second trimester, had their ferritin levels checked (20\% and $12 \%$ 
respectively) (Barroso et al., 2011). Without a measure of iron stores, practitioners cannot discern where a woman sits on the spectrum from iron sufficiency to nonanaemic iron deficiency (NAID), and IDA. This had important implications for this study in terms of observing how midwives in New Zealand identified low iron status, without a measure of iron stores. So do LMC midwives rely on haemoglobin as a single measure of maternal iron status? The specific haemoglobin and serum ferritin parameters used to define anaemia and iron deficiency in this study are explained in Chapter Three on Research Design.

\section{Serum ferritin and identifying iron deficiency}

As with haemoglobin levels, there is no clear consensus on serum ferritin parameters that define iron deficiency or absent iron stores (Table 1). There is also a range of approaches in the guidelines and recommendations to serum ferritin testing. These range from not testing ferritin, to a risk based approach, to routine (universal) testing for all women. Ferritin is also a complex multi-functional molecule that requires an additional test to accurately measure iron stores in the presence of inflammation. Because there are no clear recommendations or guidelines for New Zealand midwives on the testing of iron deficiency in pregnancy, the literature on the parameters and different approaches to testing are explored below.

Serum ferritin screening for iron deficiency early in pregnancy is widely recommended to provide a baseline, and enable early commencement of iron therapy (Breymann, Honegger, Holzgreve \& Surbek, 2010; Crowther, 2010; Elias, 2007; Milman et al., 2006; Milman, 2012a; Pasricha, 2012; Walsh et al., 2011). So it is somewhat surprising that the UK Guideline for the Management of Iron Deficiency in Pregnancy (Pavord et al., 2012) does not support the approach of universal screening of serum ferritin in pregnancy. However, Pavord et al. (2012) do recommend testing 'at risk' women (Table 1). Women without risk factors for anaemia are not tested for iron deficiency, unless they are from areas with a particularly high prevalence of at risk women (Pavord et al., 2012).

The UK approach considers unselected routine screening with serum ferritin as an expensive use of resources (Pavord et al., 2012). The UK approach may also be 
following recommendations from the WHO, although this is not implicitly stated. From a global public health perspective, the WHO (2011) also does not recommend universal serum ferritin screening in pregnancy. The WHO only recommends ferritin testing in pregnancy, prior to iron supplementation, if the population prevalence of anaemia is $<20 \%$ (Pasricha, 2012).

In the study area, clinical guidance for local general practitioner doctors on primary care management of anaemia and iron deficiency in pregnancy (Health Pathways, 2015), does not recommend routine serum ferritin testing unless MCV <80fL (Table 1). Health Pathways (2015) is included in this literature review because local LMC midwives access the website, and the Health Pathways approach may soon be adopted by other DHBs (J. Spring, personal communication, November 14, 2015). The extent to which midwives use Health Pathways (2015) is unknown.

The KNOV guideline, including the 2008 revision, does not recommend midwives test serum ferritin as a measure of iron stores at all. Instead KNOV utilises MCV to diagnose anaemia (Jans, 2012), with no emphasis on iron deficiency as a clinical issue. Midwives in the Netherlands only test serum ferritin to differentially diagnose IDA from haemoglobinopathies (Beentje \& Jens, 2011). It was clearly important for this study to look carefully at how ferritin is assessed. Therefore, the evidence for the different approaches is discussed below.

Various serum ferritin cut-off values for the definition of iron deficiency in pregnancy are debated (Milman et al., 2006; Pavord et al, 2012). This complicates diagnosis for New Zealand midwives, especially in the absence of a guideline. Serum ferritin is nonetheless recommended as the most accurate, accessible, current measure of iron stores (Pairman et al., 2015; Pasricha et al., 2013; Pavord et al., 2012; Wang et al., 2010; WHO, 2011). Serum ferritin $<15 \mu$ g has shown a specificity of $98 \%$ and sensitivity of $75 \%$ for iron deficiency, defined by the invasive gold standard of no stainable bone marrow iron; and at $<30 \mu \mathrm{g}$ a specificity of $85 \%$ and sensitivity of $90 \%$ (Walsh et al., 2011).

Unlike haemoglobin, serum ferritin is not affected by smoking or altitude (WHO, 2011). Serum ferritin is a stable glycoprotein unaffected by recent iron ingestion 
(Pavord et al., 2012), but levels are subject to daily fluctuations of 15-20\% (Crowther, 2010). As well as being cheap and cost effective, Crowther (2010) considers serum ferritin testing a valuable arsenal for New Zealand midwives to avoid over-prescribing of iron in pregnancy. Serum ferritin should also be considered valuable to avoid under-prescribing of iron in pregnancy.

However, ferritin is a complex and multi-functional molecule (Wang et al., 2010), with some limitations in the diagnosis of iron deficiency. Serum ferritin levels are affected by haemodilution of pregnancy, and drop in pregnancy because less ferritin is produced (Milman, 2006) as the iron stores are mobilised (Pavord et al., 2012). By 32 weeks gestation, serum ferritin has progressively decreased to $50 \%$ of prepregnancy levels, increasing mildly in the third trimester (Pavord et al., 2012). The WHO (2011) states that a drop in serum ferritin does not necessarily imply functional iron deficiency. Functional iron deficiency occurs when despite adequate stores, iron cannot be mobilised for erythropoiesis (Pasricha et al., 2010).

The main disadvantage of serum ferritin is that it is also an acute phase protein, and levels increase during any overt or covert inflammation (Thurnham et al., 2010; WHO, 2011). There are many possible causes of inflammation: acute and chronic infections (e.g. malaria), liver disease, arthritis, malignancy, increased alcohol intake and obesity (Friedman et al., 2012; Gartner et al., 2013; Koenig et al., 2014; Nel, Kruger, Baumgartner, Faber \& Smuts, 2015; Wang et al., 2010). Other proinflammatory states specific to pregnancy are implantation (Mor, Cardenas, Abrahams \& Guller, 2011), normal and operative birth (Lee at al., 2014), and preeclampsia (Koenig et al., 2014). These pro-inflammatory states are associated with elevated ferritin levels due to inflammation.

Recent advances in the understanding of iron physiology have increased knowledge of the multiple causes, and mechanisms, of anaemia and functional iron deficiency in the presence of inflammation. In 2000 the liver hormone hepcidin was discovered. Hepcidin regulates body iron by decreasing iron uptake in the gut and limiting utilisation of iron for erythropeiesis, when inflammation is present (Koenig et al., 2014; Wang et al., 2010). This sequestering of iron results in increased ferritin levels, 
and degrees of functional iron deficiency, or anaemia of chronic disease (ACD), also called anaemia of inflammation.

This makes ferritin levels difficult to interpret and misleading due to the potential for false normal or high ferritin results (Pasricha, 2012). Anaemia of chronic disease is now recognised as the second most prevalent cause of anaemia, after iron deficiency (Friedman et al, 2012; Munoz, Breymann, Garcia-Erce, Comin \& Bisbe, 2007). Anecdotally, the mechanisms of functional iron deficiency and inflammation are not understood by all midwives in New Zealand. Table 2 (adapted with permission from Pasricha et al. (2010)) provides an overview on interpretation of laboratory tests for iron status.

Table 2*: Overview of interpreting laboratory blood test results to assess iron status

\begin{tabular}{|c|c|c|c|}
\hline Diagnosis & Haemoglobin & $\begin{array}{r}\text { Mean cell volume } \\
\text { and mean cell } \\
\text { haemoglobin }\end{array}$ & $\begin{array}{r}\text { Serum ferritin } \\
\mu \mathrm{g} / \mathrm{L}\end{array}$ \\
\hline $\begin{array}{l}\text { Non-anaemic iron deficiency } \\
\text { (NAID) }\end{array}$ & Normal & Normal or low & $<15-30$ \\
\hline Iron deficiency anaemia (IDA) & Low & $\begin{array}{r}\text { Low (or normal in } \\
\text { early IDA) }\end{array}$ & $<15-30$ \\
\hline $\begin{array}{l}\text { Anaemia of chronic disease } \\
\text { (ACD) or inflammation }\end{array}$ & Low & $\begin{array}{r}\text { Normal (maybe } \\
\text { mildly low) }\end{array}$ & $\begin{array}{r}\text { Normal or } \\
\text { elevated (elevated } \\
\text { ferritin does not } \\
\text { imply elevated } \\
\text { iron stores) }\end{array}$ \\
\hline $\begin{array}{l}\text { IDA with coexistent chronic } \\
\text { disease or inflammation }\end{array}$ & Low & Low & $\begin{array}{r}\text { Low or normal, } \\
\text { but usually }<60- \\
100 \mu \mathrm{g} / \mathrm{L}\end{array}$ \\
\hline Thalassaemia minor & Low (or normal) & Low (or normal) & $\begin{array}{r}\text { Normal or } \\
\text { elevated }\end{array}$ \\
\hline
\end{tabular}

*Source: adapted with permission from the Medical Journal of Australia and Pasricha et al. 2010

Because of the effect of inflammation on ferritin levels, it is widely recommended that serum ferritin is tested alongside another inflammatory marker, C-reactive protein (CRP). Although midwives can order CRP tests (District Health Boards Shared 
Services, 2013), anecdotally it appears that midwives do not order CRP alongside serum ferritin. Currently, laboratories do not routinely analyse CRP with serum ferritin, so CRP testing is dependent on individual laboratory practice.

C-reactive protein is a correcting factor that indicates the need to adjust the diagnostic parameters for iron deficiency upwards, when inflammation is present i.e. CRP >5mg/L (Gartner et al., 2013; McMahon, 2010; Nel et al., 2015; Thurnham et al., 2010; WHO, 2011). C-reactive protein levels appear to be independent of pregnancy and gestational age (Pavord et al., 2012). Recommended adjustment to the serum ferritin cut-off value that defines iron deficiency, in the presence of inflammation,

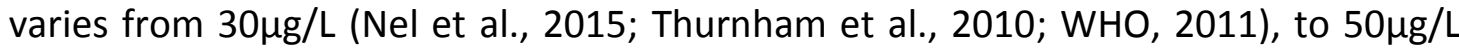
(Goonewardene et al., 2012), and up to $70 \mu \mathrm{g} / \mathrm{L}$ (Wang et al., 2010). Given that the WHO (2011) recommends serum ferritin as the best current measure of iron stores, it has become a research priority to establish alternative methods and thresholds for interpreting ferritin, in the presence of various phases of inflammation (Cheng et al., 2013; Gartner et al., 2013; Moschonis, Chrousos, Lionis, Mougios \& Manios, 2012; Nel et al., 2015; Thurnham et al., 2010).

In the immediate postpartum period there is also an increased chance of false normal or high ferritin levels, due to oxidative stress and inflammatory responses following birth. Milman (2011) suggests that serum ferritin can be accurately tested at one week postpartum, because women have reached a haemodynamic steady state with the disappearance of haemodilution. Ferritin naturally increases in response to this, rather than inflammation, and at one week will most likely accurately reflect body iron status (Milman, 2011). Alternatively, Breymann et al. (2010) says there is no value in taking postpartum ferritin levels at all to diagnose iron deficiency, because of inflammation. Iron stores as well as $\mathrm{Hb}$ should be tested antenatally, and post partum iron stores subsequently assumed (Breymann et al., 2010).

New Zealand midwives may be unaware of the importance of these aspects in the differential diagnosis of iron deficiency and IDA in pregnancy and postpartum. The affect of inflammation on iron stores is described in the literature, but not in the observational study of current practice by Barroso et al. (2011). Furthermore, the 
evidence around the interplay between ferritin and inflammation is not available for midwives in New Zealand in a form that clearly guides midwives' clinical practice. Although approaches to serum ferritin testing vary (universal vs. risk based), ferritin is still widely accepted as the best measure of iron stores, by all but the Dutch midwives. Because of the complexities around testing and interpreting serum ferritin, it was apparent from the literature review that this study should include an analysis of CRP testing, alongside analysis of serum ferritin testing for iron stores.

\section{Mean cell volume}

Anecdotally, many New Zealand midwives may not be interpreting MCV when assessing iron status. According to the Health Pathways (2015) guideline, general practitioners in the study area only test serum ferritin if microcytic anaemia is indicated by a low MCV (<80fL) (Table 1$)$. The Royal Australian and New Zealand College of Obstetricians and Gynaecologists (RANZCOG, 2013) has no guidance for testing serum ferritin for iron stores, but does recommend interpreting MCV to assist in the diagnosis of anaemia, although parameters are undefined (Table 1). Conversely, the Dutch midwives' anaemia guideline emphasises MCV, with specific parameters (Table 1). Dutch midwives say that MCV testing distinguishes physiological anaemia from anaemia (Offerhaus et al., 2004) and IDA (Jans, 2012). The advantages and disadvantages of MCV testing are considered below.

The KNOV guideline considers MCV advantageous because it is less affected by haemodilution. It is a sensitive, cheap and easily available test (Offerhaus et al., 2004). Dutch midwives test MCV only if the $\mathrm{Hb}$ result is low i.e. $\mathrm{Hb}<5^{\text {th }}$ percentile (Table 1). If $\mathrm{MCV}<80 \mathrm{fL}$, oral iron is prescribed. If $\mathrm{MCV}<70 \mathrm{fL}$, or $>100 \mathrm{fL}$, the woman is referred to the general practitioner. So unlike in New Zealand, where MCV is routinely tested alongside haemoglobin as part of the $\mathrm{CBC}$, Dutch midwives have to re-test to get a MCV result.

The MCV gives information on the average size of the RBC. Red blood cells in the normal MCV $80-98 \mathrm{fL}$ range are normocytic. Mean cell volume $<80 \mathrm{fL}$ indicates microcytic (small) RBCs, associated with iron deficiency and thalassaemia (Table 2). In mild cases of iron deficiency the MCV may not fall below normal (Pavord et al., 2012). 
However a low or falling MCV is still suggestive of iron deficiency, regardless of the haemoglobin level (McMahon, 2010).

Iron deficiency anaemia is referred to as microcytic, hypochromic anaemia because of the small, pale RBCs or erythrocytes (Miller \& Wilkes, 2015). An MCV >100 fL indicates macrocytic RBCs, associated with other forms of anaemia e.g. B12 and/or folate deficiencies (megaloblastic, macrocytic anaemia) (Goonewardene et al., 2012). Macrocytosis is also associated with alcoholism, liver disease, hypothyroidism and cancer (Crowther, 2010). In anaemia of inflammation (or ACD), the RBCs are usually normocytic (Friedman et al., 2012; Pasricha et al., 2010). To further complicate things, some people have both anaemia of inflammation and IDA, which tends to present as microcytic anaemia, with normal or high serum ferritin (Friedman et al., 2012; Pasricha et al., 2010) (Table 2). This can be difficult to diagnose (Goonewardene et al., 2012).

A study on adherence to the KNOV 2000 anaemia guideline found $49 \%$ of Dutch midwives found it difficult not to prescribe iron if a woman has a low $\mathrm{Hb}$ but acceptable MCV, saying the KNOV parameters leads to under-detection of IDA (Offerhaus et al., 2004). Authors of the KNOV guideline say the standard is based on an extensive literature review, sufficient to substantiate and facilitate change (Amelink-verburg et al., 2010). However, there does not appear to be evidence in the literature to support or reject this emphasis on MCV. There were a number of published studies on MCV, $\mathrm{Hb}$ and anaemia from the 1970s, but nothing recently. Unlike serum ferritin, the value of MCV as an effective single indicator alongside $\mathrm{Hb}$ to detect iron deficiency, has not been widely studied (Mei et al., 2005).

The KNOV anaemia guideline's reliance on MCV to diagnose iron deficiency may have limited usefulness or sensitivity as MCV is slower to reflect low or reducing iron stores, than other tests (Thomas et al., 2013). A low MCV with a low Hb may accurately reflect IDA (Table 2 ), but the diagnosis is occurring at the final stage of iron depletion when iron stores may be absent, and it may be too late and too difficult to treat with oral iron therapy. Although MCV is a useful diagnostic tool alongside haemoglobin, the scope of this study limited the inclusion of MCV in the main 
analysis. However, MCV was examined in a sub-group of the study cohort with laboratory results suggestive of anaemia of inflammation, or thalassaemia (low haemoglobin and high ferritin).

\section{Other biochemical tests for iron status}

There are many other biochemical tests for iron deficiency, each measuring a different aspect of iron physiology (Mei et al., 2005). Discussion of the literature on these biochemical tests is beyond the scope of this study. Traditional diagnostic tests within the CBC are the red cell indices: haematocrit (Hct), MCV (as discussed above), mean cell haemoglobin $(\mathrm{MCH})$ and reticulocyte counts.

The reticulocyte count is the first to increase when erythropoises is stimulated (Notebaert et al., 2007). The $\mathrm{MCH}$ indicates the amount of haem pigment in each RBC. A normal $\mathrm{MCH}$ range of $25-34 \mu \mathrm{g}$, indicates a normochromic RBC (Crowther, 2010). Pale anaemic RBCs are hypochromic. The haematocrit is the percentage of RBCs in the plasma volume, which complements measurements of haemoglobin. Values $<0.33$ may be diagnostic of anaemia in pregnancy (WHO, 2001). A high Hct $>0.45$ may indicate dehydration or decreased plasma volume associated with hypertension or pre-eclampsia (CDC, 1998; Frye, 2007).

New Zealand midwives routinely request the $C B C$, however it is uncertain how much understanding or emphasis is placed on interpreting the red cell indices. Although this study did not analyse women's red cell indices other than haemoglobin, the haematocrit and MCVs of a small sub group of women with high haemoglobin levels was of clinical interest in the study.

\section{Management and Treatment}

There are a range of approaches to preventing and treating anaemia and iron deficiency in pregnancy and postpartum, from primary care approaches of dietary advice and oral iron, to secondary/tertiary care strategies of intravenous iron or blood transfusions. Whilst the process of prescribing or recommending oral iron appears simple, there are many things to consider. It is unclear how much influence midwives have on women's iron status, as women themselves are also responsible 
for improving their diet and taking supplements when needed. The women's contribution is beyond the scope of this study. However midwives' primary care approach to testing and management is arguably a major influence on iron status in pregnancy; helping to reduce adverse outcomes associated with maternal anaemia and iron deficiency, as well as the risks and costs associated with blood transfusions and intravenous iron.

\section{Dietary recommendations}

There is a consensus in the literature that dietary advice and oral iron are the first lines of treatment for anaemia in the first and second trimesters, or throughout pregnancy when anaemia is mild (Barut \& Harma, 2009; Breymann et al., 2010; Dodd et al., 2009; Pasricha et al., 2010). However, only KNOV (Jans, 2012) and the UK (Pavord et al., 2012) guidelines incorporate dietary advice in their recommendations (Table 1).

Good nutrition is an important preventative measure, but not an effective treatment for iron deficiency (Pavord et al., 2012) or IDA (Beentje \& Jens, 2011). A UK study of the oral iron intake (diet and supplements) of 1274 pregnant women, found that iron intake was higher in vegetarians, older mothers and women with a university degree (Alwan et al., 2011). Iron intake was significantly less in women who smoked, had a long term illness or lower socio-economic status (Alwan et al., 2011). The finding that vegetarians were less likely to have a low iron intake (odds ratio $=0.5,95 \%$ confidence interval: $0.4,0.8)$ is counter to popular belief, and contradicts the Dutch midwives' recommendation that vegetarianism is a risk factor in pregnancy.

Much of the literature on dietary iron focuses on how to limit inhibitors, and encourage iron absorption. Vitamin C improves bioavailability of iron. Similarly, consuming small amounts of haem (meat) iron with non-haem iron converts ferric to ferrous iron, a more soluble and absorbable form of iron (Elias, 2007). Inhibitors of iron absorption are tannin, calcium in milk products such as cheese, polyphenols in coffee and tea, phytate in whole grains, cereals and breads, oxalic acid in spinach and beetroot (Milman, 2006), and antacids (Monti, 2004). However, as Pavord et al. (2012) say "education and counselling regarding diet may improve iron intake and 
enhance absorption but the degree of change achievable, especially in poorer individuals, remains in question" (p. 592).

\section{Oral iron supplementation}

Oral iron is not prescribed routinely for pregnant women in New Zealand and Australia (Miller \& Wilkes, 2015). Although LMC midwives prescribe oral iron within their scope of practice, there is no clear guidance as to how much iron to prescribe and at what point. The only clear guidance is for obstetric referral and/or consultation when haemoglobin is $<90 \mathrm{~g} / \mathrm{L}$, and not responding to treatment $(\mathrm{MOH}$, 2012). Midwives in New Zealand are advised to determine "the amount of supplementation required on an individual-needs basis according to the woman's blood results, the woman's diet and the gestation of the pregnancy" (Hunter \& Gunn, 2015, p. 872). Hunter and Gunn (2015) point to National Women's Hospital (2013) Guidelines, and UK Guidelines (Pavord et al., 2012), however the haemoglobin parameters and approach to oral iron supplementation in these guidelines differ. This may be confusing for midwives. It follows then, that this study wanted to explore how New Zealand midwives manage oral iron supplementation in practice.

In the UK, pregnant women are no longer routinely supplemented with iron. Studies have shown that the UK population is generally well nourished and the incidence of anaemia, iron deficiency and IDA is lower than in the past, although still a significant problem (Alwan et al., 2011; Pavord et al., 2012). Evidence of the benefits of iron therapy on clinical and functional outcomes is explored in Chapter One. Importantly though, because meta-analyses of trials on iron supplementation are inconclusive (Dodd et al., 2009; Pena-Rosas et al., 2012; Reveiz, Gyte \& Cuervo, 2010), some argue that iron supplementation should be stopped altogether (Wiegerinck \& Mole, 2012). Nonetheless, women and infants in less-developed countries, where the high prevalence of maternal anaemia and iron deficiency constitutes a serious public health issue, do benefit from routine supplementation (Brabin et al., 2001; Goonewardene et al., 2012; Pasricha et al., 2013).

Despite the controversies in the evidence, oral iron is still recommended as the first line treatment option for anaemia, NAID and IDA because it is cheap, safe and 
effective (Pavord et al., 2012). Care must be taken, however, to establish the underlying cause of IDA before commencing treatment (Pasricha et al., 2010). The choice of treatment depends on the cause (Breymann et al., 2010). For example, nutritional iron deficiency benefits from oral iron supplementation but anaemia of inflammation, or $A C D$, may not because the iron is unable to be absorbed and utilized in the body for erythropoeisis (Friedman et al., 2012; Koenig et al., 2014).

How much iron to give is also contentious. There is a move in the literature away from regimes of high daily doses of oral iron supplements, towards lower dose approaches starting earlier in pregnancy. Evidence from research demonstrates efficacy and reduced side effects with lower oral iron doses, or intermittent higher dose approaches, commenced early in pregnancy (Makrides et al., 2003; Milman et al., 2006). The benefits of these approaches are thought to improve women's ability to take iron more consistently (McMahon, 2010).

An often cited study of 301 healthy Danish pregnant women evaluated the effect of daily oral iron prophylaxis of 20,40,60 and $80 \mathrm{mg}$ doses of elemental iron (Milman et al., 2006). The study groups were stratified according to their serum ferritin levels at inclusion. There were no significant differences in iron status between women taking 40 to $80 \mathrm{mg}$ iron/day, but in women taking $20 \mathrm{mg}$ iron/day their iron status during pregnancy and postpartum was significantly lower (Milman et al., 2006).

Although the scope of this study did not include examining dosages of oral iron supplementation, the Danish study by Milman et al. (2006) is still useful because of the distinction between higher and lower dose oral iron. This study was therefore designed to describe approximately whether midwives were prescribing higher dose iron, or recommending lower dose over the counter (OTC) iron. In New Zealand, for example, two commonly prescribed iron tablets contain 105mg (Ferrous sulphate) and $65 \mathrm{mg}$ (Ferrous fumarate) of elemental iron, compared to a popular OTC iron (Thomsons organic iron) with $24 \mathrm{mg}$ of elemental iron.

Barroso et al. (2011) also observed practice around prescribing iron in relation to test results and found that of the 402 women found to be anaemic in the first or second trimester, only $49.3 \%$ had documented evidence of iron prescription. Similarly, this 
study was designed to observe practice around iron supplementation in relation to women's gestation and iron status; with the added distinction between prescribing (higher dose iron), or recommending (lower dose) iron.

Consumption of oral iron is often problematic because of the high rate of mostly gastro-intestinal (GI) side effects (10-40\%) that leads to a high rate of non-compliance (Barut \& Harma, 2009). Common side effects are nausea and constipation. Other side effects include diarrhoea, abdominal pain, vomiting, general malaise and epigastric pain. Side effects are dose-related (Bhandall \& Russell, 2006). Compliance rates for oral iron are also affected by the length of treatment required to replenish iron stores i.e. 3-6 months after normal Hb is restored (Singh, Fong \& Kuperan, 1998). However, studying factors that influence women's compliance rates with oral iron was beyond the scope of this study.

The potential for over-supplementing oral iron was also a consideration in this study. Toxicity is generally not considered to be a concern as iron absorption is regulated by iron stores (Elias, 2007). But more recent evidence recognises that higher oral iron doses may have a toxicological effect, or oxidative damage associated with excessive pooling of intestinal iron (McMahon, 2010). The risk of damage to intestinal epithelium is due to the continuous presence of relatively small amounts of excessive iron (Pavord et al., 2012), and iron-generated free radicals (Milman et al., 2006). The placenta is also particularly susceptible to free radical damage because it is highly vascular and rich in mitochondria. Markers of oxidative stress have been found to be significantly elevated in placentas of women who supplement regularly with iron (Pavord et al., 2012). High doses of oral iron may also lead to potential toxicity as high haemoglobin levels are associated with adverse fetal and maternal outcomes, as discussed in Chapter One. Because of the potential for over and under-prescribing iron, the study was designed to analyse haemoglobin and ferritin levels when midwives prescribed or recommended oral iron.

The literature around dosages and side effects of oral iron was explored to broaden understanding of the overall effects of oral iron supplementation. In the last decade, knowledge of iron metabolism and the physiological effects of low and high dose iron 
supplements has increased. Because it was not known how LMC midwives in New Zealand approach iron supplementation, the study was designed to find out how often midwives prescribed iron, or recommended over the counter iron. These actions were designed to be recorded in relation to women's iron status and gestation, to determine if midwives were prescribing appropriately, according to international evidence and guidelines.

\section{Postpartum anaemia, blood transfusion and intravenous iron}

The literature on postpartum anaemia was explored to understand the relationship between late pregnancy, and postnatal iron status. This included treatments or interventions for severe postpartum anaemia. This relationship was the initial motivation for this study. Anecdotally, it appears that a significant number of anaemic women present in labour, with a lower threshold for requiring blood transfusion or intravenous (IV) iron in the postnatal period.

Birth can be a time of significant blood loss. Women who approach birth with significant anaemia, iron deficiency or IDA may be physiologically less tolerant of blood loss (Milman, 2012b; NBA, 2015). Accordingly, improvements in low antenatal iron status, decreases the use of postpartum blood transfusions (Milman, 2011; NBA, 2015; Pavord et al., 2012; Walsh et al., 2011).

Most women with post partum anaemia, NAID or IDA will benefit sufficiently from regular oral iron so that blood transfusion or intravenous iron are not required (McMahon, 2010). However, oral iron is not considered sufficiently effective, nor the response to treatment rapid enough, to treat moderate to severe postpartum anaemia or IDA (Barut \& Harma, 2009; Singh et al., 1998). Decisions on management of haemorrhagic anaemia, take in to account the volume of blood loss, signs and symptoms, pre-partum haemoglobin levels, as well as antenatal iron stores (Breymann et al., 2010).

There is no defined threshold below which RBC's are indicated, as the decision to transfuse is made on an individual basis (Breymann et al., 2010). A blood transfusion may be indicated with an $\mathrm{Hb}$ of $<70 \mathrm{~g} / \mathrm{L}$, but may not be required if the woman is 
well-compensated (NBA, 2015). Outside of the massive obstetric haemorrhage situation, audits indicate that postpartum blood transfusions are over utilised (NBA, 2015; Pavord et al., 2012). This is despite increased costs (James et al., 2008), risks of transfusion induced sensitisation, e.g. wrong blood, infection, acute lung injury (Barut \& Harma, 2009; Breymann et al., 2010; Notebaert et al., 2007), and the potential future risk of fetal haemolytic disease (NBA, 2015; Pasricha et al., 2010; Pavord et al., 2012). Therefore, while blood transfusions have clear clinical benefits, there are significant risks, costs and disadvantages associated with them.

Intravenous iron may be used as an alternative or adjunct to blood transfusion (Munoz et al., 2007). Second generation formulations of IV iron (iron sucrose and iron polymaltose), are being superseded by third generation (ferric carboxymaltose), with large $(1000 \mathrm{mg})$ total dose iron formulations, and a fifteen minute infusion time. With proven efficacy and safety, and advantages in administration (Breymann, Gliga, Bejenariu \& Strixhova, 2007; Christoph et al., 2012; Frossier, Collingwood, Hodyl \& Dekker, 2014; Van Wyck, Martens, Seid, Baker \& Mangione, 2007), ferric carboxymaltose (ferinject) has recently been adopted for use in New Zealand hospitals, and some outpatient settings. This study gathered data on blood transfusions and IV iron to look at the link between these interventions and primary care management of maternal iron status, although this was not a main study objective or outcome.

\section{Summary of literature review}

The clinical issues around testing, diagnosis and management of anaemia and iron deficiency in pregnancy and postpartum, are complex for many reasons. There is no consensus on the definition of maternal anaemia. The often cited 1968 WHO definition of an $\mathrm{Hb}<110 \mathrm{~g} / \mathrm{L}$ is criticised for not sufficiently taking in to account normal haemodilution of pregnancy, and for not reflecting variance in different populations such as in Australasia. Similarly, there are inconsistent definitions of iron deficiency in the literature, with little in the way of clinical guidance for New Zealand midwives. 
Globally, there are only two comprehensive guidelines on the management of maternal iron status: UK guidelines on the management of iron deficiency in pregnancy (Pavord et al., 2012), and the KNOV Anaemia in Primary Care Midwifery Practice guideline (Jans, 2012). These guidelines are very different, with different parameters. However they both use evidence-based risk factors to guide the approach to testing, and they both emphasise dietary advice as a routine preventative strategy. The Dutch midwives emphasise MCV testing alongside haemoglobin testing, whereas other guidelines and literature focus on the red cell indices i.e. Hct and MCV as adjuncts to haemoglobin testing.

Although serum ferritin is widely recommended as the best measure of iron stores, an accurate interpretation of iron stores requires concurrent testing with another inflammatory marker, CRP, to adjust the ferritin cut-off in the presence of inflammation. The best parameter for interpreting ferritin in the presence of inflammation is unclear, and the focus of recent research. Without correct laboratory testing of serum ferritin, midwives may be incorrectly interpreting misleading results. In the absence of an evidence-based guideline midwives may not be aware of the complexities and challenges in testing and diagnosing of maternal anaemia and iron deficiency.

In terms of prevention and treatment of low maternal iron status, the evidence supports low dose oral iron started early in pregnancy for prevention (and to improve compliance), or higher (possibly intermittent) doses for treatment. It is beyond the scope of this study to examine dosages of oral iron, although a distinction is made between lower over the counter oral iron, and higher dose iron prescriptions. Beyond these primary care strategies, the literature supports a reduction in the use of blood transfusions, and better utilisation of intravenous iron where anaemia is moderate to severe, especially postpartum. Women who are anaemic or iron deficient as they approach birth, have a lower tolerance for blood loss, and are more likely to have low iron status postnatally.

This literature review explored the gaps in knowledge and practice around diagnosis and management of maternal iron status, from a midwives' practice point of view. 
Because so little is known about actual practice in New Zealand, this study is a starting point for identifying how LMC midwives, as primary maternity care providers test and diagnose anaemia and iron deficiency in pregnancy and postpartum. 


\section{Chapter three: Research Design}

\section{Introduction, aims and objectives}

This research was undertaken to explore primary care midwifery management of maternal anaemia and iron deficiency in New Zealand by LMC midwives. The study examined the practice of LMC midwives as the study participants, by retrospectively investigating the data of their clients who were anaemic and/or iron deficient at some point during pregnancy or postpartum. The women's retrospective data comprised a form of birth cohort, or closed cohort; followed from the study onset forward, often at set intervals, up to a fixed end date (Vandenbroucke et al., 2007).

Primary care midwifery notes were reviewed and baseline information was obtained about the study cohort. The primary care notes are the hard-copy clinical notes where the midwife enters the woman's medical and obstetric history, all primary care episodes and visits, and ongoing information such as birth summaries, consultation letters, laboratory, and ultrasound results. A copy of the primary care notes are also held by the woman. Each woman's iron status was retrospectively identified for each trimester and postpartum, up to discharge from midwifery care. Clinical data and information on the midwives' management of anaemia and iron deficiency was obtained from the primary care notes, from booking as baseline, to discharge. Further details of the design are described below.

The research was stimulated by the overarching question as to whether there may be a need for a guideline to guide New Zealand midwives' identification and management of maternal anaemia and iron deficiency. The research question was: “what is LMC midwives' practice around management of women's $\mathrm{Hb}<110 \mathrm{~g} / \mathrm{L}$ and/or serum ferritin $<20 \mathrm{mcg} / \mathrm{L}$, during pregnancy and postpartum?" Specific study objectives were:

- To ascertain levels of consistency of New Zealand LMC midwives' testing and diagnosis of maternal anaemia and iron deficiency. 
- To describe New Zealand LMC midwives' practice around recommending or prescribing iron supplementation in relation to iron status and gestation.

The exploratory nature of this study contributes to the existing but small body of global midwifery research on maternal iron status, from a unique New Zealand perspective.

\section{Research Approach/Methodology}

A descriptive study was undertaken with the main objective being an "accurate portrayal of characteristics of people, situations or groups, and/or the frequency with which certain phenomena occur" (Polit \& Beck, 2008, p.752). Descriptive research falls under the broader category of observational, non-experimental research.

The descriptive methodology of this study was used to describe the phenomenon in the more or less natural setting, with no attempt to manipulate variables, or establish cause and effect, as described by Jirowong, Johnson and Wetch (2011). The phenomenon being investigated was the primary care midwifery management of maternal anaemia and iron deficiency, because little is known about actual practice in New Zealand.

The value of observational or descriptive studies in clinical practice is endorsed by Strengthening and Reporting of Observational Studies in Epidemiology (STROBE) (Vandenbrouke et al., 2007). The STROBE guideline states that valuable evidence for health care practices requires knowledge about aetiology, pathogenesis, diagnosis and prognosis of diseases. This evidence is acquired from randomised trials about treatments and interventions. However, most clinical or public health knowledge comes from observational research, with about $90 \%$ of research papers published in clinical speciality journals describing observational research (Vandenbrouke et al., 2007).

The research methodology in this study is non-experimental, observational and quantitative. Descriptive data was collected on the study population of LMC midwives, and data from women they cared for who were identified retrospectively 
(by the LMCs) as having been anaemic and/or iron deficient at any point during pregnancy or postpartum period. The results may help direct more complex studies in the future, thereby beginning to address the lack of research on maternal iron status, specific to New Zealand.

\section{Research Methods}

A data collection tool was developed to record data from written entries in the women's maternity notes and laboratory results. This was a form of chart review, and although chart review is a convenient source of data, the complexities of obtaining high quality data are sometimes overlooked (Allison et al., 2000). The tool was therefore designed with methodological rigour to enhance validity and reliability.

Quantitative data was collected on a number of variables from the midwives and women, but no attempt was made to manipulate variables or establish cause and effect. The approach focused primarily on the description of midwives' practice. The key study variables were haemoglobin, serum ferritin and whether midwives prescribed or recommended iron. Analysis of co-relations between the variables planned to ask questions about decision making of midwives. For example, "at what stage of pregnancy are midwives more likely to prescribe iron supplements?" or "is there an association between midwives' caseloads or experience, and prescribing or recommending iron supplementation to women?"

\section{Setting}

Originally it was planned to undertake the research in two New Zealand regions. However for pragmatic reasons, and given the size and scope of the study the decision was made to undertake the research in one area only. This is a recognised limitation of the study as the population demographics vary markedly between the two main North and South Islands of New Zealand. Generalisability of the results may have been affected by this. The study is set in a South Island urban area that has four primary care maternity facilities and a large tertiary level hospital, with an annual birth rate of approximately 6000 babies. 


\section{Participants, sampling and recruitment}

Recruitment of the LMC midwives in the study group was via snowballing or network sampling methods following a presentation at a New Zealand College of Midwives (NZCOM) meeting. The sampling method of midwives was non-probability, selfselected and purposive as described by Polit and Beck (2008). Only LMC midwives were included in the study because they are the predominant providers of primary maternity care in New Zealand.

The study group of midwives were considered homogenous as they have similar characteristics that "ensures similarity of extraneous variables" such as similar training (Jirowong et al., 2011, p. 142). The disadvantage of homogeneity in the sample group is that it limits generalisation to other groups (Jirowong et al., 2011) or health professionals, such as family doctors or general practitioners.

Following ethics approval from Victoria University of Wellington (Appendix A), and the DHB (Appendix B), recruitment of LMC midwives began in May 2014 with a presentation at a NZCOM meeting. Participant information sheets (Appendix C) were circulated and contact details of interested midwives recorded. The proposed research was positively received, with midwives identifying a need for research on maternal anaemia and iron deficiency. The presentation was followed up by notices in local NZCOM newsletters. The participant information sheet was posted on the regional NZCOM Facebook page where a number of midwives reported seeing the study information for the first time. Interested midwives were followed up by phone and email to verbally confirm participation. Participant recruitment continued until the completion of data entry at the end of October 2014.

In the phone and email conversations it was clearly explained to midwives that the study aimed to simply describe midwives management of anaemia and iron deficiency where little is known, as there is no recognised standard to measure practice against. This was not an audit. It was also explained that the ethics approval gained under the Human Ethics Policy (Victoria University of Wellington, 2014) was in accordance with the Privacy Act (Office of the Privacy Commissioner, 1993). As the 
researcher, I would only be looking at, and gathering clinical data related to iron status.

For pragmatic reasons, not all women cared for by the participating midwives during the study period were included in the study, although this would have enabled estimates of prevalence of maternal anaemia and iron deficiency in New Zealand. Women who were not anaemic or iron deficient at any point in pregnancy and/or postpartum were excluded. This was the only exclusion criteria, as the purpose of the study was to review midwives' management of low maternal iron status. All women giving birth within the study period of September to December 2013 with an $\mathrm{Hb}$ of $<110 \mathrm{~g} / \mathrm{L}$ and/or serum ferritin of $<20 \mu \mathrm{g} / \mathrm{L}$ at any time throughout pregnancy and the postnatal period were included. Data was collected from four key decision points: the first trimester booking visit, second and third trimester, and postpartum, with laboratory results and midwives' management recorded at each point.

\section{Study size}

Although the external validity of an observational study is strengthened by a predetermined sample size, based on sample size calculations, the importance of sample size determination depends on the context of the study (Vandenbroucke at al., 2007). Early in the design phase, it was decided that due to the size and scope of the study, the aim was to sample as many midwives as possible within the time frame. The study aimed for a sample size of 20-30 midwives in one New Zealand area, where approximately two hundred LMCs practice. It was estimated that each midwife would provide data on approximately 10-20 women, potentially resulting in 200-600 cases. The final study size was 21 LMC midwives, and a cohort of 189 women.

\section{Design of data collection tool}

Design of the tool went through several phases. After the tool was pre-tested twice by two LMC participant midwives, it was changed to an electronic version with no hard copy. During this time the data entry plan changed from prospective entry by midwives, to retrospective entry by the researcher on to a Microsoft Excel computer 
generated spreadsheet. This spreadsheet was developed with assistance from a specialised DHB programmer and health statistician.

The advantage of entering data directly on to a computerised instrument is that it reduces opportunities for error, especially for larger complex projects with 20-30 variables, or more than 50 charts to abstract data from (Allison et al., 2000). Although time-consuming for one person, this was considered an advantage in enhancing the internal validity of the tool, by minimising inter-observer error and reducing measurement bias. Immersion in the data, from inputting to analysis, can also enhance the quality of data analysis as the researcher knows the data and can scrutinize the data for typical and extreme cases, as well as sub-groups (Polit \& Beck, 2010). However one individual 'abstractor' working in isolation can also be a disadvantage in gathering high quality data because of abstractor assumption and interpretation (Allison et al., 2000). So to enhance the tool's reliability and repeatability, factors affecting internal validity are explained in more detail below.

Quantitative, retrospective data was gathered from the case notes on midwives' and women's demographic data, laboratory results, midwives' documentation on their management of maternal iron status, and on a small number of postpartum outcomes (i.e. birth-weight, gestation at birth, and blood loss). Data on laboratory results were also collected online from the DHB to access results missing in hard-copy in the clinical notes. This included collection on data regarding inter-laboratory differences in testing of serum ferritin.

\section{Demographics}

Midwives' demographic data was gathered from a short paper questionnaire of seven closed, self-coded questions, including multiple choice questions. These midwifery characteristics included: age, years of practice, ethnicity, work setting, caseload, practice arrangements and qualifications. Midwives' demographic data was compared to demographic data from the national Midwifery Workforce Survey (MCNZ, 2012) to ascertain representativeness of the sample group. 
Demographic data on the women included: parity, age, ethnicity, time frame between pregnancies, smoking and BMI. Women's demographic data was compared with maternal demographic profiles from 2012, in the Report on Maternity (MOH, 2015). Although quality of diet and socio-economic status are both strongly associated with iron status in pregnancy, they were not included in the baseline demographics of women, due to the complexity in measuring these factors within the limited scope of study. Some data was gathered on maternal risk factors (i.e. age, parity and time interval between births), but these were not analysed in the end due to limited size and scope of the study.

\section{Mode of administration}

After the participating midwives had determined which women met the inclusion criteria, a time and place was arranged for handing over of the primary care clinical notes to the researcher. These notes were different to the hospital notes, which were not accessed for this study. Privacy and confidentiality of the midwives, and anonymity of the women and their clinical information, was maintained at all times.

The clinical notes were locked in storage when not in use. Data was entered on the researcher's password protected computer, and backed up on a hard drive and locked away securely. Maternity notes were returned to the midwives as soon as data entry was completed. Midwives were de-identified by allocating them a number, linked to their group of women from the beginning of data collection. The women were never named, in the collection of their data. Women's national health index (NHI) identifiers were entered initially on the Excel spreadsheet, and changed to a case number when entered onto the Statistical Package of Social Sciences Software (SPSS) spreadsheet. Both the midwife participants and the women's data and test results, were de-identified, becoming anonymous very early in the research process.

\section{Quantitative variables}

The study variables that were collected for the first, second and third trimester included: haemoglobin, serum ferritin, CRP, gestational age at testing, reasons for not testing, and midwives' management including: dietary advice, over the counter iron, 
iron prescription, and referral (or transfer of care) to a specialist for intravenous iron or blood transfusion. Postpartum variables also included gestation at birth, birthweight, peri-partum blood loss and timing of tests. Not all outcome variables were included in the analysis, i.e. gestation at birth and birth weight. Data was collected in the rawest form and entered as continuous variables, or coded categorical variables. The level of measurement for some variables was reorganised into categories after the initial data collection, and during statistical analysis.

Haemoglobin was the key variable that defined anaemia. The inclusion criteria of $\mathrm{Hb}<110 \mathrm{~g} / \mathrm{L}$ was selected because it is the WHO (1968) parameter for diagnosing anaemia in pregnancy, that is still maintained (NBA, 2015), and most often cited. The WHO parameter of $\mathrm{Hb}<110 \mathrm{~g} / \mathrm{L}$ may not also sufficiently account for haemodilution beyond the first trimester of pregnancy (Pavord et al., 2012). However, CDC (1998) definition of anaemia in pregnancy as $\mathrm{Hb}<105 \mathrm{~g} / \mathrm{L}$, is considered a reasonable alternative to the WHO definition, as it takes into account haemodilution of pregnancy (Paterson et al., 1994; Pavord et al., 2012). Therefore, this study defined anaemia in the second and third trimester as $\mathrm{Hb}<105 \mathrm{~g} / \mathrm{L}$. Postpartum anaemia was defined as $\mathrm{Hb}<100 \mathrm{~g} / \mathrm{L}$ as per the WHO (2000) and UK guidelines (Pavord et al., 2012). Severe postpartum anaemia is defined by Breymann et al. (2010) as $\mathrm{Hb}$ $<85 \mathrm{~g} / \mathrm{L}$, although international guidelines do not categorise postpartum anaemia according to severity (Table 1 ).

Serum ferritin was the key variable that defined iron deficiency. The cut-off for iron deficiency was ferritin $<20 \mu \mathrm{g} / \mathrm{L}$, and absent iron stores was ferritin $<12 \mu \mathrm{g} / \mathrm{L}$. These parameters are lower than UK guidelines of ferritin $<30 \mu \mathrm{g} / \mathrm{L}$ (Pavord et al., 2012), but utilised in an often cited study by Walsh et al. (2011); and consistent with the local DHB guideline with parameters for maternal for iron status (on intravenous iron use in pregnancy and postpartum).

The study cut-off for iron deficiency, in the presence of inflammation (i.e. CRP >5mg), was serum ferritin $<50 \mu \mathrm{g} / \mathrm{L}$, also consistent with the local DHB guideline. This parameter is between the ferritin $<30 \mu \mathrm{g} / \mathrm{L}$ parameter proposed by WHO (2011) and Thurnham et al., (2010), and the ferritin $<70 \mu \mathrm{g} / \mathrm{L}$ cut-off proposed by Wang et al. 
(2010). Serum ferritin parameters for defining iron deficiency, in the presence of inflammation, have not been clearly established (Gartner et al., 2013; Nel et al., 2015; Thurnham et al., 2010).

Data from the clinical notes after each trimester's blood tests, recorded up to three of the midwife's actions, as some midwives had more than one strategy to manage iron status, e.g. dietary advice and an iron prescription. Management actions were categorised as main and secondary actions, according to how midwives prioritised their strategies in the clinical notes. There were six options or strategies: no action, dietary advice, over the counter iron, iron prescription, general practitioner referral, or obstetric referral. The scope of the study limited the amount of detail regarding management, simply describing that a clinical strategy had been advised, or not.

Over the counter iron included all non-prescribed iron preparations, ranging from herbal preparations to supermarket bought supplements, including multivitamins and minerals. The variable for prescribed oral iron recorded the binary action of prescribing (yes/no), not the dose or frequency of the dose. Information on compliance or tolerance of oral iron supplements was not recorded. Oral iron supplements were operationalised primarily as outcome variables, because the action of prescribing or recommending iron was presumably influenced by changes in the predictor variables i.e. $\mathrm{Hb}$, serum ferritin and gestation.

\section{Data measurement}

The details of measurements of the variables are described below to strengthen the validity and reliability of the study, especially where there was a potential for measurement error. The STROBE recommends giving sources of data, details of methods of measurement for the variables, as well as clear definition of the types of variable, to strengthen study validity (Vandenbrouke et al., 2007). Accordingly, measurement error or bias was minimised with consistent decisions at the data entry level by the researcher.

Iron status was the most challenging to categorise in order to minimise measurement error. This was due to inconsistent testing of serum ferritin, and inconsistent testing 
of CRP alongside serum ferritin to adjust for the presence of inflammation. For example, anaemia without a measure of serum ferritin for iron stores was categorised as 'anaemic with unknown stores', rather than IDA, which was probable.

Without a concurrent CRP, serum ferritin may show as a false high/normal result. The decision was therefore made to operationalise iron sufficiency as 'confirmed' or 'unconfirmed'. Confirmed iron sufficiency was non-anaemic and ferritin $\geq 20 \mu \mathrm{g} / \mathrm{L}$ with $\mathrm{CRP}<5 \mathrm{mg} / \mathrm{L}$, or ferritin $\geq 50 \mu \mathrm{g} / \mathrm{L}$ with no CRP. Unconfirmed iron sufficiency was non-anaemic and ferritin $20-49 \mu \mathrm{g} / \mathrm{L}$ with no CRP to correct for inflammation. So the decision was made early in the study, to interpret blood test results at face value, and to make minimal assumptions about iron status based on incomplete results.

Information on methods of blood test analysis was sought from the two laboratories where midwives obtained the majority of test results, to minimise the potential for measurement error due to different analysis methods. Haematological analysis of the CBC at the DHB laboratory was automated on the Sysmex XE2100 analyser. The private laboratory used an updated version of the same method on the Sysmex XE5000. Serum ferritin was analysed at the DHB laboratory by a chemi-luminescent microparticle immuno assay (CMIA), on an Architect C8000 analyser, and via Hitashi Cobas instruments and an ECLIA method at the private laboratory. The DHB and private laboratory both tested CRP via an immune-turbidometric method on an Architect (C8000) analyser. Methods of testing are available on the website (www.labnet.health.nz/siqag). Importantly, the reported reference ranges for all the tests are standardised by the South Island Quality Assurance Group.

Measurement of blood loss as a postpartum variable was entered from recorded blood loss on women's delivery summaries. Blood loss is usually estimated, and sometimes measured when loss is significant. Estimations of peri-partum blood loss is however, notoriously inaccurate. Of primary interest in this study was midwives' management of anaemia following significant blood loss, defined as $>500 \mathrm{mls}$.

A difficulty in measuring midwives' management of maternal anaemia and iron deficiency was the documentation of clinical practice. The dictum "if it isn't written down, it didn't happen" posed challenges, because what some midwives told me 
they were doing, was not necessarily evident in their documentation. For example one midwife explained that she always dedicated a first trimester antenatal visit to dietary advice, including iron intake, however this was not documented in the clinical notes, and therefore not entered. This highlighted the fact that clinical information from a chart review is at least two steps removed from the patient, as clinicians examine and document, then abstract the information (Allison et al., 2000).

Consistent data entry was important for collection of data on iron supplementation, as the midwives' documentation varied widely. For example, where midwives documented "taking iron supplements" or "taking iron tabs", this was entered as over the counter iron, not prescription iron, unless stated as such. Doses or frequency of oral iron were not recorded. In the antenatal summary of the primary care notes where 'minerals prescribed' was ticked, but not distinguishable between iodine or iron, iron wasn't entered as having been prescribed unless clarified in the clinical notes.

Iron supplements were not presumed to have been continued once started. Unless midwives documented comments about the women taking oral iron in subsequent visits, it was presumed to have been stopped. Conversely, if there was documented evidence of continuing to take oral iron, subsequent to the initial prescription or recommendation, data was re-entered as 'oral prescription' or 'OTC iron'.

\section{Missing data}

The internal and external validity of this study was strengthened by addressing how 'missing' laboratory results were managed for the main variables of interest $(\mathrm{Hb}$ and serum ferritin). There was no missing data, as all laboratory tests not undertaken were all accounted for by cross checking documentation with hard copies, and online laboratory results. All tests not undertaken were accurately coded according to why the tests were not undertaken.

Whole groups of first, second or third trimester antenatal blood tests were not undertaken for some women. These data fields were coded as 'tests not done' when they were not requested by the LMC midwife. Other reasons for missing groups of 
blood tests results were due to women booking later in pregnancy, declining blood tests, or birthing prematurely. These were coded separately.

Because serum ferritin is not a routine test, missing ferritin results were coded as

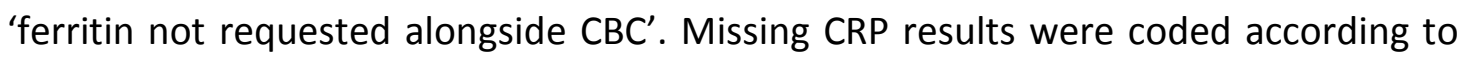
the type of laboratory where the ferritin test was analysed, as concurrent testing of CRP with ferritin is based on laboratory practice. Information on laboratory types (i.e. DHB or private), was obtained from the online laboratory results. The analysis of the reasons why blood tests were not undertaken was, therefore, an important part of the study.

\section{Data Analysis}

The focus of analysis in this study was to describe midwifery decision making and management of maternal iron status, by analysing the frequency and results of laboratory tests, and the frequency of over the counter or prescribed iron, at each trimester and postpartum. This analysis included changes in iron status, and midwives' response to this.

Analysis of data was systematically approached in several phases following data entry and data cleaning. Data cleaning was a lengthy phase, as many laboratory results were not recorded, or incomplete, in the primary care notes. Therefore, almost all of the women's results were cross-checked with on-line results. At this stage, the tests not undertaken were coded as to why they were not undertaken. Results were also coded as to which laboratory had undertaken the testing. Data cleaning occurred through every phase of analysis, and outliers and unusual or inconsistent results were investigated. Occasional data entry errors were found, and corrected, especially where continuous data was re-code or categorized.

Data was initially entered on Microsoft Office Excel worksheet, then imported and analysed by SPSS (Version 22). Analysis of baseline data was the first phase. Demographic characteristics of the midwives and the cohort of women were analysed with descriptive statistics, to ascertain the representativeness of the study groups. The midwives were compared to 2910 midwives with annual practicing 
certificates (APCs) in 2012 (MCNZ, 2012). The study women were compared to the 62,321 women who gave birth in New Zealand in 2012 (MOH, 2015).

Analysis of continuous variables in the demographic data included measuring distributions, to ascertain the appropriate measures of central tendencies for the normally distributed (mean and standard deviation (SD)) and skewed (median and inter-quartile range ) data. Normally distributed variables that could have parametric statistical tests, included the midwives' age in years, years in practice and caseload. The skewed variables that could have non-parametric statistical tests included the women's age, BMI, time since last pregnancy, and gestation at birth.

Following input from the Victoria University statistician, 95\% confidence intervals of proportions were calculated to compare differences between the cohort of women, and comparative data from $\mathrm{MOH}$ (2015). The confidence intervals were calculated on https://www.mccallum-layton.co.uk/tools/statistic-calculators/confidence-interval-

for-proportions. Confidence intervals were not calculated on midwives' demographic data as the sample size was too small.

The second phase was a descriptive analysis of the frequency of tests undertaken, categories of iron status, and midwives management strategies. This included categorising continuous demographic and clinical data into categorical variables. Initial analysis of this data resulted in the development of decision trees (Appendices $D, E \& F)$ that tracked the testing and iron status of each woman, for each trimester and postpartum. Women were grouped according to whether they had serum ferritin tested at booking, or not, as this was the main difference in practice. The decision trees provided an overview of testing and iron status, and provided a means of tracking individual cases throughout pregnancy and postpartum, which was unable to be achieved through the basic descriptive analysis.

The research question, the distribution of the data, and the types of variables directed the choice of inferential statistical tests used to explore relationships between the variables. Associations between midwives' caseloads, or years of practice, and practices of testing for iron deficiency, and prescribing iron were analysed by Pearson chi-square tests of independence. A Mann-Whitney U-test was 
also used to test the difference between third trimester ferritin levels for women who had ferritin tested at booking or not.

Measures of effect were reported alongside the statistical level of significance ( $p$ value), to enable readers to interpret the research findings without over-reliance on $p$ values (Field, 2013). As well as the 95\% confidence intervals of proportions in the descriptive analysis, Cramer's $V$ and Cohen's $d$ values were the other reported measures of effect size, or strength of association, in the chi-square analysis (for the three by two, and two by two tables respectively). Reporting the strength of the associations allows the reader to interpret the clinical significance of the study's findings, especially where the study is too undersized to demonstrate statistical significance (Peat, 2002).

Secondary analyses, that were not pre-determined, were undertaken to determine any differences between BMI and low iron status. A Mann-Whitney U-test was used to test the difference between third trimester ferritin levels (as continuous, skewed data) and normal/low-weight or over-weight/obese BMI. A Pearson's chi-square test for independence was used to test the relationship between low iron status and BMI, in a $3 \times 2$ table. BMI was categorised to low/normal BMI (<25), and overweight/obese BMI ( $\geq 25)$. Iron status had three categories: low iron status, iron sufficiency (confirmed and unconfirmed), or unknown status. These categories for iron status were flawed due to the difficulty in categorising iron status because of incomplete blood tests results. These factors were not controlled for in the analysis.

Another secondary analysis was undertaken because high BMI is a pro-inflammatory state that may mask iron deficiency, with false normal/high ferritin levels, uncorrected for inflammation by an absence of concurrent CRP testing. All women with ferritin testing at booking, but with no CRP, were analysed for each trimester. The women were categorised according to iron status and BMI: low/normal $(\mathrm{BMI}<25)$, overweight (BMI 25-29), and obese $(\mathrm{BMI} \geq 30)$. The basic descriptive analysis of proportions was repeated with the different serum ferritin parameters at booking of $<20 \mu \mathrm{g} / \mathrm{L},<30 \mu \mathrm{g} / \mathrm{L}$ and $<50 \mu \mathrm{g} / \mathrm{L}$; the latter two parameters are two proposed for iron deficiency in the presence of inflammation. The small size of the 
sub-groups, precluded statistical analysis, or use of confidence intervals, but may be clinically interesting.

\section{Validity, reliability and bias}

The validity and reliability of the study was strengthened by the methodological rigour and minimisation of bias, in the study's planning phase. The methods section above outlines how potential sources of bias were minimised, and measurement errors were avoided, with careful explanation of conceptual and operational variables. Particular attention was given to developing an instrument or tool that had good internal and external validity in the collection of high quality data for analysis.

Face, content and construct validity are types of internal validity relevant to this study. Face validity is the extent to which the instrument measured what it was supposed to measure (Cluett \& Bluff, 2006; Peat 2002). Content validity is the extent to which the instrument covered the research area of interest, and construct validity the extent to which the tool encompassed the concept, or construct being measured (Cluett \& Bluff, 2006; Peat 2002). Because a new instrument or tool was devised for this study, the internal validity of the tool is yet to be verified. Nonetheless, every effort was made to develop a tool that is highly valid and reliable.

External validity or generalisability of the results was sought by maximising the sample size of midwives and women. Although the sample size of midwives was small and statistically underpowered, the results may still be of clinical interest. A recognised limitation of the study relates to differing ethnic demographics in the two main geographical islands of New Zealand. Validity and reliability in this study was achieved with the richness of the data collection, with no missing data which resulted in high quality data for the descriptive and inferential statistical analysis.

\section{Ethics, and the Treaty of Waitangi}

This study respected the Treaty of Waitangi principles of partnership, participation and protection, as the foundations for the ethical code of conduct for practice and research for New Zealand midwives. The NZCOM (2005) upholds "each women's rights to free and informed choice and consent ... ensuring the advancement of 
midwifery knowledge [and research] is based on activities that protect the rights of women" (p. 8). Accordingly, the participant information sheet clearly explained the purpose of this study including: an invitation to participate, what the midwives' role in the study would be, potential risks and benefits, how privacy was protected, and how the information was to be collected and used (Appendix C).

Ethics approval was granted by Victoria University of Wellington (Appendix A), and the DHB (Appendix B). The DHB ethics process involved a consultation process with Te Komiti Whakarite (DHB Maori Research Committee), and a commitment to submit a final report to Te Komiti Whakarite when the research is complete.

The specific ethical issues that needed to be considered in this study were principally related to protecting the privacy and identity of the participating midwives; the safekeeping and protection of the information in the clinical documentation; and ensuring that the diagnostic tests and midwifery treatment decisions were not identifiable.

The midwives were de-identified by allocating them a number, linked to the group of women in their care. The women were never named. The women's NHIs were changed to case numbers after the initial data entry phase was completed. The participating midwives, and the women's data, were de-identified and became anonymous very early in the research process. Therefore the midwives' treatment strategies and the women's test results also became anonymous early on.

The clinical notes were held by the researcher for the minimal time possible, and locked away when not in use. The data was entered on a password protected computer, and hard-drive back-ups were also locked away. Only clinical information relevant to maternal iron status was studied in the notes, and recorded on the spreadsheet. 


\section{Chapter four: Results}

\section{Introduction}

This chapter presents the results of the study of 21 New Zealand LMC midwives' management of maternal anaemia and iron deficiency throughout pregnancy and postpartum. Section one of the results begins with the demographic and professional characteristics of the midwives and the demographic details of the cohort of 189 women whose clinical details (related to anaemia and iron deficiency) provided data for this study. Section two presents the results of the LMC midwives' practice around diagnosis and management of women's $\mathrm{Hb}<110 \mathrm{~g} / \mathrm{L}$ and /or serum ferritin $<20 \mu \mathrm{g} / \mathrm{L}$, during pregnancy and postpartum. Section three outlines results of additional analyses undertaken on iron status of women with a high $\mathrm{BMI}$, as the presence of inflammation related to high BMI, may have confounded interpretation of laboratory results for midwives.

\section{Section One: Demographics}

Twenty-one self employed, 'case-loading' LMC midwives participated in this study. The sample of midwives is comparable to the Health Workforce Survey of 2910 midwives with annual practising certificates in 2012 (MCNZ, 2012), in terms of mean age and years in practice (Table 3). However, Maori midwives were underrepresented in the study with no study midwives identifying as Maori. A higher proportion of the study midwives had larger caseloads. The urban setting also did not represent rural midwifery practice. 
Table 3: Characteristics of Lead Maternity Carer Midwife participants compared with those with a practicing certificate in $\mathbf{2 0 1 2}$

\begin{tabular}{|c|c|c|}
\hline Characteristic & $\begin{array}{r}\text { Study midwives } \\
\mathrm{n}(\%)\end{array}$ & $\begin{array}{r}\text { Midwives with } 2012 \text { APC } \\
n(\%)\end{array}$ \\
\hline $\begin{array}{l}\text { Midwives age in years } \\
\text { mean + / - SD }\end{array}$ & $47.2+/-10.425$ & 46.8 (no SD) \\
\hline $\begin{array}{l}\text { Years in Practice } \\
\text { mean +/- SD }\end{array}$ & $15.5+/-12.695$ & 14.7 (no SD) \\
\hline $1-10$ & $11(52.4)$ & $1237(42.5)$ \\
\hline $11-20$ & $2(9.5)$ & $865(29.7)$ \\
\hline $21-30$ & $5(23.8)$ & $506(17.4)$ \\
\hline $31-40$ & $3(14.3)$ & $255(8.8)$ \\
\hline $41+$ & - & $42(1.4)$ \\
\hline Not stated & - & $5(0.2)$ \\
\hline Caseload 2013 & & \\
\hline mean +/- SD & $46.3+/-14.242$ & 42.0 (no SD) \\
\hline $11-20$ & $1(4.8)$ & $77(7.2)$ \\
\hline $21-30$ & $1(4.8)$ & $89(8.4)$ \\
\hline $31-40$ & $6(28.6)$ & $152(14.3)$ \\
\hline $41-50$ & $7(33.3)$ & $198(18.6)$ \\
\hline $51-60$ & $2(9.5)$ & $180(16.9)$ \\
\hline $61-70$ & $4(19.0)$ & $101(9.5)$ \\
\hline Ethnicity & & \\
\hline Maori & $0(0)$ & $150(5.2)$ \\
\hline New Zealand and other European & $20(95.2)$ & $2587(88.9)$ \\
\hline Other & $1(4.8)$ & $44(1.5)$ \\
\hline Practice arrangement & & \\
\hline Works alone & $0(0)$ & - \\
\hline Works with one other & $4(19)$ & - \\
\hline Works with two or more & $17(81)$ & - \\
\hline Postgraduate study & & \\
\hline Completed qualification & $1(4.8)$ & $84(2.9)^{*}$ \\
\hline Currently studying & $0(0)$ & $191(6.6)$ \\
\hline Totals & 21 & 2910 \\
\hline
\end{tabular}


In the study group, and the population of all New Zealand midwives with annual practicing certificates, the largest proportion practiced for $1-10$ years, $52.4 \%$ and $42.5 \%$ respectively. Both groups had annual caseloads of $31-50$. In the study, $19 \%$ of LMC midwives had larger caseloads of $61-70$, compared to $9.5 \%$ of LMCs in the general population (MCNZ, 2012). The MCNZ (2012) did not survey practice arrangements. However $81 \%(n=17)$ of study midwives worked with two or more other midwives.

Similar representativeness was present in the women for whom this group of midwives provided care. The women were similar to the target population of 62,321 women who gave birth in New Zealand in 2012 (MOH, 2015) in terms of age, gestation at birth and parity (Table 4). However they did differ with respect to ethnicity and smoking behaviour. The study women included a high proportion (76\%, $n=143)$ of New Zealand or other European ethnicities compared to under half $(48 \%$, $n=28,894)$ in the general population. There was a small proportion of Maori $(8.5 \%$, $n=16)$ compared to $25 \%(n=15,694)$ nationally. Nationally more women in 2012 smoked (15\%) $(\mathrm{MOH}, 2015)$, than in the study group (9\%). The combined proportion of study women with overweight or obese BMIs was less than birthing women in New Zealand in 2012 (44\% vs. 51\%).

The descriptive analysis, including the measures of central tendency, did not necessarily match comparative demographic data from the MOH (2015) and MCNZ (2012). For example MCNZ (2012) data did not include standard deviation (SD) with the mean, although this measurement is included in Table 3 to demonstrate statistical accuracy of the study midwives. Similarly, MOH (2015) data did not include inter-quartile range (IQR) for the non-parametric demographic data on women, but this is included in Table 4 to demonstrate statistical accuracy of the study cohort. 
Table 4: Characteristics of women in study, compared to birthing population of women in 2012

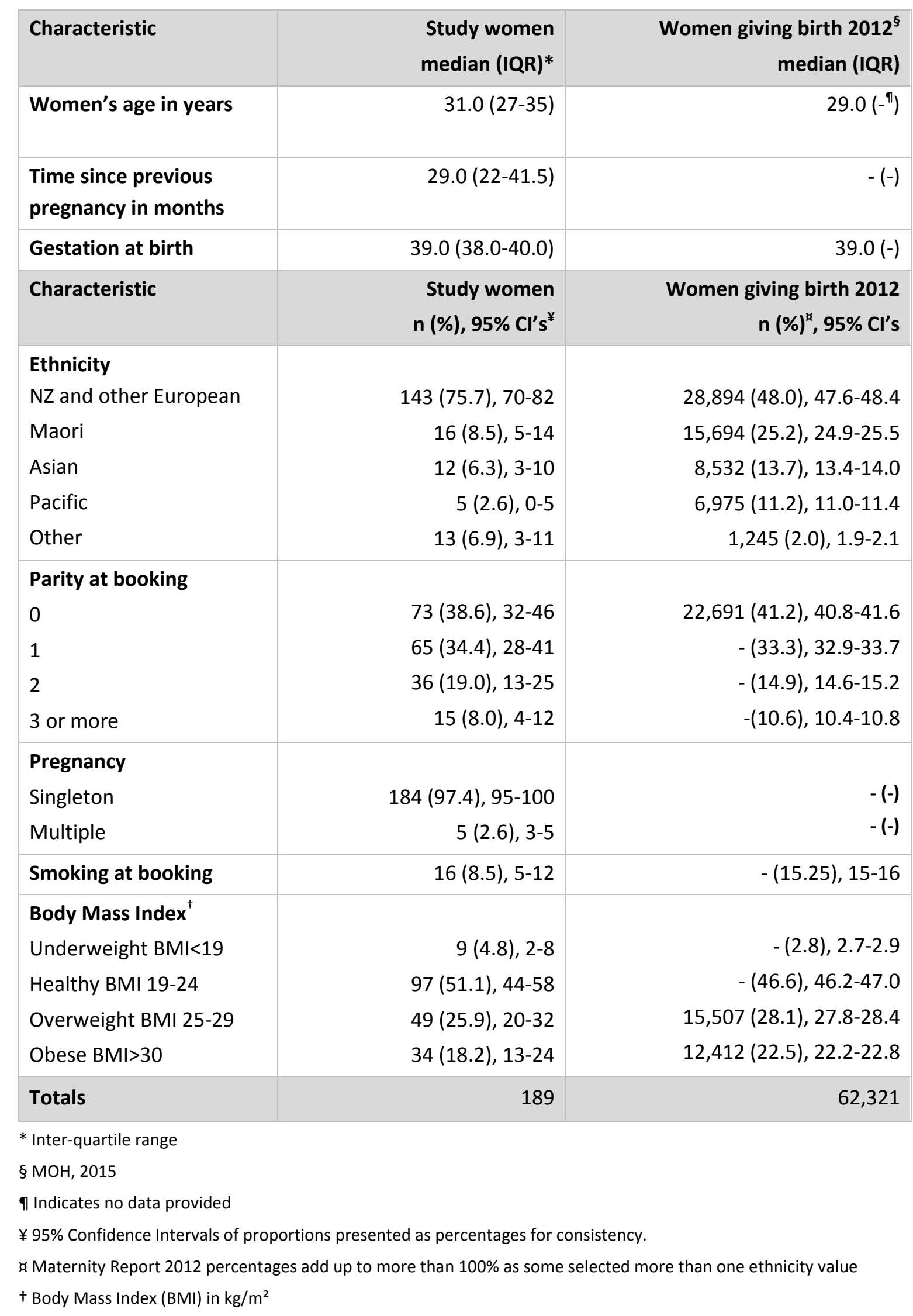




\section{Section Two: Diagnostic tests and treatments}

\section{Testing for iron status in pregnancy}

The total combined LMC's caseload was 974 women. Of these, $19.4 \%$ of women met the inclusion criteria of $\mathrm{Hb}<110 \mathrm{~g} / \mathrm{L}$ and/or serum ferritin $<20 \mu \mathrm{g} / \mathrm{L}$ at any point in pregnancy or postpartum. Haemoglobin was almost always tested in the first (98.4\%) and second (95.8\%) trimesters, but this decreased in the third trimester (82\%). Across the three trimesters haemoglobin was tested at least once for all women. Serum ferritin was more commonly tested in the second trimester (83.6\%), and third trimester $(67.7 \%)$ than at the first trimester booking (52.4\%) (Table 5).

Table 5: Testing for iron status in pregnancy by trimester.

\begin{tabular}{|l|r|r|r|}
\hline $\begin{array}{l}\text { Testing for Hb or ferritin } \\
\mathbf{N = 1 8 9}\end{array}$ & $\begin{array}{r}\text { First trimester } \\
\mathbf{n}(\%)\end{array}$ & $\begin{array}{r}\text { Second trimester } \\
\mathbf{n}(\%)\end{array}$ & $\begin{array}{r}\text { Third trimester } \\
\mathbf{n}(\%)\end{array}$ \\
\hline $\begin{array}{l}\text { Total number of complete blood } \\
\text { counts undertaken as routine } \\
\text { antenatal testing (including } \mathbf{H b})\end{array}$ & $186(98.4)$ & $181(95.8)$ & $155(82.0)$ \\
\hline No tests undertaken & & & \\
\hline Ferritin tested alone without Hb & $3(1.6)$ & $7(3.7)$ & $34(18.0)$ \\
\hline Ferritin tested with Hb & - & $1(0.5)$ & - \\
\hline
\end{tabular}

Almost half $(47.6 \%, n=90)$ of the woman did not have serum ferritin tested at booking (Table 5). Serum ferritin was not requested alongside the routine request for the complete blood count and haemoglobin for $46.0 \%$ of women in the first, $12.2 \%$ of women in the second, and $14.3 \%$ of women in the third trimester. The blood testing and iron status of individual women was tracked through each trimester, and represented in the decision trees (Appendices D, E \& F), in a way that the aggregated results represented in the table could not. For example, five women had no ferritin tested at all (Appendix E), although this is not evident in Table 6. One midwife did not request any serum ferritin tests for four of her eight clients in the study. An additional $13.8 \%$ of women $(n=26)$ had no third trimester bloods requested at all by midwives. 
Table 6: Reasons antenatal tests were not undertaken

\begin{tabular}{|c|c|c|c|c|c|c|}
\hline $\begin{array}{l}\text { Reasons tests not } \\
\text { undertaken } \\
\mathrm{N}=189(\%)\end{array}$ & $\begin{array}{r}\text { Antenatal } \\
\text { tests not } \\
\text { requested } \\
n(\%)\end{array}$ & $\begin{array}{r}\text { Ferritin not } \\
\text { requested } \\
\text { with CBC* } \\
n(\%)\end{array}$ & $\begin{array}{r}\text { Late } \\
\text { Booking } \\
\text { n (\%) }\end{array}$ & $\begin{array}{r}\text { Woman } \\
\text { declined } \\
\text { tests } \\
n(\%)\end{array}$ & $\begin{array}{r}\text { Woman } \\
\text { away } \\
\text { for tests } \\
n(\%)\end{array}$ & $\begin{array}{r}\text { Birthed } \\
\text { Pre- } \\
\text { maturely } \\
\text { n (\%) }\end{array}$ \\
\hline $\begin{array}{l}\text { No haemoglobin } \\
\text { tested } \\
\text { First trimester: } \\
3(1.6)\end{array}$ & $0(0.0)$ & $0(0.0)$ & $1(33.3)$ & $2(66.7)$ & $0(0.0)$ & $0(0.0)$ \\
\hline $\begin{array}{l}\text { No haemoglobin } \\
\text { tested } \\
\text { Second trimester: } \\
8(4.2)\end{array}$ & $6(75.0)$ & $0(0.0)$ & $1(12.5)$ & $0(0.0)$ & $1(12.5)$ & $0(0.0)$ \\
\hline $\begin{array}{l}\text { No haemoglobin } \\
\text { tested } \\
\text { Third trimester: } \\
34(18.0)\end{array}$ & $26(76.5)$ & $0(0.0)$ & $0(0.0)$ & $1(2.9)$ & $0(0.0)$ & 7 (20.6) \\
\hline $\begin{array}{l}\text { No serum ferritin } \\
\text { tested } \\
\text { First trimester: } \\
90(47.6)\end{array}$ & $0(0.0)$ & 87 (96.7) & 1 (1.1) & $2(2.2)$ & $0(0.0)$ & $0(0.0)$ \\
\hline $\begin{array}{l}\text { No serum ferritin } \\
\text { tested } \\
\text { Second trimester: } \\
31(16.4)\end{array}$ & $6(19.4)$ & $23(74.2)$ & $1(3.2)$ & $0(0.0)$ & $1(3.2)$ & $0(0.0)$ \\
\hline $\begin{array}{l}\text { No serum ferritin } \\
\text { tested } \\
\text { Third trimester: } \\
61(32.3)\end{array}$ & $26(42.6)$ & $27(44.2)$ & $0(0.0)$ & $1(1.6)$ & $0(0.0)$ & 7 (11.6) \\
\hline
\end{tabular}

*Complete blood count including haemoglobin $(\mathrm{Hb})$

\section{Iron Status}

The findings on iron status at each trimester are presented throughout the results in relation to when the midwives tested, gave dietary advice, prescribed or recommended iron. Because of incomplete antenatal test results for iron stores, either due to serum ferritin not tested, or ferritin not tested with CRP, the 'sufficient' iron status group was categorised as 'confirmed' or 'unconfirmed' (Table 7). 
Table 7: Iron status in pregnancy

\begin{tabular}{|c|c|c|c|}
\hline Iron Status & $\begin{array}{r}\text { First } \\
\text { trimester } \\
n(\%)\end{array}$ & $\begin{array}{r}\text { Second } \\
\text { trimester } \\
n(\%)\end{array}$ & $\begin{array}{r}\text { Third } \\
\text { trimester } \\
\mathbf{n}(\%)\end{array}$ \\
\hline Confirmed Iron Sufficiency* & $51(27.0)$ & $2(1.1)$ & $12(6.3)$ \\
\hline Unconfirmed Iron Sufficiency ${ }^{\S}$ & $31(16.4)$ & $17(9.0)$ & 30 (15.9) \\
\hline $\begin{array}{l}\text { Non-anaemic: } \\
\text { (ferritin not tested, iron stores } \\
\text { unknown) }\end{array}$ & $86(45.5)$ & $23(12.2)$ & $24(12.7)$ \\
\hline $\begin{array}{l}\text { Non-anaemic iron deficiency: } \\
\text { ferritin } 12-19 \mu \mathrm{g} / \mathrm{L} \text { (or } \mathrm{SF}<50 \mu \mathrm{g} / \mathrm{L} \\
\text { with CRP >5) }\end{array}$ & $13(6.9)$ & $46(24.3)$ & $42(22.2)$ \\
\hline $\begin{array}{l}\text { Non-anaemic absent iron stores: } \\
\text { ferritin<12 } \mathrm{gg} / \mathrm{L}\end{array}$ & $2(1.1)$ & $77(40.7)$ & $29(15.3)$ \\
\hline $\begin{array}{l}\text { Anaemic: } \\
\text { (ferritin not tested, iron stores } \\
\text { unknown) }\end{array}$ & $1(0.5)$ & $1(0.5)$ & $3(1.6)$ \\
\hline Iron deficiency anaemia & $1(0.5)$ & $14(7.4)$ & $11(5.8)$ \\
\hline $\begin{array}{l}\text { Possible anaemia of inflammation or } \\
\text { thalassaemia }\end{array}$ & $1(0.5)$ & $2(1.1)$ & $4(2.1)$ \\
\hline $\begin{array}{l}\text { Iron status unknown: } \\
\text { (not tested) }\end{array}$ & $3(1.6)$ & $7(3.7)$ & $34(18.0)$ \\
\hline Total study women & $189(100)$ & $189(100)$ & $189(100)$ \\
\hline \multicolumn{4}{|c|}{$\begin{array}{l}\text { * Confirmed iron sufficiency: non-anaemiac, and ferritin } \geq 20 \mu \mathrm{g} / \mathrm{L} \text { with } \mathrm{CRP}<5 \mathrm{mg} / \mathrm{L} \text {, or ferritin } \geq 50 \mu \mathrm{g} / \mathrm{L} \text { with no } \\
\text { CRP }\end{array}$} \\
\hline \multicolumn{4}{|c|}{$\begin{array}{l}\text { If First trimester anaemia } \mathrm{Hb}<110 \mathrm{~g} / \mathrm{L} \text {, second and third trimester anaemia } \mathrm{Hb}<105 \mathrm{~g} / \mathrm{L} \text { as per NICE Guidelines } \\
\text { (2014) }\end{array}$} \\
\hline
\end{tabular}

Confirmed iron sufficiency included: $\mathrm{Hb} \geq 110 \mathrm{~g} / \mathrm{L}$ (first trimester) or $\mathrm{Hb} \geq 105 \mathrm{~g} / \mathrm{L}$ (second and third trimester) with ferritin $\geq 20 \mu \mathrm{g} / \mathrm{L}$ with CRP $\leq 5 \mathrm{mg} / \mathrm{L}$; or ferritin $\geq$ $50 \mu \mathrm{g} / \mathrm{L}$ if $\mathrm{CRP}>5 \mathrm{mg} / \mathrm{L}$ (ferritin parameter adjusted as inflammation present); or ferritin $\geq 50 \mu \mathrm{g} / \mathrm{L}$ with no CRP (presence of inflammation assumed). Unconfirmed iron sufficiency included: $\mathrm{Hb} \geq 110 \mathrm{~g} / \mathrm{L}$ (first trimester) or $\mathrm{Hb} \geq 105 \mathrm{~g} / \mathrm{L}$ (second and third trimester, or postpartum) with serum ferritin 20-49 $\mu \mathrm{g} / \mathrm{L}$ with no CRP. Six antenatal 
tests with no concurrent CRP with ferritin, resulted in anaemia with normal or high ferritin ( $\geq 20 \mu \mathrm{g} / \mathrm{L}$ ) (Table 7). These tests possibly indicated anaemia of inflammation, or thalassaemia.

There was a decline in iron status from booking to late pregnancy, with the largest decline from the first to second trimester: $9.5 \%(n=18)$ had low iron status with either anaemia, non-anaemic iron deficiency (NAID) including absent iron stores, iron deficiency anaemia (IDA), or possible anaemia of inflammation (or thalassaemia) in the first trimester, $74.0 \%(n=140)$ in the second trimester, and $47.0 \%(n=89)$ in the third trimester (Table 7). This meant that nearly half of this population of women approached childbirth with a low iron status. A large proportion of women at booking, $45.5 \%(n=86)$, were non-anaemic with unknown iron stores.

A Mann-Whitney U Test comparing third trimester ferritin levels, between women who had serum ferritin tested at booking $(n=99)$, and women who did not $(n=90)$, showed no statistically significant difference $(Z=-1.05, p=.294)$.

\section{Laboratory analysis of iron status}

Difficulty in categorising iron status was confounded by variance in laboratory analysis of ferritin, when CRP was not concurrently tested with serum ferritin. This study showed $86 \%(n=331)$ of serum ferritin results were not tested with CRP (Table 8). The DHB laboratory routinely tested CRP with serum ferritin, whereas the private laboratory did not. Despite undertaking $84.7 \%$ of all antenatal serum ferritin analyses in this study, the private laboratory only tested CRP three times out of 326 , as part of other biochemical tests requested for reasons other than iron status. 
Table 8: Laboratory type and analyses of serum ferritin and C-reactive protein (CRP)

\begin{tabular}{|l|r|r|r|r|}
\hline $\begin{array}{l}\text { Serum Ferritin } \\
\text { Testing }\end{array}$ & $\begin{array}{r}\text { District Health } \\
\text { Board Laboratory } \\
\mathbf{n ~ ( \% )}\end{array}$ & $\begin{array}{r}\text { Private } \\
\text { Laboratory } \\
\mathbf{n}(\%)\end{array}$ & $\begin{array}{r}\text { Laboratory } \\
\text { Unknown } \\
\mathbf{n}(\%)\end{array}$ & $\mathbf{N = 3 8 5 ( \% )}$ \\
\hline $\begin{array}{l}\text { Serum ferritin } \\
\text { tested }\end{array}$ & $51(13.2)$ & $326(84.7)$ & $8(2.1)$ & $385(100)$ \\
\hline $\begin{array}{l}\text { Serum ferritin } \\
\text { tested with CRP* }\end{array}$ & $51(94.4)$ & $3(5.6)$ & - & $54(14.0)$ \\
\hline $\begin{array}{l}\text { Serum ferritin } \\
\text { tested without } \\
\text { CRP }\end{array}$ & $-323(97.6)$ & $8(2.4)$ & $331(86.0)$ \\
\hline \\
*C-reactive protein, an inflammatory marker: if CRP >5mg/L, serum ferritin may give false normal or false high \\
result.
\end{tabular}

\section{Antenatal prevention and treatment of anaemia and iron deficiency}

Table 9 shows the total number of strategies to prevent or treat anaemia or iron deficiency, given that some women had multiple approaches e.g. dietary advice and prescribed iron. Dietary advice was the least common documented strategy with $10.1 \%$ women receiving advice in early pregnancy, compared to $3.2 \%$ in late pregnancy (Table 9). Almost half the women (48.7\%) were prescribed oral iron by LMC midwives in the second trimester, considerably more than at booking $(4.8 \%)$ or in late pregnancy $(27.0 \%)$. This trend was the same for documented dietary advice and over the counter iron recommendations. The women with documented evidence of continuing to take iron after the initial prescription, or recommendation, were included in subsequent trimesters as having iron prescribed, or recommended. Otherwise they were presumed to have stopped taking iron. One woman received a third trimester intravenous iron infusion for severe IDA. 
Table 9: Antenatal prevention and treatment of anaemia and iron deficiency

\begin{tabular}{|l|r|r|r|}
\hline Management & $\begin{array}{r}\text { First trimester } \\
\mathbf{N}=\mathbf{1 8 9}(\%)\end{array}$ & $\begin{array}{r}\text { Second trimester } \\
\mathbf{N = 1 8 9}(\%)\end{array}$ & $\begin{array}{r}\text { Third trimester } \\
\mathbf{N}=189(\%)\end{array}$ \\
\hline $\begin{array}{l}\text { Total oral iron } \\
\text { prescriptions }\end{array}$ & $9(4.8)$ & $92(48.7)$ & $51(27.0)$ \\
\hline Total OTC* iron & $12(6.3)$ & $32(16.9)$ & $14(7.4)$ \\
\hline Total dietary advice & $19(10.1)$ & $25(13.2)$ & $6(3.2)$ \\
\hline Antenatal intravenous & $0(0)$ & $0(0)$ & $1(0.5)$ \\
\hline iron & & & \\
\hline
\end{tabular}

* OTC: Over the counter includes liquid/tablet iron supplements, multivitamins and minerals, and herbal preparations

It was not determined whether midwives prescribed based on haemoglobin or serum ferritin results, or both. The mean haemoglobin and ferritin when iron was prescribed, was lowest in the second trimester and highest in the first trimester (Table 10). The ranges of haemoglobin and ferritin where iron was prescribed were wide, from 106-141 g/L and 13-36 $\mathrm{gg} / \mathrm{L}$ in the first, 95-133 g/L and 3-67 $\mu \mathrm{g} / \mathrm{L}$ in the second, and 84-138 $\mathrm{g} / \mathrm{L}$ and 6-90 $\mu \mathrm{g} / \mathrm{L}$ in the third trimester. Midwives prescribed iron with an $\mathrm{Hb}$ of $>130 \mathrm{~g} / \mathrm{L}$ for $1.1 \%(n=2), 1.6 \%(n=3)$, and $2.6 \%(n=5)$ of first, second and third trimester women. For $70 \%(n=7)$ of these oral iron prescriptions where $\mathrm{Hb}$ $>130 \mathrm{~g} / \mathrm{L}$, the women had absent (serum ferritin $<12 \mu \mathrm{g} / \mathrm{L}$ ) or deficient iron stores (serum ferritin 13-20 $\mu \mathrm{g} / \mathrm{L})$. All the women with high haemoglobins $(\mathrm{Hb}>130 \mathrm{~g} / \mathrm{L})$ were normocytic with MCV $>80 \mathrm{fL}$, and high haematocrits $\geq 0.38$, indicating a degree of haemoconcentration. 
Table 10: Comparison of antenatal haemoglobin and serum ferritin when dietary advice offered, over the counter iron recommended or prescribed

\begin{tabular}{|l|l|r|r|r|}
\hline Laboratory Tests & First line management & $\begin{array}{r}\text { First } \\
\text { trimester }\end{array}$ & $\begin{array}{r}\text { Second } \\
\text { trimester }\end{array}$ & $\begin{array}{r}\text { Third } \\
\text { trimester }\end{array}$ \\
\hline $\begin{array}{l}\text { Haemoglobin } \\
\text { Mean (range) }\end{array}$ & Where iron prescribed & $\begin{array}{r}121.3 \mathrm{~g} / \mathrm{L} \\
(106-141 \mathrm{~g} / \mathrm{L})\end{array}$ & $\begin{array}{r}113.9 \mathrm{~g} / \mathrm{L} \\
(95-133 \mathrm{~g} / \mathrm{L})\end{array}$ & $\begin{array}{r}116.0 \mathrm{~g} / \mathrm{L} \\
(84-138 \mathrm{~g} / \mathrm{L})\end{array}$ \\
\hline & Where OTC* iron & $126.7 \mathrm{~g} / \mathrm{L}$ & $114.3 \mathrm{~g} / \mathrm{L}$ & $109.8 \mathrm{~g} / \mathrm{L}$ \\
& Recommended & $(115-140 \mathrm{~g} / \mathrm{L})$ & $(103-130 \mathrm{~g} / \mathrm{L})$ & $(94-124 \mathrm{~g} / \mathrm{L})$ \\
\hline & Where dietary advice & $130.8 \mathrm{~g} / \mathrm{L}$ & $117.8 \mathrm{~g} / \mathrm{L}$ & $142 \mathrm{~g} / \mathrm{L}$ \\
\hline Merritin & given & $(118-144 \mathrm{~g} / \mathrm{L})$ & $(104-126 \mathrm{~g} / \mathrm{L})$ & \\
\hline Mean (range) & Where iron prescribed & $22.8 \mu \mathrm{g} / \mathrm{L}$ & $12.3 \mu \mathrm{g} / \mathrm{L}$ & $17.2 \mu \mathrm{g} / \mathrm{L}$ \\
\hline & Where OTC iron & $30.0 \mu \mathrm{g} / \mathrm{L}$ & $10.8 \mu \mathrm{g} / \mathrm{L}$ & $11.0 \mu \mathrm{g} / \mathrm{L}$ \\
\hline & Recommended & $(7-67 \mu \mathrm{g} / \mathrm{L})$ & $(5-20 \mu \mathrm{g} / \mathrm{L})$ & $(5-18 \mu \mathrm{g} / \mathrm{L})$ \\
\hline & Where dietary advice & $41.9 \mu \mathrm{g} / \mathrm{L}$ & $12.6 \mu \mathrm{g} / \mathrm{L}$ & $69 \mu \mathrm{g} / \mathrm{L}$ \\
\hline & Given & $(11-73 \mu \mathrm{g} / \mathrm{L})$ & $(4-22 \mu \mathrm{g} / \mathrm{L})$ & \\
\hline
\end{tabular}

* OTC: Over the counter includes liquid/tablet iron supplements, multivitamins and minerals, and herbal iron preparations

$\S$ Single value therefore no range

The mean haemoglobin where over the counter iron was recommended, was higher compared to prescribed iron, in the first (126.7 g/L vs $121.3 \mathrm{~g} / \mathrm{L})$ and second trimester (114.3 vs $113.9 \mathrm{~g} / \mathrm{L})$, but not in the third trimester $(109.8 \mathrm{~g} / \mathrm{L}$ vs $116.0 \mathrm{~g} / \mathrm{L})$ (Table 10). The mean serum ferritin where over the counter iron was recommended was higher, compared to prescribed iron only in the first trimester $(30.0 \mu \mathrm{g} / \mathrm{L}$ vs 22.8 $\mu g / L)$.

Table 11 shows the one main strategy of midwives per woman, whereas Table 9 showed all the strategies. The midwives prescribed and recommended iron most commonly for NAID and absent iron stores, throughout pregnancy (Table 11). Midwives prescribed iron for $38.5 \%$, and recommended over the counter iron for $23.1 \%$ of the 13 women with NAID in the first trimester, $45.7 \%$ and $21.7 \%$ (of the 46 ) in the second, and $23.8 \%$ and $7.1 \%$ (of the 42 ) in the third trimester respectively. Similarly, midwives prescribed iron and recommended iron, for $67.5 \%$ and $15.6 \%$ of (the 77) women with absent iron stores in the second trimester, and 55.2\% and $10.3 \%$ (of the 29 ) in the third trimester respectively. Only one of the two women with 
absent iron stores at booking were managed, with over the counter iron. Midwives did not prescribe or recommend iron for six of the 15 women $(40 \%)$ with NAID or absent iron stores in the first trimester, 28 of $123(22.8 \%)$ in the second, and 39 of the $71(54.9 \%)$ in the third trimester.

Table 11: Main documented approach to management of iron status in pregnancy

\begin{tabular}{|c|c|c|c|}
\hline $\begin{array}{l}\text { Iron status when main documented } \\
\text { approach occurred }\end{array}$ & $\begin{array}{r}\text { First } \\
\text { trimester } \\
n \text { (\% of iron } \\
\text { status) }\end{array}$ & $\begin{array}{r}\text { Second } \\
\text { trimester } \\
n \text { (\% of iron } \\
\text { status) }\end{array}$ & $\begin{array}{r}\text { Third } \\
\text { trimester } \\
\mathrm{n} \text { (\% of iron } \\
\text { status) }\end{array}$ \\
\hline Prescribed Iron ( $n=151)$ & 9 & 92 & 50 \\
\hline Confirmed Iron Sufficiency* & $1(2.0)$ & $0(0)$ & $3(25.0)$ \\
\hline Unconfirmed Iron Sufficiency ${ }^{\S}$ & $0(0)$ & $4(23.5)$ & $6(20.0)$ \\
\hline $\begin{array}{l}\text { Non-anaemic } \\
\text { (ferritin not tested, iron stores unknown) }\end{array}$ & $1(1.2)$ & $3(13.0)$ & $3(12.5)$ \\
\hline $\begin{array}{l}\text { Non-anaemic iron deficiency } \\
\text { ferritin } 12-19 \mu \mathrm{g} / \mathrm{L} \text { (or SF }<50 \mu \mathrm{g} / \mathrm{L} \text { with CRP } \\
>5 \text { ) }\end{array}$ & $5(38.5)$ & $21(45.7)$ & $10(23.8)$ \\
\hline $\begin{array}{l}\text { Non-anaemic absent iron stores } \\
\text { ferritin }<12 \mu \mathrm{g} / \mathrm{L}\end{array}$ & $0(0)$ & $52(67.5)$ & $16(55.2)$ \\
\hline $\begin{array}{l}\text { Anaemic }^{\pi} \\
\text { (ferritin not tested, iron stores unknown) }\end{array}$ & $0(0)$ & $0(0)$ & $0(0)$ \\
\hline Iron deficiency anaemia ${ }^{*}$ & $0(0)$ & $10(71.4)$ & $7(63.6)$ \\
\hline $\begin{array}{l}\text { Possible anaemia of inflammation or } \\
\text { thalassaemia }\end{array}$ & $1(100.0)$ & $2(100.0)$ & $2(50.0)$ \\
\hline Iron status unknown (not tested) & $1(33.3)$ & $0(0)$ & $3(8.8)$ \\
\hline Over the counter iron (OTC) ${ }^{\dagger}$ Iron $(n=47)$ & 12 & 27 & 8 \\
\hline Confirmed Iron Sufficiency & $1(2.0)$ & $0(0)$ & $0(0)$ \\
\hline Unconfirmed Iron Sufficiency & $3(9.7)$ & $1(5.9)$ & $0(0)$ \\
\hline $\begin{array}{l}\text { Non-anaemic } \\
\text { (ferritin not tested, iron stores unknown) }\end{array}$ & $4(4.7)$ & $3(13.0)$ & $0(0)$ \\
\hline $\begin{array}{l}\text { Non-anaemic iron deficiency } \\
\text { ferritin } 12-19 \mu \mathrm{g} / \mathrm{L} \text { (or SF }<50 \mu \mathrm{g} / \mathrm{L} \text { with CRP } \\
>5 \text { ) }\end{array}$ & $3(23.1)$ & $10(21.7)$ & $3(7.1)$ \\
\hline $\begin{array}{l}\text { Non-anaemic absent iron stores } \\
\text { ferritin }<12 \mu \mathrm{g} / \mathrm{L}\end{array}$ & $1(50.0)$ & $12(15.6)$ & $3(10.3)$ \\
\hline
\end{tabular}




\begin{tabular}{|c|c|c|c|}
\hline $\begin{array}{l}\text { Iron status when main documented } \\
\text { approach occurred }\end{array}$ & $\begin{array}{r}\text { First } \\
\text { trimester } \\
\mathrm{n} \text { (\% of iron } \\
\text { status) }\end{array}$ & $\begin{array}{r}\text { Second } \\
\text { trimester } \\
\mathrm{n} \text { (\% of iron } \\
\text { status) }\end{array}$ & $\begin{array}{r}\text { Third } \\
\text { trimester } \\
\mathrm{n} \text { (\% of iron } \\
\text { status) }\end{array}$ \\
\hline $\begin{array}{l}\text { Anaemic } \\
\text { (ferritin not tested, iron stores unknown) }\end{array}$ & $0(0)$ & $0(0)$ & $0(0)$ \\
\hline Iron deficiency anaemia & $0(0)$ & $1(7.1)$ & $1(9.1)$ \\
\hline $\begin{array}{l}\text { Possible anaemia of inflammation or } \\
\text { thalassaemia }\end{array}$ & $0(0)$ & $0(0)$ & $0(0)$ \\
\hline Iron status unknown (not tested) & $0(0)$ & $0(0)$ & $1(2.9)$ \\
\hline Dietary Advice ( $n=24)$ & 17 & 6 & 1 \\
\hline Confirmed Iron Sufficiency & $2(3.9)$ & $1(50.0)$ & $0(0)$ \\
\hline Unconfirmed Iron Sufficiency & $7(22.6)$ & $0(0)$ & $1(3.3)$ \\
\hline $\begin{array}{l}\text { Non-anaemic } \\
\text { (ferritin not tested, iron stores unknown) }\end{array}$ & $5(5.8)$ & $1(4.3)$ & $0(0)$ \\
\hline $\begin{array}{l}\text { Non-anaemic iron deficiency } \\
\text { ferritin } 12-19 \mu \mathrm{g} / \mathrm{L} \text { (or SF }<50 \mu \mathrm{g} / \mathrm{L} \text { with CRP } \\
>5 \text { ) }\end{array}$ & $1(7.7)$ & $2(4.3)$ & $0(0)$ \\
\hline $\begin{array}{l}\text { Non-anaemic absent iron stores } \\
\text { ferritin }<12 \mu \mathrm{g} / \mathrm{L}\end{array}$ & $0(0)$ & $1(1.3)$ & $0(0)$ \\
\hline $\begin{array}{l}\text { Anaemic } \\
\text { (ferritin not tested, iron stores unknown) }\end{array}$ & $1(100.0)$ & $0(0)$ & $0(0)$ \\
\hline Iron deficiency anaemia & $0(0)$ & $1(7.1)$ & $0(0)$ \\
\hline $\begin{array}{l}\text { Possible anaemia of inflammation or } \\
\text { thalassaemia }\end{array}$ & $0(0)$ & $0(0)$ & $0(0)$ \\
\hline Iron status unknown (not tested) & $1(33.3)$ & $0(0)$ & $0(0)$ \\
\hline \multirow{2}{*}{\multicolumn{4}{|c|}{$\begin{array}{l}\text { * Confirmed iron sufficiency: non-anaemiac, and ferritin } \geq 20 \mu \mathrm{g} / \mathrm{L} \text { with } \mathrm{CRP}<5 \mathrm{mg} / \mathrm{L} \text {, or ferritin } \geq 50 \mu \mathrm{g} / \mathrm{L} \text { with no } \\
\text { CRP } \\
\text { § Unconfirmed iron sufficiency: non-anaemic, ferritin } 20-49 \mu \mathrm{g} / \mathrm{L} \text { with no } \mathrm{CRP} \text { to correct for inflammation. } \\
\text { 9 First trimester anaemia } \mathrm{Hb}<110 \mathrm{~g} / \mathrm{L} \text {, second and third trimester anaemia } \mathrm{Hb}<105 \mathrm{~g} / \mathrm{L} \text { as per NICE Guidelines } \\
\text { (2014) }\end{array}$}} \\
\hline & & & \\
\hline \multicolumn{4}{|c|}{$¥$ Anaemia with iron deficiency or absent iron stores } \\
\hline Q Anaemic and ferritin $\geq 20 \mu \mathrm{g} / \mathrm{L}$, without CRP: possible & emia of inflamm & on, or thalassaem & \\
\hline
\end{tabular}


In the one case of IDA at booking where iron was neither prescribed nor recommended in the first trimester, an intravenous iron infusion was required in the third trimester. For women with known IDA in the second and third trimesters, the midwives prescribed iron $71.4 \%$ (10 of 14 ), and $63.6 \%$ (7 of 11 ) of the time, respectively (Table 11). None of the anaemic women, with unknown ferritin levels, were prescribed or recommended iron in the first $(n=1)$, second $(n=1)$, and third $(n=3)$ trimesters (Tables $7 \& 11$ ). Midwives prescribed iron unnecessarily for four women with unknown iron status and 21 women who were either non-anaemic (ferritin unknown), or had confirmed or unconfirmed iron sufficiency during pregnancy (Table 11).

Seven antenatal study women were anaemic with a normal-high, or high serum ferritin $\geq 20 \mu \mathrm{g} / \mathrm{L}$, and no CRP to adjust for inflammation, indicating possible anaemia of inflammation or thalassaemia. Five of these women were prescribed oral iron, although none of the five had microcytic red cells (i.e. MCV $<80 \mathrm{fL}$ ). The second trimester blood test results of one woman who was prescribed iron, highlighted the difficulty in interpreting iron status without a concurrent measure of inflammation: $\mathrm{Hb} 98 \mathrm{~g} / \mathrm{L}$, Hct $0.30 \mathrm{~L} / \mathrm{L}, \mathrm{MCV} 94 \mathrm{fL}$, serum ferritin $41 \mu \mathrm{g} / \mathrm{L}$, and no CRP.

Iron status was most frequently managed by midwives in the second trimester, prescribing and recommending to $48.7 \%$ and $16.9 \%$ of 140 women with recognised low iron status, respectively. In the first trimester 17 women had recognised low iron status and midwives did not prescribe or recommend for $47.1 \%$, compared to $23.6 \%$ of 140 women in the second trimester, and $51.7 \%$ of 89 women in the third trimester. Approaching birth, $47.0 \%$ of women still had low iron status, and $18.0 \%$ had unknown iron status.

\section{Midwives' years in practice, caseloads and testing for iron deficiency in pregnancy}

Testing for haemoglobin was more consistently undertaken throughout pregnancy, than testing of serum ferritin for iron deficiency (Table 5), therefore analysis focused on ferritin testing. Midwives were grouped according to years in practice or caseloads, aligned with the 2012 Workforce Survey of midwives with annual practicing certificates (MCNZ, 2012). 
The highest proportion of women with serum ferritin tested throughout pregnancy, were cared for by midwives with either $11-20$ or 31-40 years in practice, although the number of midwives (and women) in each group was small: two $(n=16)$ and three $(n=33)$ (Table 12). Eleven midwives with 1-10 years in practice, caring for the largest group of 80 women, were least likely to have tested serum ferritin throughout pregnancy. For example $76.3 \%(n=80)$ had second trimester ferritin testing, compared to $100 \%(n=16)$ of women with midwives with $11-20$ years in practice, and $94.0 \%(n=31)$ of women with midwives with $31-40$ years in practice.

Table 12: Midwives' years in practice and ferritin testing

\begin{tabular}{|c|c|c|c|c|}
\hline $\begin{array}{l}\text { Midwives years in } \\
\text { practice (\%) }\end{array}$ & $\begin{array}{l}\text { Number of } \\
\text { women (\%) }\end{array}$ & $\begin{array}{r}\text { First } \\
\text { trimester } \\
\text { ferritin testing } \\
n(\%)\end{array}$ & $\begin{array}{r}\text { Second } \\
\text { trimester } \\
\text { ferritin testing } \\
n(\%)\end{array}$ & $\begin{array}{r}\text { Third } \\
\text { trimester } \\
\text { ferritin testing } \\
n(\%)\end{array}$ \\
\hline $\begin{array}{l}1-10 \text { years } \\
11(52.4)\end{array}$ & $80(42.3)$ & $38(47.5)$ & $61(76.3)$ & $50(62.5)$ \\
\hline $\begin{array}{l}11-20 \text { years } \\
2(9.5)\end{array}$ & $16(8.5)$ & $10(62.5)$ & $16(100)$ & $13(81.3)$ \\
\hline $\begin{array}{l}21-30 \text { years } \\
5(23.8)\end{array}$ & $60(31.7)$ & $30(50.0)$ & $50(83.3)$ & $39(65.0)$ \\
\hline $\begin{array}{l}31-40 \text { years } \\
3(14.3)\end{array}$ & 33 (17.5) & $21(63.6)$ & 31 (94.0) & $26(78.8)$ \\
\hline $21(100)$ & $189(100)$ & 99 & 158 & 128 \\
\hline
\end{tabular}

Midwives were regrouped for Pearson's chi-square test of independence (Table 13). Categories were 1-20 and 21-40 years in practice, and ferritin testing yes/no, for each trimester separately. In the $2 \times 2$ table chi-square analysis of midwives' years in practice and frequency of ferritin testing, $0 \%$ of cells had an expected count $<5$ for each trimester. There was no statistical association, or effect of association, between LMC midwives years in practice and ferritin testing in the first $\left(X^{2}(1, N=189)=.271\right.$, $p=.603$, phi=-.048), second $\left(X^{2}(1, N=189)=1.171, p=.279\right.$, phi=-.093), or third trimesters $\left(X^{2}(1, N=189)=.223, p=.637\right.$, phi=-.046). The $95 \%$ confidence intervals of 
proportions for years in practice and ferritin testing also showed no difference between the groupings (Table 13).

Table 13: Midwives' years in practice (regrouped) and ferritin testing

\begin{tabular}{|c|c|c|c|c|}
\hline $\begin{array}{l}\text { Midwives years in } \\
\text { practice (\%) }\end{array}$ & $\begin{array}{l}\text { Number of } \\
\text { women (\%) }\end{array}$ & $\begin{array}{r}\text { First } \\
\text { trimester } \\
\text { ferritin testing } \\
\mathrm{n} \mathrm{( \% )} \\
95 \% \mathrm{Cl}\end{array}$ & $\begin{array}{r}\text { Second } \\
\text { trimester } \\
\text { ferritin testing } \\
\mathrm{n}(\%) \\
95 \% \mathrm{Cl}\end{array}$ & $\begin{array}{r}\text { Third } \\
\text { trimester } \\
\text { ferritin testing } \\
\mathrm{n}(\%) \\
95 \% \mathrm{Cl}^{*}\end{array}$ \\
\hline $\begin{array}{l}1-20 \text { years in practice } \\
13(61.9)\end{array}$ & $96(50.8)$ & $\begin{array}{r}48(50.0) \\
40.0-60.0\end{array}$ & $\begin{array}{l}77(80.2) \\
72.2-88.2\end{array}$ & $\begin{array}{r}63(65.6) \\
56.1-75.1\end{array}$ \\
\hline $\begin{array}{l}21-40 \text { years in practice } \\
8 \text { (38.1) }\end{array}$ & $93(49.2)$ & $\begin{array}{l}51(54.8) \\
44.7-64.9\end{array}$ & $\begin{array}{l}81(87.1) \\
80.3-93.9\end{array}$ & $\begin{array}{r}65(69.9) \\
60.6-79.2\end{array}$ \\
\hline $21(100)$ & $189(100)$ & 99 & 158 & 128 \\
\hline \multicolumn{5}{|c|}{$\begin{array}{l}\text { * } 95 \% \text { Confidence Interval of proportions presented as percentages for consistency. } \\
\text { Thirteen midwives with higher annual caseloads (i.e. } 41-50 \text { or }>50 \text { ) cared for most } \\
\text { women ( } n=146) \text { (Table } 14) \text {. Midwives with the highest caseload }(>50) \text { tested more } \\
\text { serum ferritin proportionately, than those with other caseloads, in the first }(58.2 \%) \\
\text { and second }(92.4 \%) \text { trimester, ranking third with } 77.2 \% \text { in the third trimester. The } \\
\text { two midwives with the smallest annual caseloads of } \leq 30 \text { consistently ranked second }\end{array}$} \\
\hline
\end{tabular}


Table 14: Midwives' annual caseloads and ferritin testing

\begin{tabular}{|c|c|c|c|c|}
\hline $\begin{array}{l}\text { Midwives annual } \\
\text { caseloads (\%) }\end{array}$ & $\begin{array}{l}\text { Number of } \\
\text { women (\%) }\end{array}$ & $\begin{array}{r}\text { First } \\
\text { trimester } \\
\text { ferritin testing } \\
\mathrm{n}(\%)\end{array}$ & $\begin{array}{r}\text { Second } \\
\text { trimester } \\
\text { ferritin testing } \\
\mathrm{n}(\%)\end{array}$ & $\begin{array}{r}\text { Third } \\
\text { trimester } \\
\text { ferritin testing } \\
n(\%)\end{array}$ \\
\hline $\begin{array}{l}\text { Caseload } \leq 30 \\
2(9.5)\end{array}$ & $14(7.4)$ & 8 (57.1) & $12(85.7)$ & 11 (78.6) \\
\hline $\begin{array}{l}\text { Caseload 31-40 } \\
6 \text { (28.6) }\end{array}$ & $29(15.3)$ & $15(51.7)$ & 22 (75.9) & $23(79.3)$ \\
\hline $\begin{array}{l}\text { Caseload } 41-50 \\
7 \text { (33.3) }\end{array}$ & $67(35.5)$ & $30(44.8)$ & $51(76.1)$ & $33(49.3)$ \\
\hline $\begin{array}{l}\text { Caseload >50 } \\
6(28.6)\end{array}$ & $79(41.8)$ & $46(58.2)$ & $73(92.4)$ & $61(77.2)$ \\
\hline $21(100)$ & $189(100)$ & 99 & 158 & 128 \\
\hline
\end{tabular}

Midwives were regrouped for Pearson's chi-square test of independence (Table 15). Categories were 1-40 (small), 41-50 (medium), and 51-70 (large) caseloads, and ferritin testing yes/no, for each trimester separately. In the $3 \times 2$ table, chi-square analysis of midwives' caseloads and ferritin testing, $0 \%$ of cells had an expected count $<5$, for each trimester.

There was no statistically significant association or effect, between LMC midwives' caseloads, and proportion of ferritin testing in the first trimester $\left(X^{2}(1, N=189)=2.7\right.$, $p=.265$, Cramer's $V=.12$ ). There was a significant association, and a small measure of effect, between LMC midwives' caseloads, and frequency of ferritin testing in the second trimester $\left(X^{2}(1, N=189)=7.845, p=.02\right.$, Cramer's $\left.V=.20\right)$. The association between LMC midwives' caseloads, and frequency of ferritin testing in the third trimester, was strongly significant with a moderately strong measure of effect $\left(X^{2}(1\right.$, $\mathrm{N}=189)=16.245, p=.0003$, Cramer's $\mathrm{V}=.293$ ). The $95 \%$ confidence interval of proportions for ferritin testing also showed significant differences between caseloads for the second and third trimester (Table 15). 
Table 15: Midwives' annual caseload (regrouped) and ferritin testing

\begin{tabular}{|c|c|c|c|c|}
\hline $\begin{array}{l}\text { Midwives annual } \\
\text { caseloads (\%) }\end{array}$ & $\begin{array}{l}\text { Number of } \\
\text { women (\%) }\end{array}$ & $\begin{array}{r}\text { First } \\
\text { trimester } \\
\text { ferritin testing } \\
\mathrm{n}(\%) \\
95 \% \mathrm{Cl}^{*}\end{array}$ & $\begin{array}{r}\text { Second } \\
\text { trimester } \\
\text { ferritin testing } \\
\mathrm{n}(\%) \\
95 \% \mathrm{Cl}^{*}\end{array}$ & $\begin{array}{r}\text { Third } \\
\text { trimester } \\
\text { ferritin testing } \\
\mathrm{n}(\%) \\
95 \% \mathrm{Cl}\end{array}$ \\
\hline $\begin{array}{l}\text { Caseload 1-40 } \\
8 \text { (38.1) }\end{array}$ & $43(22.8)$ & $\begin{array}{r}23(53.5) \\
38.6-68.4\end{array}$ & $\begin{array}{c}34(79.1) \\
67.0-91.3\end{array}$ & $\begin{array}{c}34(79.1) \\
67.0-91.3\end{array}$ \\
\hline $\begin{array}{l}\text { Caseload 41-50 } \\
7(33.3)\end{array}$ & $67(35.5)$ & $\begin{array}{c}30(44.8) \\
32.9-56.7\end{array}$ & $\begin{array}{c}51(76.1) \\
65.9-86.3\end{array}$ & $\begin{array}{c}33(49.3) \\
37.3-61.3\end{array}$ \\
\hline $\begin{array}{l}\text { Caseload >50 } \\
6(28.6)\end{array}$ & 79 (41.7) & $\begin{array}{c}46(58.2) \\
47.3-69.0\end{array}$ & $\begin{array}{c}73(92.4) \\
86.6-98.2\end{array}$ & $\begin{array}{r}61(77.2) \\
67.8-86.5\end{array}$ \\
\hline $21(100)$ & $189(100)$ & 99 & 158 & 128 \\
\hline
\end{tabular}

Midwives' years in practice, caseloads and iron supplementation in pregnancy

Midwives with 31-40 years in practice prescribed more iron (66.7\%) and offered more dietary advice (60.6\%) in the second trimester, compared to midwives with 2130 years practice who prescribed iron (35.0\%) and gave dietary advice $(3.3 \%)$ the least (Table 16). Conversely midwives with $21-30$ years practice recommended more over the counter iron (including liquid/tablet iron supplements, herbal preparations, multivitamins and minerals) in the second and third trimester, whilst they prescribed iron the least. 
Table 16: Midwives' years in practice and management of antenatal iron status

\begin{tabular}{|c|c|c|c|c|c|}
\hline $\begin{array}{l}\text { Midwives years in } \\
\text { practice (\%) }\end{array}$ & $\begin{array}{l}\text { Number of } \\
\text { women (\%) }\end{array}$ & Strategy & $\begin{array}{r}\text { First } \\
\text { trimester } \\
\mathrm{n}(\%)\end{array}$ & $\begin{array}{r}\text { Second } \\
\text { trimester } \\
n(\%)\end{array}$ & $\begin{array}{r}\text { Third } \\
\text { trimester } \\
\mathbf{n}(\%)\end{array}$ \\
\hline \multirow[t]{3}{*}{$\begin{array}{l}1-10 \text { years } \\
11(52.4)\end{array}$} & $80(42.3)$ & $\begin{array}{l}\text { Oral iron } \\
\text { prescription }\end{array}$ & $4(5.0)$ & $40(50.0)$ & $20(25.0)$ \\
\hline & & OTC* iron & $2(2.5)$ & 9 (11.3) & $4(5.0)$ \\
\hline & & $\begin{array}{l}\text { Dietary } \\
\text { advice }\end{array}$ & $6(7.5)$ & $12(15.0)$ & $0(0)$ \\
\hline \multirow[t]{3}{*}{$\begin{array}{l}11-20 \text { years } \\
2(9.5)\end{array}$} & $16(8.5)$ & $\begin{array}{l}\text { Oral iron } \\
\text { prescription }\end{array}$ & $0(0)$ & $9(56.3)$ & $9(56.3)$ \\
\hline & & OTC iron & $4(25.0)$ & $5(31.3)$ & $2(12.5)$ \\
\hline & & $\begin{array}{l}\text { Dietary } \\
\text { advice }\end{array}$ & $1(6.3)$ & $5(31.3)$ & $0(0)$ \\
\hline \multirow[t]{3}{*}{$\begin{array}{l}21-30 \text { years } \\
5(23.8)\end{array}$} & $60(31.7)$ & $\begin{array}{l}\text { Oral iron } \\
\text { prescription }\end{array}$ & $4(6.7)$ & $21(35.0)$ & $13(21.7)$ \\
\hline & & OTC iron & $6(10.0)$ & $13(36.7)$ & $8(13.3)$ \\
\hline & & $\begin{array}{l}\text { Dietary } \\
\text { advice }\end{array}$ & $9(15.0)$ & $2(3.3)$ & $2(3.3)$ \\
\hline \multirow[t]{3}{*}{$\begin{array}{l}31-40 \text { years } \\
3(14.3)\end{array}$} & $33(17.5)$ & $\begin{array}{l}\text { Oral iron } \\
\text { prescription }\end{array}$ & $1(3.0)$ & $22(66.7)$ & $9(27.3)$ \\
\hline & & OTC iron & $0(0)$ & $2(6.1)$ & $0(0)$ \\
\hline & & $\begin{array}{l}\text { Dietary } \\
\text { advice }\end{array}$ & $2(6.1)$ & $20(60.6)$ & $3(9.1)$ \\
\hline $21(100)$ & $189(100)$ & & & & \\
\hline
\end{tabular}

Midwives were regrouped for Pearson's chi-square test of independence (Table 17). Categories were 1-20 and 21-40 years in practice, and iron prescription yes/no, for each trimester separately. In the $2 \times 2$ table, chi-square analysis of midwives' years in 
practice and frequency of oral iron prescriptions for each trimester, two cells (50\%) had an expected count $<5$ in the first trimester, and $0 \%$ of cells had $<5$ in the second and third trimesters.

There was no statistically significant association, or measure of effect, between midwives' years in practice and prescribing of iron in the first trimester $\left(X^{2}(1, N=189)\right.$ $=.002, p=.961$, phi=-.028). In the second $\left(X^{2}(1, \mathrm{~N}=189)=.265, p=.606\right.$, phi $\left.=-.48\right)$ and third $\left(X^{2}(1, N=189)=.273, p=.601\right.$, phi=-.50) trimesters, there was no statistically significant association, between midwives' years in practice and prescribing of iron, although there was a medium effect (Table 17).

Table 17: Midwives' years in practice (regrouped) and oral iron prescriptions

\begin{tabular}{|c|c|c|c|c|}
\hline $\begin{array}{l}\text { Midwives years in } \\
\text { practice (\%) }\end{array}$ & $\begin{array}{l}\text { Number of } \\
\text { women (\%) }\end{array}$ & $\begin{array}{r}\text { First } \\
\text { trimester } \\
\text { iron } \\
\text { prescriptions } \\
\mathrm{n}(\%) \\
95 \% \mathrm{Cl}^{*}\end{array}$ & $\begin{array}{r}\text { Second } \\
\text { trimester } \\
\text { iron } \\
\text { prescriptions } \\
\mathrm{n}(\%) \\
95 \% \mathrm{Cl}^{*}\end{array}$ & $\begin{array}{r}\text { Third } \\
\text { trimester } \\
\text { iron } \\
\text { prescriptions } \\
n(\%) \\
95 \% \mathrm{Cl}^{*}\end{array}$ \\
\hline $\begin{array}{l}1-20 \text { years in practice } \\
13(61.9)\end{array}$ & $96(50.8)$ & $\begin{array}{l}4(4.2) \\
0.2-8.2\end{array}$ & $\begin{array}{r}49(51.0) \\
41.0-61.0\end{array}$ & $\begin{array}{c}28(29.2) \\
20.1-38.3\end{array}$ \\
\hline $\begin{array}{l}21-40 \text { years in practice } \\
8(38.1)\end{array}$ & $93(49.2)$ & $\begin{array}{r}5(5.4) \\
8.1-10.0\end{array}$ & $\begin{array}{r}43(46.2) \\
32.9-53.1\end{array}$ & $\begin{array}{c}23(22.6) \\
14.1-31.1\end{array}$ \\
\hline $21(100)$ & $189(100)$ & 9 & 92 & 51 \\
\hline
\end{tabular}

Only a small proportion of women (4.8\%) were prescribed or recommended OTC iron $(6.3 \%)$ in the first trimester (Table 9). In the second trimester, the proportion of iron prescribed was highest (54.4\%) from midwives with annual caseloads $>50$, and lowest (42.9\%) from midwives with caseloads of $\leq 30$ (Table 18). Although in the third trimester, midwives with caseloads of $\leq 30$, prescribed the most $(50.0 \%)$ for their proportion of women. 
Table 18: Midwives' annual caseloads and management of antenatal iron status

\begin{tabular}{|c|c|c|c|c|c|}
\hline $\begin{array}{l}\text { Midwives annual } \\
\text { caseloads (\%) }\end{array}$ & $\begin{array}{l}\text { Number of } \\
\text { women (\%) }\end{array}$ & Strategy & $\begin{array}{r}\text { First } \\
\text { trimester } \\
\mathrm{n}(\%)\end{array}$ & $\begin{array}{r}\text { Second } \\
\text { trimester } \\
n(\%)\end{array}$ & $\begin{array}{r}\text { Third } \\
\text { trimester } \\
\mathrm{n}(\%)\end{array}$ \\
\hline \multirow[t]{3}{*}{$\begin{array}{l}\text { Caseload } \leq 30 \\
2(9.5)\end{array}$} & $14(7.4)$ & $\begin{array}{l}\text { Oral iron } \\
\text { prescription }\end{array}$ & $1(7.1)$ & 6 (42.9) & $7(50.0)$ \\
\hline & & OTC* iron & $0(0)$ & $2(14.3)$ & $0(0)$ \\
\hline & & $\begin{array}{l}\text { Dietary } \\
\text { advice }\end{array}$ & $0(0)$ & $3(21.4)$ & $0(0)$ \\
\hline \multirow[t]{3}{*}{$\begin{array}{l}\text { Caseload 31-40 } \\
6(28.6)\end{array}$} & $29(15.3)$ & $\begin{array}{l}\text { Oral iron } \\
\text { prescription }\end{array}$ & $2(6.9)$ & $14(48.3)$ & $4(13.8)$ \\
\hline & & OTC iron & $3(10.3)$ & $6(20.7)$ & $4(13.8)$ \\
\hline & & $\begin{array}{l}\text { Dietary } \\
\text { advice }\end{array}$ & $2(6.9)$ & $3(10.3)$ & $0(0)$ \\
\hline \multirow[t]{3}{*}{$\begin{array}{l}\text { Caseload } 41-50 \\
7 \text { (33.3) }\end{array}$} & $67(35.5)$ & $\begin{array}{l}\text { Oral iron } \\
\text { prescription }\end{array}$ & $2(3.0)$ & $29(46.5)$ & $14(20.9)$ \\
\hline & & OTC iron & $1(1.5)$ & 12 (17.9) & $9(13.4)$ \\
\hline & & $\begin{array}{l}\text { Dietary } \\
\text { advice }\end{array}$ & $4(6.0)$ & $14(48.3)$ & $1(1.5)$ \\
\hline \multirow[t]{3}{*}{$\begin{array}{l}\text { Caseload >50 } \\
6(28.6)\end{array}$} & $79(41.8)$ & $\begin{array}{l}\text { Oral iron } \\
\text { prescription }\end{array}$ & $4(5.1)$ & $43(54.4)$ & $26(32.9)$ \\
\hline & & OTC iron & 9 (11.4) & $13(16.5)$ & $5(6.3)$ \\
\hline & & $\begin{array}{l}\text { Dietary } \\
\text { advice }\end{array}$ & $12(15.2)$ & $17(21.5)$ & $1(1.3)$ \\
\hline $21(100)$ & 189 (100) & & & & \\
\hline
\end{tabular}

Midwives were regrouped for Pearson's chi-square test of independence (Table 19). Categories were 1-40, 41-50, and 51-70, and iron prescription yes/no, for each trimester separately. In the $3 \times 2$ table chi-square analysis of midwives' caseloads and frequency of oral iron prescriptions, three cells (50\%) had an expected count $<5$ in the first trimester, and $0 \%$ of cells had $<5$ in the second and third trimesters.

There was no statistical association, or measure of effect, between midwives' caseload and oral iron prescribing in the first $\left(X^{2}(1, N=189)=.947, p=.623\right.$, Cramer's 
$\mathrm{V}=.07)$, second $\left(X^{2}(1, \mathrm{~N}=189)=1.908, p=.385\right.$, Cramer's $\left.\mathrm{V}=.10\right)$, or third $\left(X^{2}(1, \mathrm{~N}=189)\right.$ $=2.712, p=.258$, Cramer's $V=.12$ ) trimesters. The $95 \%$ confidence intervals of proportions, for caseloads and iron prescriptions, showed no difference between the groupings (Table 19).

Table 19: Midwives' caseload (regrouped) and oral iron prescriptions

\begin{tabular}{|c|c|c|c|c|}
\hline $\begin{array}{l}\text { Midwives annual } \\
\text { caseloads (\%) }\end{array}$ & $\begin{array}{l}\text { Number of } \\
\text { women (\%) }\end{array}$ & $\begin{array}{r}\text { First } \\
\text { trimester } \\
\text { iron } \\
\text { prescriptions } \\
n(\%) \\
95 \% \mathrm{Cl}^{*}\end{array}$ & $\begin{array}{r}\text { Second } \\
\text { trimester } \\
\text { iron } \\
\text { prescriptions } \\
n(\%) \\
95 \% \mathrm{Cl}^{*}\end{array}$ & $\begin{array}{r}\text { Third } \\
\text { trimester } \\
\text { iron } \\
\text { prescriptions } \\
n(\%) \\
95 \% \mathrm{Cl}\end{array}$ \\
\hline $\begin{array}{l}\text { Caseload 1-40 } \\
8 \text { (38.1) }\end{array}$ & $43(22.8)$ & $\begin{array}{r}3(7.0) \\
0.6-14.6\end{array}$ & $\begin{array}{r}20(46.5) \\
31.6-61.4\end{array}$ & $\begin{array}{l}11(25.6) \\
12.6-38.6\end{array}$ \\
\hline $\begin{array}{l}\text { Caseload } 41-50 \\
7(33.3)\end{array}$ & $67(35.4)$ & $\begin{array}{l}2(3.0) \\
1.0-7.0\end{array}$ & $\begin{array}{r}29(43.3) \\
31.4-55.2\end{array}$ & $\begin{array}{r}14(20.9) \\
11.2-30.6\end{array}$ \\
\hline $\begin{array}{l}\text { Caseload >50 } \\
6(28.6)\end{array}$ & $79(41.8)$ & $\begin{array}{r}4(5.1) \\
0.3-10.0\end{array}$ & $\begin{array}{l}43(54.4) \\
43.4-65.4\end{array}$ & $\begin{array}{r}26(32.9) \\
22.5-43.3\end{array}$ \\
\hline $21(100)$ & $189(100)$ & 9 & 92 & 51 \\
\hline
\end{tabular}

\section{Postpartum management of anaemia}

Estimated blood loss (EBL) was documented on every delivery summary in the primary care notes: $20.1 \%$ of women had EBL $>500 \mathrm{mls}$ (Table 20). Midwives management of postpartum anaemia was analysed in relation to late pregnancy iron status, and blood loss (>500 $\mathrm{mls}$ ) around the time of birth. 
Table 20: Late pregnancy iron status, peri-partum blood loss, and management of postnatal anaemia

\begin{tabular}{|c|c|c|c|c|c|}
\hline Clinical Status & $\begin{array}{r}\begin{array}{r}\text { Total } \\
\text { women }\end{array} \\
\text { N=189 } \\
n(\%)\end{array}$ & $\begin{array}{r}\text { Hb tested } \\
\text { within } 72 \text { hrs } \\
\text { postpartum } \\
N=43 \\
n(\%)\end{array}$ & $\begin{array}{r}\text { Hb tested } \\
\geq 10 \text { days } \\
\text { postpartum } \\
N=9 \\
n(\%)\end{array}$ & $\begin{array}{l}\begin{array}{c}\text { Oral iron } \\
\text { prescription }\end{array} \\
\qquad \begin{array}{r}N=20 \\
n(\%)\end{array}\end{array}$ & $\begin{array}{r}\text { OTC* } \\
\text { Iron } \\
\text { N=1 } \\
\mathrm{n}(\%)\end{array}$ \\
\hline \multicolumn{6}{|l|}{$\begin{array}{l}\text { Estimated blood loss } \\
\text { (EBL) } \mathrm{mls}\end{array}$} \\
\hline $\mathrm{EBL} \leq 500 \mathrm{mls}$ & 151 (79.9) & 15 (34.9) & $3(33.3)$ & $6(30.0)$ & $1(100)$ \\
\hline EBL $501-750 \mathrm{mls}$ & $17(9.0)$ & 9 (20.9) & $2(22.2)$ & $2(10.0)$ & $0(0)$ \\
\hline EBL 751-1000 mls & $15(7.9)$ & $13(30.2)$ & $2(22.2)$ & $6(30.0)$ & $0(0)$ \\
\hline EBL $1001-1500 \mathrm{mls}$ & $1(0.5)$ & $1(2.3)$ & $0(0)$ & $1(5.0)$ & $0(0)$ \\
\hline EBL $1501-2000 \mathrm{mls}$ & $3(1.6)$ & $3(7.0)$ & $1(1.1)$ & $3(15.0)$ & $0(0)$ \\
\hline EBL $2001-3000 \mathrm{mls}$ & $2(1.1)$ & $2(4.7)$ & $1(1.1)$ & $2(10.0)$ & $0(0)$ \\
\hline $\begin{array}{l}\text { Total EBL 501- } \\
3000 \mathrm{mls}\end{array}$ & $38(20.1)$ & $28(65.1)$ & $6(66.7)$ & $14(70.0)$ & $0(0)$ \\
\hline $\begin{array}{l}\text { Third trimester iron } \\
\text { status unknown } \\
\text { with EBL }>500 \mathrm{mls}\end{array}$ & $7(3.7)$ & $5(11.6)$ & $3(33.3)$ & $5(25.0)$ & $0(0)$ \\
\hline $\begin{array}{l}\text { Third trimester } \\
\text { ferritin }<20 \mu \mathrm{g} / \mathrm{L} \text { or } \\
\mathrm{IDA}^{\S} \text {, and } \mathrm{EBL} \\
>500 \mathrm{mls}\end{array}$ & $16(8.5)$ & $11(25.6)$ & $4(44.4)$ & $6(30.0)$ & $0(0)$ \\
\hline $\begin{array}{l}\text { Postpartum } \\
\text { anaemia } \\
\mathrm{Hb}<100 \mathrm{~g} / \mathrm{L}^{\Uparrow}\end{array}$ & $21(11.1)$ & $21(48.8)$ & $4(44.4)$ & $7(35.0)$ & $0(0)$ \\
\hline $\begin{array}{l}\text { Severe postpartum } \\
\text { anaemia } \\
\mathrm{Hb}<85 \mathrm{~g} / \mathrm{L}^{¥}\end{array}$ & $3(1.6)$ & $3(7.0)$ & $2(22.2)$ & $2(10.0)$ & $0(0)$ \\
\hline \multicolumn{6}{|c|}{$\begin{array}{l}\text { * OTC: Over the counter includes liquid/tablet iron supplements, multivitamins and minerals, and herbal } \\
\text { preparations }\end{array}$} \\
\hline \multicolumn{6}{|c|}{$\S$ Iron deficiency anaemia (IDA): anaemia with iron deficiency or absent iron stores } \\
\hline ף UK Guidelines for postpa & anaemia parar & eters (Pavord et al. & 2012) & & \\
\hline
\end{tabular}

Forty-three women $(22.8 \%)$ had their haemoglobin tested after birth. The midwives did not test serum ferritin to measure iron stores postpartum. Of the 38 women with $E B L>500 \mathrm{mls}, 73.6 \%(n=28)$ had haemoglobin tested by the LMC midwife or staff in the birthing facility, in the 72 hours after birth; 14 (36.9\%) were prescribed oral iron (Table 13). All five women with EBL $>1500$ mls had $\mathrm{Hb}$ testing within 72 hours of 
birth and oral iron prescriptions, with two of the five showing as non-anaemic when haemoglobin was re-tested after 10 days postpartum (Table 20 \& Appendix F). For an overview of postnatal management and tracking of individual cases refer to the Postnatal Decision Tree (Appendix F).

Seven women with EBL $>500$ mls had unknown iron status in late pregnancy, but most were followed up postpartum. Five (71.4\%) of these women had haemoglobin tested within 72 hours postpartum, two were anaemic and one was severely anaemic and received a blood transfusion. Five $(71.4 \%)$ were prescribed iron, three $(42.9 \%)$ had haemoglobin re-tested after 10 days and were found to be non-anaemic (Table 20 \& Appendix F). One woman with unknown iron status in late pregnancy, with a postpartum haemorrhage of $3000 \mathrm{mls}$, was prescribed oral iron for anaemia after birth with $\mathrm{Hb} 90 \mathrm{~g} / \mathrm{L}$, but did not have subsequent testing or follow-up for iron status.

Sixteen women (42.1\%) with EBL > $500 \mathrm{mls}$ at birth had low iron status (NAID or IDA) in late pregnancy. Yet only eleven of these sixteen women (68.75\%) had early postpartum haemoglobin testing (Table 20). Within case analysis of the data showed five were anaemic $(\mathrm{Hb} 86-100 \mathrm{~g} / \mathrm{L})$, another two severely anaemic $(\mathrm{Hb}<85 \mathrm{~g} / \mathrm{L})$. Six $(37.5 \%)$ were prescribed iron, and two (12.5\%) were tested later and were nonanaemic (Appendix F).

Midwives did not request haemoglobin testing after birth, for five of the sixteen women with low iron status in late pregnancy, and EBL $>500 \mathrm{mls}$. Three of these women with EBL 501-750mls, had no documented follow-up, and only one of the two women with EBL 751-1000mls were prescribed iron with no other follow-up (Appendix F).

Overall, almost half of the women tested in the early postpartum ( $48.8 \%$ of 43 ) were anaemic with $\mathrm{Hb}<100 \mathrm{~g} / \mathrm{L}$, yet only seven of these (33.3\% of 21 ) were prescribed iron or had documented evidence of oral iron supplementation. Of the three severely anaemic $(\mathrm{Hb}<85 \mathrm{~g} / \mathrm{L})$ postpartum women $(14.3 \%$ or $1.6 \%$ of the cohort), two were prescribed iron (Table 13) and one also received a blood transfusion (Appendix F). 
Midwives' years in practice, caseloads and management of postnatal iron status

The overall number of postpartum women tested, and treated for anaemia was small. This precluded inferential statistical analysis of postpartum management of anaemia in relation to midwives caseloads or years in practice. Midwives with 11-20 years in practice tested less haemoglobin (12.5\%) in the early postpartum period, compared to other groups of midwives (Table 21). The proportion of iron prescriptions was similar for all years in practice, ranging from 9.1-12.5\%.

Table 21: Midwives' years in practice and postpartum management of iron status

\begin{tabular}{|c|c|c|c|c|c|}
\hline $\begin{array}{l}\text { Midwives years in } \\
\text { practice (\%) }\end{array}$ & $\begin{array}{l}\text { Number of } \\
\text { women (\%) }\end{array}$ & $\begin{array}{r}\text { Hb tested } \\
\text { early* } \\
n(\%)\end{array}$ & $\begin{array}{r}\text { Hb tested } \\
\text { later }^{\S} \\
n(\%)\end{array}$ & $\begin{array}{r}\text { Oral iron } \\
\text { prescription } \\
\mathrm{n}(\%)\end{array}$ & $\begin{array}{l}\text { OTC }^{\text {I }} \\
\text { iron } \\
n(\%)\end{array}$ \\
\hline $\begin{array}{l}1-10 \text { years } \\
11(52.4)\end{array}$ & $80(42.3)$ & $19(23.8)$ & $2(2.5)$ & $9(11.25)$ & 1 (1.25) \\
\hline $\begin{array}{l}11-20 \text { years } \\
2(9.5)\end{array}$ & $16(8.5)$ & $2(12.5)$ & $1(6.25)$ & $2(12.5)$ & $0(0)$ \\
\hline $\begin{array}{l}21-30 \text { years } \\
5(23.8)\end{array}$ & $60(31.7)$ & $15(25.0)$ & $3(5.0)$ & $6(10.0)$ & $0(0)$ \\
\hline $\begin{array}{l}31-40 \text { years } \\
3(14.3)\end{array}$ & 33 (17.5) & $7(21.2)$ & $3(9.1)$ & $3(9.1)$ & $0(0)$ \\
\hline $21(100)$ & $189(100)$ & 43 & 9 & 20 & 1 \\
\hline
\end{tabular}

* Hb tested within 72 hours postpartum

$\S \mathrm{Hb}$ tested $\geq 10$ days postpartum

ๆ OTC: Over the counter includes liquid/tablet iron supplements, multivitamins and minerals, and herbal preparations

When grouped according to caseload, the range of proportions for women being prescribed postpartum iron was 6.9-14.3\% (Table 22). Midwives with smaller $(\leq 30)$ and larger $(>50)$ caseloads tested more haemoglobin in the early postpartum, as well as after 10 days, and prescribed oral iron more than midwives with moderate caseloads (31-50), although numbers were small. 
Table 22: Midwives' caseloads and postpartum management of iron status

\begin{tabular}{|c|c|c|c|c|c|}
\hline $\begin{array}{l}\text { Midwives annual } \\
\text { caseloads (\%) }\end{array}$ & $\begin{array}{r}\text { Number of } \\
\text { women (\%) }\end{array}$ & $\begin{array}{r}\text { Hb tested } \\
\text { early* } \\
n(\%)\end{array}$ & $\begin{array}{r}\text { Hb tested } \\
\text { later }^{\S} \\
n(\%)\end{array}$ & $\begin{array}{r}\text { Oral iron } \\
\text { prescription } \\
\mathrm{n}(\%)\end{array}$ & $\begin{array}{l}\text { OTC }^{\text {I }} \\
\text { iron } \\
n(\%)\end{array}$ \\
\hline $\begin{array}{l}\text { Caseload } \leq 30 \\
2(9.5)\end{array}$ & $14(7.4)$ & $5(35.7)$ & $2(14.3)$ & $2(14.3)$ & $0(0)$ \\
\hline $\begin{array}{l}\text { Caseload 31-40 } \\
6(28.6)\end{array}$ & $29(15.3)$ & $8(27.6)$ & $0(0)$ & $2(6.9)$ & $1(3.4)$ \\
\hline $\begin{array}{l}\text { Caseload } 41-50 \\
7 \text { (33.3) }\end{array}$ & $67(35.5)$ & $8(11.9)$ & $0(0)$ & $5(7.5)$ & $0(0)$ \\
\hline $\begin{array}{l}\text { Caseload >50 } \\
6(28.6)\end{array}$ & $79(41.8)$ & $22(27.8)$ & $7(8.9)$ & $11(13.9)$ & $0(0)$ \\
\hline $21(100)$ & $189(100)$ & 43 & 9 & 20 & 1 \\
\hline \multicolumn{6}{|c|}{ * Hb tested within 72 hours postpartum } \\
\hline
\end{tabular}

\section{Section Three: Other analyses}

\section{$\mathrm{BMI}$ and iron status}

The proportion of study woman with high BMI $\left(>25 \mathrm{~kg} / \mathrm{m}^{2}\right)$ was $44.1 \%(95 \% \mathrm{Cl} 36.8$ 51.0\%), compared to 50.6\% (95\% Cl 50.2-51.0\%) of women giving birth in 2012 (Table 4). Because obesity is a pro-inflammatory state that may mask true iron deficiency, all women with first trimester serum ferritin testing, without CRP to correct for inflammation $(n=77)$, were analysed according to BMI categories and their subsequent second and third trimester iron status (Table 23).

Three different first trimester serum ferritin parameters were used to categorise and compare groups: $<20 \mu \mathrm{g} / \mathrm{L}$ as highly specific for iron deficiency (Wang et al., 2010); $<30 \mu \mathrm{g} / \mathrm{L}$ (Thurnham et al., 2010; WHO, 2011) and $<50 \mu \mathrm{g} / \mathrm{L}$ (as per the local DHB IV iron policy), as suggested parameters for iron deficiency in the presence of inflammation. Sizes of the BMI sub-groups were small ranging from 4-21. In the entire group, presence of inflammation was unknown where ferritin $<30 \mu \mathrm{g} / \mathrm{L}$ or $<50 \mu \mathrm{g} / \mathrm{L}$, and no CRP, therefore iron sufficiency was unconfirmed. 
The greatest drop in proportion of unconfirmed iron sufficiency from the first to second trimester occurred in women with $\mathrm{BMI} \geq 30$ (Table 23). In the first trimester ferritin $<30 \mu \mathrm{g} / \mathrm{L}$ and $\mathrm{BMI} \geq 30$ group $(n=4)$, the proportion of unconfirmed iron sufficiency dropped from $50.0 \%(n=2)$ in the first, to $0 \%$ in the second trimester. The greatest drop was in the ferritin $<50 \mu \mathrm{g} / \mathrm{L}$ and $\mathrm{BMI} \geq 30$ group $(\mathrm{n}=9)$, where unconfirmed iron sufficiency dropped from $77.8 \%(n=7)$ in the first to $0 \%$ in the second trimester. This group appeared more iron replete at booking with serum ferritin levels up to $50 \mu \mathrm{g} / \mathrm{L}$, but more had low iron status subsequently. The proportion of all women with low iron status increased most markedly from the first to second trimesters for all BMI groups (Table 23).

Women were regrouped for a Pearson's chi-square test of independence. Categories were low/normal $\mathrm{BMI}<25$, and overweight/obese $\mathrm{BMI} \geq 25$; and low iron status, confirmed and unconfirmed iron sufficiency. In the $2 \times 3$ table, chi-square analysis of BMI and iron status, $50 \%$ (2) of cells had an expected count of $<5$ in the first trimester. Zero cells had an expected count of $<5$ in the second and third trimesters. There was no statistically significant association or effect, between BMI groups and frequencies of iron status in the first $\left(X^{2}(1, \mathrm{n}=186)=1.057, p=.590\right.$, Cramer's $V=$ $.075)$, second $\left(X^{2}(1, \mathrm{n}=182)=1.881, p=.390\right.$, Cramer's $\left.V=.102\right)$ and third $\left(X^{2}(1\right.$, $\mathrm{n}=155)=1.406, p=.495$, Cramer's $V=.95)$ trimesters.

A Mann-Whitney $U$ Test comparing third trimester ferritin levels, between women with low/normal BMI $<25$ ( $\mathrm{n}=71$, median $\mathrm{SF}=18 \mu \mathrm{g} / \mathrm{L}$ ), and overweight/obese $\mathrm{BMI}$ $\geq 25(\mathrm{n}=57$, median $=14 \mu \mathrm{g} / \mathrm{L})$, and third trimester ferritin levels showed some statistical difference $(U=1618, Z=-1.95, p=.05)$. 
Table 23: Comparison of Body Mass Index (BMI)* and subsequent iron status of women with serum ferritin $<20 \mu \mathrm{g} / \mathrm{L},<30 \mu \mathrm{g} / \mathrm{L}, \mathrm{and}<50 \mu \mathrm{g} / \mathrm{L}$ uncorrected $^{\S}$ for inflammation (no CRP) in the first trimester.

\begin{tabular}{|c|c|c|c|c|c|c|c|c|c|c|c|c|}
\hline & \multicolumn{4}{|c|}{$\begin{array}{l}\text { First trimester ferritin <20 } \mu \mathrm{g} / \mathrm{L} \text { (no CRP) } \\
\qquad \mathrm{n}=11(\%)\end{array}$} & \multicolumn{4}{|c|}{$\begin{array}{l}\text { First trimester ferritin }<30 \mu \mathrm{g} / \mathrm{L} \text { (no CRP) } \\
\qquad \mathrm{n}=\mathbf{2 1}(\%)\end{array}$} & \multicolumn{4}{|c|}{$\begin{array}{l}\text { First trimester ferritin }<50 \mu \mathrm{g} / \mathrm{L} \text { (no CRP) } \\
\qquad \mathrm{n}=45(\%)\end{array}$} \\
\hline & $\begin{array}{l}\text { All BMIs } \\
\mathrm{N}=11(\%)\end{array}$ & $\begin{array}{r}\mathrm{BMI}<25 \\
\mathrm{n}=4(\%)\end{array}$ & $\begin{array}{r}\text { BMI } 25-29 \\
n=5(\%)\end{array}$ & $\begin{array}{r}\mathrm{BMI} \geq 30 \\
\mathrm{n}=2(\%)\end{array}$ & $\begin{array}{l}\text { All BMIs } \\
\mathrm{N}=21(\%)\end{array}$ & $\begin{array}{r}\text { BMI <25 } \\
n=9(\%)\end{array}$ & $\begin{array}{r}\text { BMI } 25-29 \\
n=8(\%)\end{array}$ & $\begin{array}{r}\mathrm{BMI} \geq 30 \\
n=4(\%)\end{array}$ & $\begin{array}{l}\text { All BMls } \\
\mathrm{N}=45(\%)\end{array}$ & $\begin{array}{l}\text { BMI <25 } \\
n=18(\%)\end{array}$ & $\begin{array}{r}\text { BMI } 25-29 \\
n=18(\%)\end{array}$ & $\begin{array}{r}\mathrm{BMI} \geq 30 \\
\mathrm{n}=9(\%)\end{array}$ \\
\hline $\begin{array}{l}\text { Unconfirmed Iron } \\
\text { sufficiency" } \\
\text { First trimester } \\
\text { Second trimester } \\
\text { Third trimester }\end{array}$ & $\begin{array}{r}0(0) \\
2(18.2) \\
1(9.1)\end{array}$ & $\begin{array}{r}0(0) \\
1(25.0) \\
0(0)\end{array}$ & $\begin{array}{r}0(0) \\
1(20.0) \\
1(20.0)\end{array}$ & $\begin{array}{l}0(0) \\
0(0) \\
0(0)\end{array}$ & $\begin{array}{r}10(47.6) \\
2(9.5) \\
3(14.3)\end{array}$ & $\begin{array}{l}5(55.6) \\
1(11.1) \\
1(11.1)\end{array}$ & $\begin{array}{l}3(37.5) \\
1(12.5) \\
1(12.5)\end{array}$ & $\begin{array}{r}2(50.0) \\
0(0) \\
1(25.0)\end{array}$ & $\begin{array}{r}33(73.3) \\
3(6.7) \\
11(24.4)\end{array}$ & $\begin{array}{r}13(72.2) \\
2(11.1) \\
5(27.8)\end{array}$ & $\begin{array}{r}13(72.2) \\
1(5.6) \\
3(16.7)\end{array}$ & $\begin{array}{r}7(77.8) \\
0(0) \\
3(33.3)\end{array}$ \\
\hline $\begin{array}{l}\text { Non-anaemic iron } \\
\text { deficiency } \\
\text { First trimester } \\
\text { Second trimester } \\
\text { Third trimester }\end{array}$ & $\begin{array}{r}9(81.8) \\
1(9.1) \\
5(45.5)\end{array}$ & $\begin{array}{r}3(75.0) \\
0(0) \\
1(25.0)\end{array}$ & $\begin{array}{r}4(80.0) \\
0(0) \\
3(60.0)\end{array}$ & $\begin{array}{l}2(100) \\
1(50.0) \\
1(50.0)\end{array}$ & $\begin{array}{l}9(42.9) \\
3(14.3) \\
9(42.9)\end{array}$ & $\begin{array}{l}3(33.3) \\
1(11.1) \\
5(55.6)\end{array}$ & $\begin{array}{l}4(50.0) \\
1(12.5) \\
3(37.5)\end{array}$ & $\begin{array}{l}2(50.0) \\
1(25.0) \\
2(50.0)\end{array}$ & $\begin{array}{r}9(20.0) \\
8(17.8) \\
13(28.9)\end{array}$ & $\begin{array}{l}3(16.7) \\
2(11.1) \\
6(33.3)\end{array}$ & $\begin{array}{l}4(22.2) \\
4(22.2) \\
5(27.8)\end{array}$ & $\begin{array}{l}2(22.2) \\
2(22.2) \\
2(22.2)\end{array}$ \\
\hline $\begin{array}{l}\text { Absent iron stores } \\
\text { First trimester } \\
\text { Second trimester } \\
\text { Third trimester }\end{array}$ & $\begin{array}{r}1(9.1) \\
4(36.6) \\
1(9.1)\end{array}$ & $\begin{array}{l}1(25.0) \\
2(50.0) \\
1(25.0)\end{array}$ & $\begin{array}{r}1(20.0) \\
2(40.0) \\
0(0)\end{array}$ & $\begin{array}{l}0(0) \\
0(0) \\
0(0)\end{array}$ & $\begin{array}{r}1(4.8) \\
10(47.6) \\
2(9.5)\end{array}$ & $\begin{array}{l}1(11.1) \\
6(66.7) \\
1(11.1)\end{array}$ & $\begin{array}{r}0(0) \\
3(37.5) \\
1(12.5)\end{array}$ & $\begin{array}{r}0(0) \\
1(25.0) \\
0(0)\end{array}$ & $\begin{array}{r}1(2.2) \\
24(53.3) \\
6(13.3)\end{array}$ & $\begin{array}{r}1(5.6) \\
11(61.1) \\
2(11.1)\end{array}$ & $\begin{array}{r}0(0) \\
8(44.4) \\
3(16.7)\end{array}$ & $\begin{array}{r}0(0) \\
5(55.6) \\
1(11.1)\end{array}$ \\
\hline $\begin{array}{l}\text { Iron deficiency } \\
\text { Anaemia } \\
\text { First trimester } \\
\text { Second trimester } \\
\text { Third trimester }\end{array}$ & $\begin{array}{r}1(9.1) \\
2(18.2) \\
0(0)\end{array}$ & $\begin{array}{l}0(0) \\
0(0) \\
0(0)\end{array}$ & $\begin{array}{r}0(0) \\
2(40.0) \\
0(0)\end{array}$ & $\begin{array}{l}0(0) \\
0(0) \\
0(0)\end{array}$ & $\begin{array}{l}1(4.8) \\
2(9.5) \\
1(4.8)\end{array}$ & $\begin{array}{l}0(0) \\
0(0) \\
0(0)\end{array}$ & $\begin{array}{l}1 \text { (12.5) } \\
2(25.0) \\
1(12.5)\end{array}$ & $\begin{array}{l}0(0) \\
0(0) \\
0(0)\end{array}$ & $\begin{array}{l}1(2.2) \\
4(8.9) \\
3(6.7)\end{array}$ & $\begin{array}{r}0(0) \\
1(5.6) \\
1(5.6)\end{array}$ & $\begin{array}{r}1(5.6) \\
3(16.7) \\
1(5.6)\end{array}$ & $\begin{array}{l}0(0) \\
0(0) \\
0(0)\end{array}$ \\
\hline $\begin{array}{l}\text { Non-anaemic } \\
\text { (ferritin unknown) } \\
\text { First trimester } \\
\text { Second trimester } \\
\text { Third trimester }\end{array}$ & $\begin{array}{r}0(0) \\
2(18.2) \\
0(0)\end{array}$ & $\begin{array}{r}0(0) \\
1(25.0) \\
0(0)\end{array}$ & $\begin{array}{l}0(0) \\
0(0) \\
0(0)\end{array}$ & $\begin{array}{r}0(0) \\
1(50.0) \\
0(0)\end{array}$ & $\begin{array}{r}0(0) \\
3(14.3) \\
0(0)\end{array}$ & $\begin{array}{r}0(0) \\
1(11.1) \\
0(0)\end{array}$ & $\begin{array}{l}0(0) \\
0(0) \\
0(0)\end{array}$ & $\begin{array}{r}0(0) \\
2(50.0) \\
0(0)\end{array}$ & $\begin{array}{r}0(0) \\
4(8.9) \\
3(6.7)\end{array}$ & $\begin{array}{r}0(0) \\
1(5.6) \\
2(11.1)\end{array}$ & $\begin{array}{r}0(0) \\
1(5.6) \\
2(11.1)\end{array}$ & $\begin{array}{r}0(0) \\
2(22.2) \\
0(0)\end{array}$ \\
\hline
\end{tabular}




\begin{tabular}{|c|c|c|c|c|c|c|c|c|c|c|c|c|}
\hline & \multicolumn{4}{|c|}{$\begin{array}{l}\text { First trimester ferritin <20 } \mu \mathrm{g} / \mathrm{L} \text { (no CRP) } \\
\qquad \mathrm{n}=11(\%)\end{array}$} & \multicolumn{4}{|c|}{$\begin{array}{l}\text { First trimester ferritin }<30 \mu \mathrm{g} / \mathrm{L} \text { (no CRP) } \\
\qquad \mathrm{n}=\mathbf{2 1}(\%)\end{array}$} & \multicolumn{4}{|c|}{$\begin{array}{l}\text { First trimester ferritin }<50 \mu \mathrm{g} / \mathrm{L} \text { (no CRP) } \\
\qquad \mathrm{n}=45(\%)\end{array}$} \\
\hline & $\begin{array}{l}\text { All BMIs } \\
\mathrm{N}=11(\%)\end{array}$ & $\begin{array}{r}\mathrm{BMI}<25 \\
\mathrm{n}=4(\%)\end{array}$ & $\begin{array}{r}\text { BMI } 25-29 \\
n=5(\%)\end{array}$ & $\begin{array}{r}\mathrm{BMI} \geq 30 \\
\mathrm{n}=2(\%)\end{array}$ & $\begin{array}{l}\text { All BMls } \\
\mathrm{N}=21(\%)\end{array}$ & $\begin{array}{r}\mathrm{BMI}<25 \\
\mathrm{n}=9(\%)\end{array}$ & $\begin{array}{r}\text { BMI } 25-29 \\
n=8(\%)\end{array}$ & $\begin{array}{r}\mathrm{BMI} \geq 30 \\
\mathrm{n}=4(\%)\end{array}$ & $\begin{array}{l}\text { All BMls } \\
n=45(\%)\end{array}$ & $\begin{array}{l}\mathrm{BMI}<25 \\
\mathrm{n}=18(\%)\end{array}$ & $\begin{array}{r}\text { BMI 25-29 } \\
n=18(\%)\end{array}$ & $\begin{array}{r}\mathrm{BMI} \geq 30 \\
\mathrm{n}=9(\%)\end{array}$ \\
\hline $\begin{array}{l}\text { Anaemic (ferritin } \\
\text { unknown) } \\
\text { First trimester } \\
\text { Second trimester } \\
\text { Third trimester }\end{array}$ & $\begin{array}{r}0(0) \\
0(0) \\
1(9.1)\end{array}$ & $\begin{array}{l}0(0) \\
0(0) \\
0(0)\end{array}$ & $\begin{array}{r}0(0) \\
0(0) \\
1(20.0)\end{array}$ & $\begin{array}{l}0(0) \\
0(0) \\
0(0)\end{array}$ & $\begin{array}{r}0(0) \\
1(4.8) \\
1(4.8)\end{array}$ & $\begin{array}{l}0(0) \\
0(0) \\
0(0)\end{array}$ & $\begin{array}{r}0(0) \\
1(12.5) \\
1(12.5)\end{array}$ & $\begin{array}{l}0(0) \\
0(0) \\
0(0)\end{array}$ & $\begin{array}{r}0(0) \\
1(2.2) \\
1(2.2)\end{array}$ & $\begin{array}{l}0(0) \\
0(0) \\
0(0)\end{array}$ & $\begin{array}{r}0(0) \\
1(5.6) \\
1(5.6)\end{array}$ & $\begin{array}{l}0(0) \\
0(0) \\
0(0)\end{array}$ \\
\hline $\begin{array}{l}\text { Possible anaemia } \\
\text { of inflammation } \\
\text { First trimester } \\
\text { Second trimester } \\
\text { Third trimester }\end{array}$ & $\begin{array}{r}0(0) \\
0(0) \\
1(9.1)\end{array}$ & $\begin{array}{r}0(0) \\
0(0) \\
1(25.0)\end{array}$ & $\begin{array}{l}0(0) \\
0(0) \\
0(0)\end{array}$ & $\begin{array}{l}0(0) \\
0(0) \\
0(0)\end{array}$ & $\begin{array}{r}0(0) \\
0(0) \\
2(9.5)\end{array}$ & $\begin{array}{r}0(0) \\
0(0) \\
1(11.1)\end{array}$ & $\begin{array}{r}0(0) \\
0(0) \\
1(12.5)\end{array}$ & $\begin{array}{l}0(0) \\
0(0) \\
0(0)\end{array}$ & $\begin{array}{r}1(2.2) \\
0(0) \\
2(4.4)\end{array}$ & $\begin{array}{r}0(0) \\
0(0) \\
1(5.6)\end{array}$ & $\begin{array}{r}0(0) \\
0(0) \\
1(5.6)\end{array}$ & $\begin{array}{l}0(0) \\
0(0) \\
0(0)\end{array}$ \\
\hline $\begin{array}{l}\text { Iron status } \\
\text { unknown } \\
\text { First trimester } \\
\text { Second trimester } \\
\text { Third trimester }\end{array}$ & $\begin{array}{r}0(0) \\
0(0) \\
2(18.2)\end{array}$ & $\begin{array}{r}0(0) \\
0(0) \\
1(25.0)\end{array}$ & $\begin{array}{l}0(0) \\
0(0) \\
0(0)\end{array}$ & $\begin{array}{r}0(0) \\
0(0) \\
1(50.0)\end{array}$ & $\begin{array}{r}0(0) \\
0(0) \\
3(14.3)\end{array}$ & $\begin{array}{r}0(0) \\
0(0) \\
1(11.1)\end{array}$ & $\begin{array}{l}0(0) \\
0(0) \\
0(0)\end{array}$ & $\begin{array}{r}0(0) \\
0(0) \\
1(25.0)\end{array}$ & $\begin{array}{r}0(0) \\
1(2.2) \\
6(13.3)\end{array}$ & $\begin{array}{l}1(5.6) \\
1(5.6) \\
1(5.6)\end{array}$ & $\begin{array}{r}0(0) \\
0(0) \\
2(11.1)\end{array}$ & $\begin{array}{r}0(0) \\
0(0) \\
3(33.3)\end{array}$ \\
\hline $\begin{array}{l}\text { Total low iron } \\
\text { status } \\
\text { First trimester } \\
\text { Second trimester } \\
\text { Third trimester }\end{array}$ & $\begin{array}{r}11(100) \\
7(63.6) \\
7(63.6)\end{array}$ & $\begin{array}{l}4(100) \\
2(50.0) \\
2(50.0)\end{array}$ & $\begin{array}{l}5(100) \\
4(80.0) \\
4(80.0)\end{array}$ & $\begin{array}{r}2(100) \\
1(50.0) \\
1(50.0)\end{array}$ & $\begin{array}{l}11(52.4) \\
16(76.2) \\
13(61.9)\end{array}$ & $\begin{array}{l}4(44.4) \\
7(77.8) \\
6(66.7)\end{array}$ & $\begin{array}{l}5(62.5) \\
7(87.5) \\
6(75.0)\end{array}$ & $\begin{array}{l}2(50.0) \\
2(50.0) \\
1(25.0)\end{array}$ & $\begin{array}{l}11(24.4) \\
37(82.2) \\
23(51.1)\end{array}$ & $\begin{array}{r}4(22.2) \\
14(77.8) \\
10(55.6)\end{array}$ & $\begin{array}{r}5(27.8) \\
16(88.9) \\
10(55.6)\end{array}$ & $\begin{array}{l}2(22.2) \\
7(77.8) \\
3(33.3)\end{array}$ \\
\hline
\end{tabular}

* Body Mass Index (BMI) in $\mathrm{kg} / \mathrm{m}^{2}$

$\S$ Uncorrected serum ferritin i.e. without C-reactive protein (CRP). CRP is a marker of acute and chronic inflammation, and correcting test alongside serum ferritin for diagnosing iron deficiency: if $C R P>5$, serum ferritin may indicate false normal or false high result, therefore the ferritin parameter for diagnosing iron deficiency increases from ferritin $<20 \mu \mathrm{g} / \mathrm{L}$ to $<30 \mathrm{\mu g} / \mathrm{L}$ (WHO, 2011), or $<50 \mu \mathrm{g} / \mathrm{L}$ (Thurnham et al., 2010). In the absence of CRP, uncorrected serum ferritin $\geq 20 \mu \mathrm{g} / \mathrm{L}$ may indicate false positive or false normal iron stores, therefore not detecting iron deficiency.

I) Unconfirmed iron sufficiency: no CRP with serum ferritin to correct for inflammation, possible false positive or false normal indication of iron stores.

$¥$ Low $\mathrm{Hb}$ and ferritin $\geq 20 \mu \mathrm{g} / \mathrm{L}$, without CRP: possible anaemia of inflammation, or functional iron deficiency 


\section{Summary of results}

In this descriptive study of LMC midwives management of maternal anaemia and iron deficiency, the main difference in practice was in testing of serum ferritin, especially in the first trimester where almost half of the women did not have their iron stores measured. Haemoglobin testing was shown to be consistently undertaken throughout pregnancy. There was no statistical association between testing, or not testing serum ferritin at booking, and subsequent low iron status, although the results may be clinically significant.

There was a wide range in LMC practice throughout pregnancy and postpartum in testing for iron status, in prescribing or recommending over the counter iron, and in offering dietary advice. There was a statistically significant difference in ferritin testing according to midwives' caseloads, but not according to years in practice, although there was evidence of effect.

Iron status was difficult to categorise as iron stores were frequently not measured, or serum ferritin was not tested with CRP in order to adjust for inflammation. A private laboratory undertook most of the serum ferritin testing, and almost all were not analysed with CRP. Confirmed and unconfirmed categories of iron status were analysed in relation to midwives response and management of women's iron status. There was no missing data, as all tests not undertaken were accounted for.

The proportions of iron deficiency and absent iron stores were probably underestimated, especially in the first trimester with just under half of the women presenting as non-anaemic, with no measure of ferritin. The most common documented strategy for first trimester management of iron status was dietary advice, for one in 10 women. The largest decline in iron status was in the second trimester, when almost half of the women (48.7\%) were prescribed iron. Subsequently, almost half of the women (47.1\%) still had low iron status in late pregnancy. The range of haemoglobin and serum ferritin where iron was prescribed or recommended throughout pregnancy, was wide. 
Overall, midwives tested $22.8 \%$ of the women's haemoglobins postpartum. Only three quarters of women with $E B L>500 \mathrm{mls}(n=38)$ had their haemoglobin tested early in the postpartum period. Over half of these women had had either low or unknown iron status in the third trimester. Over half of all women tested postpartum had anaemia or severe anaemia, most had no documented evidence of prescribed or recommended oral iron intake.

Results of secondary analysis of BMI and iron status, using different serum ferritin parameters to adjust for inflammation throughout pregnancy, showed no statistical significance. However there was statistically significant association between overweight/obese BMI and lower ferritin levels in the third trimester. 


\section{Chapter five: Discussion}

\section{Introduction}

This study described and examined primary care midwives' management of iron status in pregnancy and postpartum, as little is known about practice in New Zealand. Even in countries where guidelines and recommendations exist, the actual practice of identifying and managing maternal iron status has not been well described (Barrosso et al., 2011). The five key findings that will be discussed in this chapter are:

- Testing for iron stores by maternity primary care providers was inconsistent, especially at booking when under half of the women who had their $\mathrm{Hb}$ tested (46.0\% of $98.4 \%)$, did not have serum ferritin tested.

- Of the 385 serum ferritin tests undertaken, only $14 \%$ were tested with CRP to allow for adjustment of ferritin parameters, in the presence of inflammation.

- Despite midwives prescribing iron for $48.7 \%$ of second trimester women, and recommending OTC iron for $16.9 \%, 47.1 \%$ of women still had low iron status, and $18.0 \%$ unknown iron status as they approached birth.

- Despite the high proportion (65.1\%) of low or unknown iron status, and $20.1 \%$ with $\mathrm{EBL}>500 \mathrm{mls}$ at birth, midwives tested only $22.8 \%$ of haemoglobins in the early postpartum period. Only $10.6 \%$ of women had documented evidence of prescribed oral iron intake, and $0.5 \%$ had evidence of OTC iron supplementation, in the postpartum period.

- Women who appeared to be iron sufficient at booking, with ferritin up to 50 $\mu \mathrm{g} / \mathrm{L}$ (and no CRP to adjust for inflammation) ( $\mathrm{n}=45$ ), had the largest decline to low iron status in the second trimester, especially for women with BMI $\geq 25$ $(n=27)$. The largest drop in iron status was in women with $B M I \geq 30$ and ferritin up to $50 \mu \mathrm{g} / \mathrm{L}(\mathrm{n}=9$ ), with $77.8 \%$ unconfirmed iron sufficiency at booking, and $0 \%$ being iron sufficient in the second trimester. There was a significant difference $(p=.05)$ between third trimester ferritin levels in women with $\mathrm{BMI} \geq 25$ (Md SF 14 $\mu \mathrm{g} / \mathrm{L})$ and $\mathrm{BMI}<25$ (Md SF $18 \mu \mathrm{g} / \mathrm{L})$. 


\section{Consistencies and inconsistencies when testing for iron status}

Haemoglobin has been used for decades as the primary measure of iron status, and proxy measure for iron deficiency (Goonewardene et al., 2012; Milman, 2006). Most of the 189 women in the study did have haemoglobin testing at booking (98.4\%), and in the second (95.8\%) and third trimesters (82.0\%). This was comparably higher than haemoglobin testing of 2013 women in a UK study by Barrosso et al. (2011) (88.7\%, $83.8 \%$ \& $72.4 \%$ respectively). However, haemoglobin alone is a poor measure of iron status as the $\mathrm{Hb}$ is the last red cell indice to drop before end stage iron deficiency anaemia (Mei et al., 2005; Pasricha, 2012; Walsh et al., 2011).

The WHO and CDC anaemia parameters used in the study were $\mathrm{Hb}<110 \mathrm{~g} / \mathrm{L}$ for the first, and $\mathrm{Hb}<105 \mathrm{~g} / \mathrm{L}$ for the second and third trimesters. In the first trimester $45.5 \%$ of women $(\mathrm{N}=189), 12.2 \%$ in the second trimester, and $12.7 \%$ third trimester women were non-anaemic with unknown iron stores. Without a measure of serum ferritin for iron stores, it could not be discerned where women sat on the spectrum from iron sufficiency to deficiency, or depletion, before iron deficiency anaemia. Therefore iron deficiency was probably undetected by the study midwives, especially at booking when an $\mathrm{Hb}$ cut-off value of $110 \mathrm{~g} / \mathrm{L}$ has been demonstrated to miss over 90\% of NAID (Walsh et al., 2011). Although there was no statistical association between testing, or not testing serum ferritin at booking, and third trimester ferritin levels, results were likely to be confounded by the variability of iron supplementation, which was not controlled for. Although this was a study limitation, the results may still be clinically relevant. Given current available technologies, haemoglobin and serum ferritin are the most efficient combination of tests in detecting changes to iron status in populations (Mei et al., 2005).

A recent UK study (Daru et al., 2015) examined the views and opinions of multidisciplinary maternity clinicians, finding that all clinicians were interested in testing for NAID as a target condition, if proven to be effective at improving maternal and neonatal outcomes. In this study, the main difference in primary maternity care was inconsistent testing of serum ferritin, especially at booking. Just over half of the women $(52.4 \%, \mathrm{n}=99)$ had serum ferritin testing in the first trimester, with $83.6 \%$ 
and $67.7 \%$ in the second and third trimesters. Only five women had no serum ferritin testing at all during pregnancy, with four of these cared for by one midwife. However, the rate of serum ferritin testing was notably higher than in Barrosso et al.'s (2011) UK study of 2013 women where ferritin was tested $10.2 \%, 7.2 \%$ and $3.8 \%$ at the first, second and third trimesters, respectively.

Antenatal serum ferritin testing in pregnancy is not routinely undertaken in New Zealand, especially at booking. There are no national guidelines for testing of maternal iron status for New Zealand midwives. However, the results show that testing for iron deficiency is very common; $97.4 \%$ of women did get tested at some stage. Authors in a prominent New Zealand midwifery text book (Hunter \& Gunn, 2015) do not offer clear recommendations for midwives, saying serum ferritin can be done at booking, and repeated with second trimester bloods. Hunter and Gunn (2015) suggest that if serum ferritin is not tested at booking, midwives may discuss the option of an additional early pregnancy test or undertake second trimester bloods earlier at 24 weeks gestation.

The most common reason for not testing serum ferritin in the study, was that it was not requested alongside other routine antenatal bloods for $46.0 \%$ of women $(n=87)$ in the first, $12.2 \%(n=23)$ in the second, and $14.3 \%(n=27)$ in the third trimester. Importantly, many of the first antenatal bloods may have been requested by general practitioners when pregnancy was confirmed, although there was no way of knowing this proportion, within the study. General practitioners refer to the online Health Pathways (2015) primary care resource, which does not recommend testing serum ferritin unless $M C V<80$. So it is not only $L M C$ midwives who request blood tests, especially at booking.

An additional $13.7 \%(n=26)$ of women did not have any third trimester blood tests (including haemoglobin or ferritin) requested by midwives, excluding the seven women who birthed prematurely. Although NZCOM (2005) suggests considering CBC at 36 weeks, and Grigg and Tracy (2015) state there is no debate regarding routine screening of women for anaemia, no specific recommendations around timing of haemoglobin testing are made. 
Given the recent focus on maternal iron deficiency (Grigg, 2015) it was surprising that recently educated midwives with 1-10 years in practice were least likely to test serum ferritin throughout pregnancy, although no statistical significance was demonstrated. This may have been due to the small sample size. Midwives with larger annual caseloads of $41-50$, or $>50$ appeared to test serum ferritin more throughout pregnancy, with a statistical significance $p=0.02$, and $p=.0003$ demonstrated in the second and third trimesters, respectively. These findings might indicate a more pro-active, risk-averse approach to managing iron status in pregnancy, by midwives with more years in practice and higher caseloads.

\section{Limited testing and understanding of C-reactive protein}

This study demonstrated that in the DHB area, current testing of CRP alongside serum ferritin relies on individual laboratory practices. According to the Laboratory Test Schedule (DHBSS, 2013) midwives are able to request CRP, but none of the study midwives requested CRP alongside serum ferritin. Of the 385 ferritin tests undertaken, only $14 \%$ were tested with CRP, and $94.4 \%$ of these were tested in the DHB laboratory. Of the 326 (84.7\%) serum ferritin tests analysed in the private laboratory, 99.1\% ( $n=323$ ) were not tested with CRP to adjust for inflammation. As a result, a large and unknown proportion of women may have had false normal or high ferritin results, potentially misleading midwives with the appearance of a normal iron store result.

Studies show that serum ferritin unadjusted for inflammation is associated with a $14 \%$ (Thurnham et al., 2010) to $17.2 \%$ (Nel et al., 2015) underestimation of iron deficiency. In New Zealand, Midwifery: preparation for practice acknowledges the value of checking CRP with ferritin (Hunter \& Gunn, 2015), but no practice recommendations are made. Anecdotally midwives in New Zealand do not appear to understand the significance of CRP testing with serum ferritin, or how to interpret the results. 


\section{Prescribing in relation to iron status in pregnancy}

There was a significant decline in iron status of women in the study from booking to late pregnancy. Low iron status included anaemia (with unknown ferritin levels), IDA, NAID, absent iron stores and possible anaemia of inflammation. The largest decline in iron status was from the first to second trimester, most likely due to normal physiological haemodilution. However, despite midwives prescribing iron for $48.7 \%$ of second trimester women, and recommending over the counter iron for $16.9 \%$, $47.1 \%$ of women still had low iron status, and $18.0 \%$ had unknown iron status as they approached birth.

The reasons why many women in late pregnancy had low iron status were not clear, but maybe due to many factors or a combination of factors, including: the normal increased demand for iron in late pregnancy, poor dietary habits, other risk factors (e.g. short time interval between births, multiple pregnancy, multi-parity, poor socioeconomic status), midwives' under-recognition of low iron status, delay in management, under-prescribing, or unnecessary prescribing, or women's noncompliance with iron supplementation.

Studies show that compliance of oral iron supplements is low, often around $50 \%$ in clinical trials (NBA, 2015), and likely to be less in real life. It is recommended that all pregnant women should have good dietary advice including discussion on inhibiters (e.g. tannins) and promoters (e.g. vitamin C) of iron absorption (Hunter \& Gunn, 2015; Pavord et al., 2012). However midwives' documented dietary advice, including how to maximise iron absorption from supplements and minimise side effects, was limited with only $10.1 \%, 13.2 \%$ and $3.2 \%$ of women receiving documented advice from the first to third trimesters, respectively.

The overall proportion of women receiving iron prescriptions for each trimester (4.8\%, 48.7\%, and 26.5\%) exceeded iron prescriptions observed (8.5\%, 19.0\% and 14.5\%) in Barroso et al.'s (2011) study. Still, more women in this study had low iron status, than were prescribed or recommended OTC oral iron, throughout pregnancy. Midwives did not prescribe or recommend iron for $47.1 \%(8 / 17)$ of women with 
recognised low iron status in the first trimester, $23.6 \%(33 / 140)$ in the second trimester, and $51.7 \%(46 / 89)$ in the third trimester.

The study demonstrated a very wide range of practice with likely under-recognition of low iron status, and under or over prescribing. Midwives prescribed unnecessarily for a few women with unknown iron status $(n=4)$, or for women who were either non-anaemic (ferritin unknown), or who were iron sufficient during pregnancy $(n=21)$. It could not be determined whether midwives prescribed based on haemoglobin or ferritin results, or both; or if midwives based iron prescriptions on reported symptoms, and/or their clinical experience. However, the ranges of haemoglobin and serum ferritin where iron was prescribed were wide, from 106-141 $\mathrm{g} / \mathrm{L}$ and $13-36 \mu \mathrm{g} / \mathrm{L}$ (respectively) in the first, $95-133 \mathrm{~g} / \mathrm{L}$ and 3-67 $\mu \mathrm{g} / \mathrm{L}$ in the second, and $84-138 \mathrm{~g} / \mathrm{L}$ and $6-90 \mu \mathrm{g} / \mathrm{L}$ in the third trimester.

In the UK, clinicians have expressed concern about raising haemoglobin levels in pregnancy too high, with iron supplementation (Daru et al., 2015), due to potential risks of increased maternal blood viscosity, hypertension and decreased placental perfusion (Pena-Rosas et al., 2012). In New Zealand, the Ministry of Health (2006) recommends prescribing iron only when anaemia is diagnosed. Some midwives in this study prescribed iron with an $\mathrm{Hb}$ of $>130 \mathrm{~g} / \mathrm{L}$ for $1.1 \%, 1.6 \%$ and $2.6 \%$ of first, second and third trimester women. All of these women had a degree of haemoconcentration (Hct $\geq 0.38 \mathrm{~L} / \mathrm{L}$ ), and were normocytic ( $\mathrm{MCV}>80 \mathrm{fL}$ ); although 72.7\% were iron deficient or with absent iron stores. These findings suggest that midwives may not recognise the clinical significance of interpreting $\mathrm{Hb}$ with other red cell indices such as MCV and haematocrit, rather than in isolation. It is recommended that NZ midwives assess the $\mathrm{CBC}$ and serum ferritin two to four weeks after commencing oral iron therapy to avoid risks of iron overload and ensure correct diagnosis of iron deficiency or IDA (Hunter \& Gunn, 2015). This was inconsistently undertaken in the study.

Because of a lack of CRP testing in the study, some results of iron status were interpreted cautiously, but considered clinically significant. The seven anaemic antenatal women with normal, or high serum ferritin $\geq 20 \mu \mathrm{g} / \mathrm{L}$ levels, and no CRP to 
adjust for inflammation, were suggestive of functional iron deficiency (anaemia of inflammation or chronic disease), or thalassaemia. Five of these women (71.4\%) were prescribed oral iron, which is recommended only if there is evidence of microcytic iron deficiency (MCV<80 fL) (Thomas et al., 2013), yet all five women had MCV values $\geq 80 \mathrm{fL}$.

Midwives' management of possible anaemia of inflammation implied a lack of practitioner understanding of current evidence, and knowledge of hepcidin-mediated iron metabolism and sequestering, in the presence of inflammation. The blood test results of one case highlighted the clinically significant challenge of interpreting iron status without a concurrent measure of inflammation: Hb $98 \mathrm{~g} / \mathrm{L}, \mathrm{Hct} 0.30 \mathrm{~L} / \mathrm{L}, \mathrm{MCV}$ $94 \mathrm{fL}, \mathrm{SF} 41 \mu \mathrm{g} / \mathrm{L}$, and no CRP. Anaemia of chronic disease is more challenging to treat than iron deficiency, and should begin with treatment of the underlying cause of infection/inflammation once confirmed (Friedman et al., 2012; Koenig et al., 2014). The use of iron in ACD is also controversial because of poor intestinal absorption, and it may increase growth of microorganisms and the risk of bacteremia (Friedman et al., 2012). Furthermore, women may have both IDA and ACD (Friedman et al., 2012), requiring a very considered interpretation of laboratory tests, and treatment approach.

Chi-square statistical analysis of the association between midwives years in practice, annual caseloads, and prescribing of iron showed no statistical association, although there was some small-medium evidence of effect. There appeared to be an inverse relationship between prescribing and recommending OTC iron. For example, in the second trimester midwives with 31-40 years practice gave more dietary advice and prescribed more iron, but recommended OTC iron less. Similarly, midwives with annual caseloads $>50$ prescribed more but recommended less OTC iron in the second trimester. It is unclear why midwives with more experience and higher caseloads may be more pro-active and risk-averse in their management of maternal iron status. This is a question that could be posed in future research. 


\section{Limited testing and management of postnatal iron status}

Although midwifery educators in New Zealand acknowledge that postpartum iron deficit and IDA is undertreated, resulting in poorer outcomes for women (Hunter \& Gunn, 2015), there are no clear recommendations on how midwives should manage iron status appropriately. In this study midwives management of postpartum iron status was infrequent and inconsistent. Only $10.6 \%$ of women had documented evidence of prescribed oral iron intake, and $0.5 \%$ had evidence of over the counter iron supplementation. Despite the high proportion (65.1\%) of third trimester women with low or unknown iron status, and $20.1 \%$ with EBL $>500 \mathrm{mls}$ at birth, only $22.8 \%$ of women had haemoglobin tested in the early postpartum period. Yet it is well known that the development of postpartum anaemia is a reflection of pre-partum anaemia as well as the magnitude of blood loss (Milman, 2012a).

Peri-partum anaemia and blood loss are strongly associated with $20 \%$ of global maternal mortality (Pena-Rosas et al., 2012). In New Zealand blood loss $>1999 \mathrm{mls}$ is the leading cause of preventable severe acute maternal morbidity (SAMM) (Lawton et al., 2014). Just over $20 \%$ of the women in this study had an estimated blood loss $>500 \mathrm{mls}$. When comparing the proportion of women with excessive blood loss, defined as $>1000 \mathrm{mls}(\mathrm{MOH}, 2011)$, fewer women in the study $(0.5 \%)$ lost 1000 $1500 \mathrm{mls}$, compared to $3.6 \%$ at the local DHB for all births in 2014. A slightly larger proportion (2.7\%) of women in the study had an EBL $>1500 \mathrm{mls}$, compared to $2.1 \%$ in the DHB in 2014. The study incidence of blood transfusion was small (0.5\%), less than $2.4 \%$ in the local tertiary level hospital, and not associated with any SAMM.

None of the study women were given IV iron in the postnatal period, although two women had severe anaemia $(\mathrm{Hb}<85 \mathrm{~g} / \mathrm{L})$ even 10 days after birth. Although these women were prescribed oral iron, IV iron may have been underutilised then as a more effective and appropriate treatment than oral iron for moderate-severe postpartum anaemia (Breymann et al., 2007; Breymann et al., 2010; McMahon, 2010; Van Wyck et al., 2007). Barrosso et al. (2011) also found that IV iron was underutilised despite there being guidelines for use. One explanation in this study is that in 2013 , iron polymaltose was in use but with limited utilisation due to the five 
hour infusion time. Anecdotally, more (third generation) IV iron is being used now, with the advantage of carboxymaltose's total dose and rapid infusion time, especially in the postpartum period. With over three quarters of women with unknown iron status in the postpartum period, an unknown number of women may have benefitted from IV iron, especially since many had low iron status before birth.

The overall proportion of women with $\mathrm{Hb}$ tested around the time of birth (22.8\%) was small, and less than $30.0 \%$ cited in a UK study on the management of anaemia (Barroso et al., 2011). It was concerning that almost half $(48.8 \%, n=21)$ of the study women who had $\mathrm{Hb}$ tested were anaemic, yet only $33.3 \%(n=7)$ of these women had evidence of prescribed or recommended oral iron intake and follow up from their midwives. Although the study midwives did test postpartum $\mathrm{Hb}$ for women who had both low iron status in the third trimester, and EBL $>500 \mathrm{mls}$, a considerable $31.3 \%$ did not have their iron status checked at all.

Very few women had follow up for iron status after the early postpartum period. Of particular concern was the one woman with unknown iron status in late pregnancy, with a postpartum haemorrhage of $3000 \mathrm{mls}$, who was prescribed oral iron for anaemia after birth with $\mathrm{Hb} 90 \mathrm{~g} / \mathrm{L}$, but did not have subsequent testing or follow-up for iron status. These findings reflect Barroso et al.'s (2011) study that identified no consistent policy for postnatal screening, discrepant practice, and the suggestion of uncertainty amongst health professionals regarding appropriate management.

In the study by Daru et al. (2015), 'Hb levels prior to birth' was identified as the most important outcome measure for research in to iron supplementation, in the opinion of $55.9 \%$ midwives, obstetricians and anaesthetists. This is not reflected in this study, where a high proportion of poor/unknown iron status in late pregnancy was a preventable clinical factor for postpartum anaemia, related primarily to inactions by the health care providers.

Physiologically, postpartum intravascular fluid volumes and iron levels revert to prepregnant steady states over four to six weeks (Milman, 2012b). However, the effects of maternal postpartum anaemia and iron deficiency are often underestimated, despite the evidence of adverse outcomes for women and babies (Bodnar et al., 
2005; Milman, 2011). These outcomes of fatigue, lethargy, irritability, poor wound healing, decreased lactation, increased risk of postnatal depression, and poor maternal-infant bonding will be familiar to many midwives and other health professionals. Yet, the findings from this study suggest that these (often) subjective, yet significant costs to women may be underestimated by LMC midwives in New Zealand. The importance of postpartum iron status appears to also be underestimated in a UK study (Daru et al., 2015) with only $17.2 \%$ and $15.2 \%$ of midwives, obstetricians and anaesthetists considering 'postpartum $\mathrm{Hb}$ ' and 'maternal quality of life' as important outcome measures.

\section{BMI, unconfirmed iron sufficiency, and subsequent low iron status}

The $44.1 \%$ proportion of high BMI women $\left(>25 \mathrm{~kg} / \mathrm{m}^{2}\right)$ in the study was less than the $50.6 \%$ of high BMI women in the population of 62,321 women giving birth in New Zealand in $2012(\mathrm{MOH}, 2015)$ (Table 3). This proportion is nonetheless high, and reflects the global obesity epidemic. Obesity is a pro-inflammatory state and associated with lower iron status, due to hepcidin mediated sequestering and downregulation of iron uptake, (Gartner et al., 2013; Koenig et al., 2014).

The iron status of women who had ferritin tested at booking without CRP ( $n=77)$, was analysed in relation to $\mathrm{BMI}$, because without concurrent measures of CRP to indicate inflammation, serum ferritin levels can appear misleadingly normal or high (Nel et al, 2015; Pasricha et al., 2013; Thurnham et al., 2010). The study found that in the first trimester, the proportion of obese women $(\mathrm{BMI} \geq 30)$ who appeared to be iron sufficient, but had low iron status subsequently, was greater than women with lower BMIs. The drop in second trimester iron status was greatest for the women with BMI $\geq 30$ ( $n=9)$ with serum ferritin levels up to $50 \mu \mathrm{g} / \mathrm{L}$ at booking. (Serum ferritin $<50 \mu \mathrm{g} / \mathrm{L}$ was the study parameter for iron deficiency in the presence of inflammation.) Of these women, $77.8 \%$ appeared iron sufficient in the first trimester, but none were iron sufficient in the second trimester.

Although the study size was small, there was a statistically significant association $(p=.05)$ between third trimester ferritin levels of women with BMI <25 (median SF 18 
$\mu \mathrm{g} / \mathrm{L}$ ), and $\mathrm{BMI} \geq 25$ (median SF $14 \mu \mathrm{g} / \mathrm{L}$ ). This result may be clinically significant. Women with higher BMls may have lower iron status in pregnancy because the proinflammatory state may lead to functional iron deficiencies, and/or masking of true iron deficiencies, resulting in a lack of recognition and under-treatment by health professionals.

These observational findings reflect results in other studies where obesity is statistically associated with low iron status in non-pregnant populations (Gartner et al., 2013; Moschonis et al., 2012; Nel et al., 2015; Thurnham et al., 2010). Although reviews (Friedman et al., 2012; Koenig et al., 2014, Wang et al., 2010) state obesity in pregnancy is associated with low iron status, there are no published clinical trials to date which demonstrate this. Mor et al. (2011) propose that the implantation of pregnancy causes maternal inflammation. Theoretically this may exacerbate the possible obesity related inflammation observed in this study, especially in the first trimester.

\section{Study strengths and limitations}

\section{The study population}

The study population of 21 midwives is comparable to midwives with annual practicing certificates in 2012 (MCNZ, 2012), although Maori midwives were underrepresented in the study. LMC midwives who did not network via local NZCOM meetings or newsletters, or who were not conveniently accessible to the researcher in the tertiary level birthing unit, or rural midwives, did not participate in the study. The small accessible study populations of midwives and women were not necessarily generalisable to New Zealand LMC midwives and birthing women, but they were well defined and overall representative groups.

In terms of age, gestation at birth and parity, the cohort of 189 women was representative of women giving birth in New Zealand. Maori women were underrepresented however, compared to the population of birthing women $(\mathrm{MOH}, 2015)$. Fewer women smoked in the study, and although the proportion of overweight and 
obese women was high, it was less than the national birthing population $(\mathrm{MOH}$, 2015).

\section{Study strengths}

Polit and Beck (2008) describe generalisability as an almost impossible ideal that researchers' must strive for. The validity, integrity and applicability of this study, was enhanced by the representativeness of the sample, the vigorous research methods, no missing data, and the extensive literature review.

The extensive literature review and synthesis of the evidence and meta-analyses are cornerstones of evidence-based practice (Polit \& Beck, 2010). However the literature review outlined the limitations of meta-analyses, where data on iron status and supplementation could not be pooled due to heterogeneity of study populations, parameters, interventions and outcome measures. From a New Zealand perspective this study highlighted that 'no evidence of an effect' is distinct from 'evidence of no effect' (Pasricha, 2010).

The external validity of this study was enhanced by being immersed in, and knowing the data very well. There was no missing data, as all tests not undertaken were accounted for in terms of the reasons the tests were not done. As researcher I collected, inputted (twice) and analysed the data, and was able to scrutinize the data to look within cases (Appendices D-F), as well as having the overview of the aggregated data. This enabled the recognition of extreme cases, and sub-groups. Immersion in the data in this way is known as "qualitizing of quantitative data" (Polit \& Beck, 2010, p. 1456).

\section{Study limitations}

A significant study limitation was the documentation of midwives practice. Data on midwives' management of iron status relied on documentation in the primary care notes. Midwives may not have documented all strategies to improve women's iron status therefore these strategies may have been underestimated in the study. The study also did not distinguish who ordered the first trimester blood tests, with many women booking with LMCs after the initial antenatal blood tests were requested by 
general practitioner doctors. This reflects the complexity of primary care arrangements in New Zealand (MOH, 2015).

The study described midwives practice, but the reasons for poor iron status are multi-factorial and complex, including the role of women in improving their own health and well being. This was not investigated in this study as was any exploration of the partnership between women and midwives in working together to improve maternal iron status.

Analysis of data was mostly limited to descriptive statistics because the study sample size was small. Inferential statistical tests that were undertaken were underpowered, but still the findings have implications in informing further research. Although there was no statistical association between testing or not testing serum ferritin at booking, and third trimester ferritin levels, other variables such as iron supplementation were not controlled for. This was a study limitation.

\section{Implications for education, practice and research}

\section{Implications for education}

- This study suggests similar findings to Daru et al.'s (2015) survey, that maternity health care professionals have a lack of understanding of the natural history of non-anaemic iron deficiency (NAID) and iron deficiency anaemia (IDA). This lack of understanding is complicated by recent evidence on the effects of inflammation on iron status.

- Consistent, evidence based education is required for student midwives, practising midwives and other primary health care providers (e.g. general practitioners) to fill the gaps between knowledge and practice, regarding:

- Recognition of low iron status. This includes education on the timing of tests for iron stores, the importance of concurrent CRP testing with serum ferritin, the interpretation of all lab results (including MCV and $\mathrm{Hct}$ ), especially in the presence of inflammation. 
- Alternative approaches to oral iron prophylaxis and treatment, such as low dose iron started early in pregnancy, or intermittent dosing of higher dose oral iron, are likely to improve women's compliance by reducing side effects, if advice on improving absorption is included.

\section{Implications for primary care midwifery practice}

- A clear national midwifery or multi-disciplinary evidence-based guideline for the management of maternal iron status should be developed. The aim of the guideline would be for midwives and primary health care providers to provide consistent care to improve outcomes for mothers and babies, and reduce adverse outcomes associated with anaemia and iron deficiency, especially around the time of birth and postpartum. The current lack of a national, or even local guideline, reflects the problematic lack of guidelines in many countries (Milman, $2012 b)$, that leads to discrepant practice and uncertainty by health professionals (Barosso et al., 2011), as indicated in this study.

- Primary maternity care providers should undertake first trimester testing of serum ferritin with CRP, as well as haemoglobin, either for all women, or alternatively as a risk-based approach, to maximise treatment time with oral iron.

- Midwives and primary maternity care providers should identify and pro-actively manage women at high risk of low iron status in pregnancy: short time interval between births ( $\leq 12$ months), multiparity, multiple pregnancy, obesity, teenagers, smokers, poor diet, poor SES, certain ethnicities (e.g. Indian) including screening for haemoglobinopathies (in high risk ethnicities), chronic inflammation, and poor socio-economic status.

- More emphasis should be placed by midwives and primary maternity care providers on prevention and treatment of postpartum anaemia and iron deficiency, including follow up of at risk women with low iron status in pregnancy, or where there has been significant blood loss $>1000 \mathrm{mls}$, as per the revised Dutch midwives guideline (Beentje \& Jans, 2012).

- Development of consistent laboratory practices around concurrent testing of CRP alongside serum ferritin to allow for adjustment of the threshold for iron 
deficiency, in the presence of inflammation. For example, serum ferritin and CRP ought to be printed on the 'midwife only' laboratory request forms.

\section{Recommendations for future research}

This was the first such study on management of maternal anaemia in New Zealand. As a result of this study, and in view of the global evidence and gaps in knowledge, there are multiple recommendations for future research to be undertaken in New Zealand:

- A large scale study to determine the prevalence of maternal anaemia and iron deficiency in NZ; to determine the optimal statistical and functional cut-offs for defining anaemia in this population, as described by Pasricha et al. (2013).

- A larger replication of this study on midwives management of maternal iron status, in a different geographical area with greater ethnic representation of Maori in particular, to verify the findings in this study.

- A multi-disciplinary study of New Zealand clinicians' opinions and priorities towards different levels of maternal anaemia and iron deficiency, similar to Daru et al. (2015), although from a sociological perspective to explore different professional frameworks and philosophies that might affect management.

- A large scale intervention or observational study (e.g. oral vs. IV iron, for moderate-severe postpartum anaemia) including functional maternal outcome measures (i.e. quality and duration of breastfeeding, quality of life, physical and psychological well-being), as well as laboratory indices.

\section{Conclusion}

The aim of this research was to describe New Zealand LMC midwives management of maternal anaemia and iron deficiency, by retrospectively gathering clinical data from women in their care in 2013. This study was a snapshot of 21 midwives' management included testing, diagnosis, dietary advice, recommending or prescribing iron in relation to maternal iron status and gestation. This research begins to fill the gap between knowledge and practice about midwives primary care management of anaemia and iron deficiency in pregnancy and postpartum, as little is known about 
actual practice in New Zealand, or overseas. The specific aims of this research were met. This research also adds to the small international body of midwifery research, mostly from midwives in the Netherlands, from a unique New Zealand perspective.

The main conclusion is that this research suggests a need for a comprehensive evidence-based midwifery, or multi-disciplinary guideline, on the primary-care management of maternal iron status. Although midwives consistently tested haemoglobin levels, testing of serum ferritin was inconsistent especially in the first trimester when almost half of the woman did not have a measure of iron stores. General practitioners may also have requested some of the antenatal blood tests on confirmation of pregnancy. Without a measure of iron stores, midwives could not discern where women sat on the spectrum from iron sufficiency to non-anaemic iron deficiency, before end-stage iron deficiency anaemia.

Despite international recommendations for either routine, or a risk-based approach to serum ferritin testing, measurement of maternal iron stores appears to be ad hoc in New Zealand. However the literature suggests that this is a global issue. Clinical guidance on the management of maternal iron deficiency should address concurrent testing of serum ferritin with C-reactive protein; to avoid misleading false-positive results, and to enable accurate interpretation of iron stores, in the presence of acute or chronic infection or inflammation. This study indicated that women with high BMIs may have lower iron stores possibly due to the pro-inflammatory state, although the study was small and the results should be interpreted cautiously. Given the worldwide obesity epidemic, more research is required to examine the association between high BMI, and low maternal iron status in New Zealand.

There was a very wide range of midwives' practice in prescribing iron, with some midwives not prescribing for low iron status, and some midwives over-prescribing for unknown iron status or unknown iron stores. Despite midwives prescribing iron for almost half of the second trimester women, over half still had low iron status or unknown iron status as they approached birth. This potentially had implications for women in terms of lowered tolerance to blood loss, and increased likelihood of blood transfusion and IV iron, although this was not evident in the study. 
Low iron status in the postnatal period is associated with fatigue and lethargy, impaired maternal-infant interactions, poor breastfeeding and postnatal depression. Yet midwives only tested haemoglobin levels of under a quarter of postpartum women, and only a tenth of women had evidence of postnatal iron supplementation. These results indicate a short-fall in practice, with potential implications for women. Given the insidious nature of adverse effects related to anaemia and iron deficiency, research is required in New Zealand on maternal outcomes, especially in the postpartum period

Although this study was small, and even without further research, these results point to the second main conclusion that midwives need more education on the complexities of maternal anaemia and iron deficiency. The line between normal physiological anaemia of pregnancy, and anaemia associated with pathology remains blurred. Like Barroso et al.'s (2011) UK study, the study's results indicate that midwives in New Zealand, may not understand the natural progression from iron deficiency to iron deficiency anaemia. However with improved education, there is sufficient knowledge and evidence so midwives can interpret other red cell indices (i.e. $\mathrm{MCV}, \mathrm{MCH}$ and $\mathrm{Hct}$ ) as well as haemoglobin, serum ferritin and $\mathrm{CRP}$, to more accurately recognise and diagnose anaemia and iron deficiency in pregnancy and in the postpartum period.

Finally, until a large population and prevalence study is undertaken in New Zealand on haemoglobin parameters throughout pregnancy, the 'normal' haemoglobin parameters for our population of birthing women will remain unclear. Until then midwives walk a fine line between 'abnormalising' normal physiological anaemia of pregnancy, and 'normalising' low maternal iron status. 


\section{Reference List}

Allen, L. (2000). Anaemia and iron deficiency: effects on pregnancy outcome. The American Journal of Clinical Nutrition, 71(5), 1280S-1284S.

Allison, J., Wall, T., Spettell, C., Calhoun, J., Fargason, C., Kobylinski, R., ... Kiefe, C. (2000). The art and science of chart review. Journal on Quality Improvement, 26(3), 115-136.

Alwan, N., Greenwood, D., Simpson, N., McArdle, H., Godfrey, K. \& Cade, J. (2011). Dietary iron intake during early pregnancy and birth outcomes in a cohort of British women. Human Reproduction, 26(4), 911-919. doi:10.1093/humrep/der005

Amelink-Verburg, M.P., Herschderfer, K.C., Offerhaus, P.M. \& Buitendijk, S.E. (2010). The development of evidence based midwifery in the Netherlands: the journey from midwifery knowledge to midwifery research to midwifery standards of practice. Evidence - Based Midwifery (pp. 17-XV). Retrieved from http://search.proquest.com.helicon.vuw.ac.nz/docview/189244783/citation/ $\underline{13680267 \mathrm{~B}}$

Andersson, O., Hellstrom-Westas, L., Andersson, D., \& Domellof, M. (2011). Effect of delayed versus early umbilical cord clamping on neonatal outcomes and iron status at 4 months: a randomised controlled trial. British Medical Journal, 2011(343), 1-12. doi:10.1136/bmj.d7157

Baddock, S. (2015).The physiology of conception and pregnancy. In Pairman, S., Pincombe, J., Thorogood, C., \& Tracy, S. (Eds.), Midwifery: preparation for practice ( $3^{\text {rd }}$ ed.) (pp. 461-500). NSW, Australia: Elsevier.

Barroso, F., Allard, S., Kahan, B., Connolly, C., Smethurst, H., Choo, L., Khan, K., \& Stanworth, S. (2011). Prevalence of maternal anaemia and its' predictors: a multi-centre study. British Journal of Obstetrics \& Gynecology and Reproductive Biology, 2011 (159), 99-105. doi: 10.1016/j.ejogrb.2011.07.041

Barut, A., \& Harma, M., (2009). Intravenous iron treatment for iron deficiency anaemia in pregnancy. Journal Turkish-German Gynecological Association, 2009(10), 109-15.

Beard, J.L., Hendricks, M.K., Perez, E.M., Murray-Kolb, L.E., Berg, A., Vernon-Feagans, L., ...Tomlinson, M. (2005). Maternal iron deficiency anaemia affects postpartum emotions and cognition. Journal of Nutrition, 135(2), 267-272. Retrieved from http://www.jn.nutrition.org/content/135/2/267.long 
Beentjes, M., \& Jans, S., (2012). Revised professional standard: Anaemia in midwifery practice. Ned Tijdscher Geneeskd, 156(5), A3711. Retrieved from http://www.ntrg.nl/artikeln/herziene-beroepsstandard-anemie-deverloskundige-praktijk

Bhandall, N., \& Russell, R. (2006). Intravenous versus oral iron therapy for postpartum anaemia. BJOG An International Journal of Obstetrics and Gynaecology, 1-5. doi: 10.1111/j.1471-0528.2006.01062.x

Bodnar, L.M., Cogswell, M.E., \& McDonald, T. (2005). Have we forgotten the significance of postpartum iron deficiency? American Journal of Obstetrics and Gynaecology,193(1), 36-44.

Brabin, B., Hakimi, M., \& Pelletier, D. (2001). Iron-deficiency anaemia and pregnancyrelated maternal mortality. Journal of Nutrition, 2001(131), 604-615.

Breymann, C., Gliga, F., Bejenariu, C., \& Strixhova, N. (2007). Comparative efficacy and safety of intravenous ferric carboxymaltose in the treatment of postpartum iron deficiency anaemia. International Journal of Gynaecology and Obstetrics,101(1), 67-73. doi:10.1016/j.ijgo.2007.10.009

Breymann, C., Honegger, C., Holzgreve, W., \& Surbek, D. (2010). Diagnosis and treatment of iron-deficiency during pregnancy and postpartum. Arch Gynecol Obstet, 282, 577-580. doi: 10.1007/s00404-010-1532-z

Campbell, N. (2013). Consensus guidelines: helping decision making. New Zealand College of Midwives Midwifery News, December 2013(71), 4-5.

Centres for Disease Control and Prevention. (1998). Recommendations to prevent and control iron deficiency in the Unites States. Retrieved from http://www.cdc.govt/mmwr/preview/mmwrhtml

Cheng, H., Bryant, C., Rooney, K., Steinbeck, K., Griffen, H., Petocz, P., \& O’Connor, H. (2013). Iron, hepcidin and inflammatory status of young healthy overweight and obese women in Australia. Plos One, 8(7), 1-6.

Christian, P., Khatry, S., Katz, J., Pradhan, E., LeClerq, S., Shrestha, S.,...Sommer, A., (2003). Effects of alternative micronutrient supplements on low birth weight in rural Nepal: double blinded randomized community trial. British Medical Journal, 326(7396), 571-576. doi: 10.1136/bmj.3267389.571

Christian, P., Stewart, P., LeClerq, S., Wu, L., Katz, J, West, K., \& Khatry, S., (2009). Antenatal and postnatal iron supplementation and childhood mortality in rural Nepal: a prospective follow-up in a randomized, controlled community trial. American Journal of Epidemiology, 170(170), 1127-36 
Christoph, P., Schuller, C., Studer, H., Irion, O., Martinez, B., Tejada, D., \& Surbek, D., (2012). Intravenous iron treatment in pregnancy: comparison of high-dose ferric carboxymaltose vs. iron sucrose. Journal of Perinatal Medicine, 40(2012), 469-474. doi: 10.1515/.jpm-2011-0231

Cluett, E.R., \& Bluff, R. (2006). Principles and practice of research in midwifery $\left(2^{\text {nd }}\right.$ ed.).Edinburgh: Churchill Livingstone.

Cogswell, M., Parvanta, I., Ickes, L., Yip, R., \& Brittenham, G., (2003). Iron supplementation during pregnancy, anaemia and birth weight: a randomized controlled trial. American Journal of Clinical Nutrition, 78(4), 773-781.

Corwin, E.J., Murray-Kolb, L.E., \& Beard, J.L. (2003). Low haemoglobin level is a risk factor for postpartum depression. The Journal of Nutrition, 133(12), 4139-42. Retrieved from http://search.proquest.com/docprintview/197440653/Record/136711D3069 5FCE8D8A

Crowther, S. (2010). Blood tests for investigating maternal wellbeing. The Practising Midwife, 13(7), 48-52.

Daru, J., Moores, R., Dodds, J., Rayment, J., Allard, S., \& Khan, K. (2015). Non-anaemic iron deficiency in pregnancy: the views of health service users and health care professionals. Transfusion Medicine, 25, 27-32. doi: 10.1111/tme.12184

District Health Boards Shared Services (DHBSS), (2013). Laboratory Test Schedule. Retrieved from http://www.dhbsharedservices.health.nz/Site/Laboratory/

Dixon, L. (2014). What constitutes evidence? New Zealand College of Midwives Midwifery News, December 2014(75), 9-10.

Dodd, J.M., Dare, M.R., \& Middleton, P. (2009). Treatment for women with postpartum iron deficiency anaemia. The Cochrane Database of Systematic Reviews 4, 1-32. doi: 10.1002/14651858.CD004222.pub2.

Elias, S. (2007). Iron supplementation - is it necessary for healthy pregnancy? New Zealand College of Midwives Journal, October 2007 (37), 7-10.

Emery, D., \& Barry, D. (2004). Comparison of Maori and non-Maori maternal and fetal iron parameters. The New Zealand Medical Journal, 117(1195), 1-6. Retrieved from http://search.proquest.com/docview/1033756335?accountid=14782

Field, A. (2013). Discovering statistics using IBM SPSS statistics ( $4^{\text {th }}$ edition). London: Sage. 
Friedman, A., Chen, Z., Ford, P., Johnson, C., Lopez, A., Shander, A., Waters, J., \& van Wyck, D. (2012). Iron deficiency anaemia in women across the life span. Journal of Women's Health, 21(12), 1282-1288. doi: 10.1089/jwh.2012.3713

Frossier, B., Collingwood, J., Hodyl, N., \& Dekker, G., (2014). Intravenous ferric carboxymaltose for anaemia in pregnancy. BioMed Central, 14(115), 1-12. doi: 10.1186/1471-2393-14-115

Frye, A. (2007). Understanding diagnostic tests in the childbearing year $\left(7^{\text {th }}\right.$ ed.). Portland: Labrys Press.

Gartner, A., Berger, J., Bour, A., Ati, J., Traissac, P., Landais, E., Kabbaj, S., \& Delpeuch, F. (2013). Assessment of iron deficiency in the context of the obesity epidemic: importance of correcting serum ferritin concentrations for inflammation. American Journal of Clinical Nutrition, 2013(98), 821-6. doi: 10.3945/ajen.112.054551

Gibbons, M., \& Wratten, J., (2015). Nutrition and physical activity foundations for pregnancy, childbirth and lactation. In Pairman, S., Pincombe, J., Thorogood, C., \& Tracy, S. (Eds.), Midwifery: preparation for practice ( $3^{\text {rd }}$ ed.) (pp. 501522). NSW, Australia: Elsevier.

Goonewardene, M., Sheheta, M., \& Hamad, A. (2012). Anaemia in pregnancy. Best Practice \& Research Clinical Obstetrics and Gynaecology, 26(2012), 3-24.

Graves, B., \& Barger, M. (2001). A "conservative" approach to iron supplementation during pregnancy. Journal of Midwifery \& Women's Health, 46(3), 159-166.

Grigg, C., \& Tracy, S. (2013). New Zealand's unique maternity system. Women and Birth, 26(2013), e59-e64. doi: 10.1016/j.wombi.2012.09.006

Grigg, C., (2015). Working with women in pregnancy. In Pairman, S., Pincombe, J., Thorogood, C., \& Tracy, S. (Eds.), Midwifery: preparation for practice ( $3^{\text {rd }}$ ed.) (pp. 564-606). NSW, Australia: Elsevier.

Guilliland, K., \& Pairman, S. (1995). The Midwifery Partnership: A model for practice. Wellington: Victoria University of Wellington.

Haider, B., Olofin, I., Wang, M., Spiegelman, D., Ezzati, M., \& Fawzi, W. (2013). Anaemia, prenatal iron use, and risk of adverse pregnancy outcomes: systematic review and meta-anaysis. British Medical Journal, 2013(346), 1-19. doi: 10.1136/bmj.f3443

Health Pathways (2015). Anaemia and iron deficiency anaemia in pregnancy. Retrieved from http://www.healthpathways.org.nz 
Hunter, M., \& Gunn, J. (2015). Pharmacology and prescribing. In Pairman, S., Pincombe, J., Thorogood, C., \& Tracy, S. (Eds.), Midwifery: preparation for practice ( ${ }^{\text {rd }}$ ed.) (pp. 858-890). NSW, Australia: Elsevier.

James, A.H., Patel, S.T., Watson, W., Zaidi, Q.R., Mangione, A., \& Goss, T.F. (2008). An assessment of medical resource utilization and hospitalization cost associated with a diagnosis of anaemia in women with obstetrical bleeding in the United States. Journal of Women's Health, 17 (8), 1279-1284. doi: 10.1089/jwh.2007.0605

James, D.K., Steer, P.J., Weiner, C.P., \& Gonik, B. (2006). High risk pregnancy: management options ( $3^{\text {rd }}$ ed.). Philadelphia, PA: Elsevier Saunders.

Jans, S. (2012). Screening for anaemia and haemoglobinopathy before and during pregnancy: a question of ethnicity? (Doctoral dissertation). Radboud University, Nijmegen, the Netherlands.

Jirowong, S., Johnson, M., \& Wetch, A. (2011). Research Methods in Nursing and Midwifery - pathways to evidence based practice. Victoria, Australia: Oxford University Press.

Jordan, S. (2010). Pharmacology for midwives: the evidence base for safe practice $\left(2^{\text {nd }}\right.$ ed.). New York: Palgrave Macmillan.

Koenig, M., Tussing-Humphreys, L., Day, J., Cadwell, B., \& Nemeth, E. (2014). Hepcidin and iron homeostasis during pregnancy. Nutrients, 2014(6), 30623083. doi: $10.3390 /$ nu6083062

Lawton, B., MacDonald, E., Brown, S., Wilson, L., Stanley., Tait, J., ...Geller, S. (2014). Preventability of severe acute maternal morbidity. American Journal of Obstetrics \& Gyncology, 2014(210), 1-6. doi: 10.1016/j.ajog.2013.12.032

Lee, S., Guillet, R., Cooper, E., Westerman, M., Orlando, M., Pressman, E., \& O’Brien. (2014). Maternal inflammation at delivery affects assessment of maternal iron status. The Journal of Nutrition, (2014), 1524-1532. doi: 10.3945/jn.114.191445

Makrides, M., Crowther, C., Gibson, R.A., Gibson, R.S., \& Skeaff, C. (2003). Efficacy and tolerability of low-dose iron supplements during pregnancy: a randomized controlled trial. American Journal of Clinical Nutrition, 2003(78), 145-53.

McMahon, L. (2010). Iron deficiency in pregnancy. Obstetric Medicine,(3),17-24. doi: 10.1258/om.2010.100004. 
Mei, Z., Cogswell, M., Parvanta, I., Lynch, S., Beard, J., Stoltzfus, R., \& GrummerStrawn, L. (2005). Haemoglobin and ferritin are currently the most efficient indicators of population response to iron interventions: an analysis of nine randomized controlled trials. Journal of Nutrition, 2005(135), 1974-1980.

Meinzen-Derr, J., Guerrero, M., Altaye, M., Ortega-Gallegos, H., Ruiz-Palacios, G., \& Morrow, A. (2006). Risk of infant anaemia is associated with exclusive breastfeeding and maternal anaemia in a Mexican cohort. The journal of nutrition, 136(2), 452-458.

Midwifery Council of New Zealand (MCNZ) (2012). Midwifery Workforce Survey 2012. Retrieved from http://www.midwiferycouncil.health.nz/workforcedata/

Miller, S., \& Wilkes, L., (2015). Working in partnership. In Pairman, S., Pincombe, J., Thorogood, C., \& Tracy, S. (Eds.), Midwifery: preparation for practice ( $3^{\text {rd }}$ ed.) (pp. 412-427). NSW, Australia: Elsevier.

Milman, N. (2006). Iron and pregnancy - a delicate balance. Ann Hematol, 2006(85), 559-565. doi:10.1007/s00277-006-0108-2

Milman, N., Byg, K., Bergholt, T., Eriksen, L. \& Hvas, A. (2006). Body iron and individual prophylaxis in pregnancy - should the iron dose be adjusted according to serum ferritin? Ann Hematol, 2006 (85), 567-573. doi: 10.1007/s00277-006-0141-1

Milman, N. (2011). Postpartum anaemia I: definition, prevalence, causes and consequences. Ann Hematol, 2011(90), 1247-1253. doi: 10.1007/s00277-011$1279-z$

Milman, N. (2012a). Oral iron prophylaxis in pregnancy: not too little and not too much! Journal of Pregnancy, 2012(514345), 1-8. doi:10.1155/2012/514345.

Milman, N. (2012b). Postpartum anaemia Il: prevention and treatment. Ann Hematol, 2012(91), 143-154. doi: 10.1007/s00277-011-1381-z

Ministry of Health. (2006). Food and nutrition guidelines for healthy pregnant and breastfeeding women: a background paper. Wellington, New Zealand: Ministry of Health. Retrieved from http://www.health.govt.nz/publications/food-and-nutrition-guidelinehealthy-pregnant-and-breastfeeding-women

Ministry of Health. (2007). Primary maternity services notice (section 88). Wellington, New Zealand: Ministry of Health. Retrieved from 
http://www.health.govt.nz/our-work/life-stages/maternity-services/primarymaternity-services-notice-section-88

Ministry of Health. (2011). New Zealand maternity clinical indicators. Wellington, New Zealand: Ministry of Health. Retrieved from http://www.health.govt.nz

Ministry of Health. (2012). Guidelines for consultation with obstetric and related medical services (referral guidelines). Wellington, New Zealand: Ministry of Health. Retrieved from http://www.health.govt.nz/publication/guidelinesconsultation-obstetric-and-related-medical-services-referral-guidelines

Ministry of Health. (2015). Report on Maternity, 2012. Wellington, New Zealand: Ministry of Health. Retrieved from http://www.health.govt.nz/publication/report-maternity-2012

Monti, D. (2004). Iron deficiency and iron deficiency anaemia: what Popeye didn't know. International Journal of Childbirth Education, 20(2), 12-14.

Mor, G., Cardenas, I., Abrahams, V., \& Guller, S. (2011). Inflammation and pregnancy: the role of the immune system at the implantation site. Annals of the New York Acadamy of sciences, 2011(1221), 80-87. doi: 10.1111/j.17496632.2010.05938.x

Morton, S., Saraf, R., Bandara, K., Bartolomew, K., Gilchrist, C., Atatoa-Carr, P., ...Grant, C., (2014). Maternal and perinatal predictors of newborn iron status. New Zealand Medical Journal, 127(1402), 62-77. Retrieved from http://www.nzma.org.nz/journal/read-the-journal/all-issues/2010-2019/2014

Moschonis, G., Chrousos, G., Lionis, C., Mougios, V., \& Manios, Y. (2012). Association of total body and visceral fat mass with iron deficiency in preadolescents: the Healthy Grow Study. British Journal of Nutrition, 2011(108), 710-719. doi: 10.1017/S0007114511005952

Munoz, M., Breymann, C., Garcia-Erce, J., Comin, J., \& Bisbe, E. (2007). Efficacy and safety of intravenous iron therapy as an alternative/adjunct to allogenic blood transfusion. Vox Sanguinis, 2007(94), 172-183. doi: 10.1111/j.14230410.2007.01014.x

National Blood Authority. (2015). Patient Blood Management Guidelines: Module 5 Obstetrics and Maternity. NBA, Canberra, Australia.

National Institute for Health and Clinical Excellence. (2014). Antenatal Care. Retrieved from http://www.nice.org.uk/guidance/cg62

National Institute for Health and Clinical Excellence. (2015). Postnatal Care. Retrieved from http://www.nice.org.uk/guidance/cg37 
National Women's Hospital. (2013). Pathway for iron supplementation in pregnant women. Retrieved from http://nationalwomenshealth.adhb.govt.nz

Nel, E., Kruger, H., Baumgartner, J., Faber, M., \& Smuts, C. (2015). Differential ferritin interpretation methods that adjust for inflammation yield discrepant iron deficiency prevalence. Maternal and child nutrition, (2015), 1-8.

New Zealand College of Midwives. (2005). Midwives handbook for practice ( $3^{\text {rd }}$ ed.). ISBN 0-476-01172-8

Notebaert, E., Chauny, J., Albert, M., Fortier, S., Leblanc, N., \& Williamson, D.R. (2007). Short-term benefits and risks of intravenous iron: a systematic review and meta-analysis. Transfusion, 47, 1905-1918. doi: 10:1111/j.15372995.2007.01415.x

Offerhaus, P., Fleuren, M., \& Wensing, M. (2004). Guidelines on anaemia: effect on primary-care midwives in The Netherlands. Midwifery, 2005(21), 204-211. doi:10.1016/j.midw.2004.10.005

Office of the Privacy Comissioner. (1993). Privacy Act 1993. Retrieved from http://www.legislation.govt.nz/act/public/1993

Pairman, S., Pincombe, J., Thorogood, C., \& Tracy, S. (Eds.) (2015). Midwifery: preparation for practice ( $3^{\text {rd }}$ ed.). NSW, Australia: Elsevier.

Pasricha, S., Flecknoe-Brown, S. C., Allen, K. J., Gibson, P. R., McMahon, L. P., Olynyk, J. K., ... Robinson, K. L. (2010). Diagnosis and management of iron deficiency anaemia: a clinical update. Medical Journal of Australia, 193(9), 525-532.

Pasricha, S. (2012). Should we screen for iron deficiency anaemia? A review of the evidence and recent recommendations. Pathology, 44(2), 139-147. doi: 10.1097/PAT.Ob013e32834e8291

Pasricha, S., Drakesmith, H., Black, J., Hipgrave, D., \& Biggs, B. (2013). Control of iron deficiency anaemia in low and middle income countries. Blood, 121(14), 26072617. doi: 10.1182/blood-2012-09-453522

Paterson, J., Davis, J., Gregory, M., Holt, S., Pachulski, A., Stamford, D., ...Jarret, A. (1994). A study on the effects of low haemoglobin on postnatal women. Midwifery, 1994(10), 77-86.

Pavord, S., Myers, B., Robinson, S., Allard, S., Strong, J., \& Oppenheimer, C. (2012). UK guidelines on the management of iron deficiency in pregnancy. British Journal of Haematology, 2012, 156, 588-600. doi: 10.1111/j.13652141.2011.09012.x 
Peat, J. (2002). Health science research: a handbook of quantitative methods. Sydney: Allen \& Unwin.

Pena-Rosas, J., \& Viteri, F. (2006). Effects of routine oral iron supplementation with or without folic acid for women during pregnancy. Cochrane database of systematic reviews, 2006(3). 1-139. Retrieved from https://www.apps.who.int.rhl/reviews/langs/CD004736ru.pdf

Pena-Rosas, J., De-Regil, L., Dowswell, T., \& Viteri, F. (2012). Intermittent oral iron supplementation during pregnancy. Cochrane database of systematic reviews, 2012(7), 1-121. doi: 10.1002/14651858.CD009997

Perez, E.M., Hendricks, M.K., Beard, J.L., Murray-Kolb, L.E., Berg, A., Tomlinson, M., ...Vernon-Feagons, L. (2005). Mother-infant interactions and infant development are altered by maternal iron deficiency anaemia. Journal of Nutrition, 135(4), 850-855. Retrieved from http://in.nutrition.org/content/135/4/850.long

Perinatal Maternal Mortality Review Committee, (2015). Ninth Annual Report of the Perinatal Maternal Mortality Review Committee: Reporting Mortality 2013. Wellington: Health Quality \& Safety Commission. Retrieved from http://www.hqsc.govt.nz/our-programmes/mrc/pmmrc

Polit, D.F. \& Beck, C.T. (2008). Nursing research: generating and assessing evidence for nursing practice $\left(8^{\text {th }}\right.$ ed.). Philadelphia: Lippincott Williams \& Wilkins.

Polit, D.F. \& Beck, C.T. (2010). Generalization in quantitative and qualitative research: Myths and strategies. International Journal of Nursing Studies, 47(11), 1451-1468. doi: 10.1016/j.ijnurstu.2010.06.004

Rasmussen, K. (2001). Is there a causal relationship between iron deficiency or irondeficiency anaemia and weight at birth, length of gestation and perinatal mortality? American Society for Nutritional Sciences (2001), 590S-603S.

Rasmussen, S., Bergsjo, P., Jacobsen, G., Haram, K., \& Bakketeig, L. (2005). Haemoglobin and serum ferritin in pregnancy - correlation with smoking and body mass index. European Journal of Obstetrics \& Gynecology and Reproductive Biology, 2005(123), 27-34. doi:10.1016/j.ejogrb.2005.02.012

Reveiz, L., Gyte, G., \& Cuervo, L. (2007). Treatments for iron-deficiency anaemia in pregnancy. Cochrane Database of Systematic Reviews, 2007(2), 1-2. doi:10.1002/14651858.CD003094.pub2 
Rioux, F., Savoie, N., \& Allard, J. (2006). Is there a link between postpartum anaemia and discontinuation of breastfeeding? Canadian Journal of Dietetic Practice and Research, 67(2), 72-76.

Ross, S., Fahrbach, K., Frame, D., Scheye, R., Connelly, B., \& Glaspy, J. (2003). The effect of anaemia treatment on selected health-related quality-of-life domains: a systematic review. Clinical therapeutics, 25(6), 1786-1805.

Rosto, E. (Ed.). (2009). Pathophysiology made incredibly easy ( $4^{\text {th }}$ ed.). Pensylvania: Lippincott Williams \& Wilkins.

Royal Australian and New Zealand College of Obstetricians and Gynaecologists.

(2013). Routine antenatal assessment in the absence of pregnancy complications. Retrieved from http://www.ranzcog.edu.au/component/docman/doc download/958-c-obs-3

Smith, M. (2010). General considerations and causes of anaemia and iron deficiency. Retrieved from http://redbook.streamliners.co.nz/7933.htm

Spiby, H. \& Munro, J. (2010). Evidence based midwifery: current status and future priorities. In Evidence - Based Midwifery (167-XVII). Retrieved from http://search.proquest.com.helicon.vuw.ac.nz/docview/189244700/1368026 $\underline{7 \mathrm{~B} 9 \mathrm{C} 2505}$

Singh, K., Fong, Y.F., \& Kuperan, P. (1998). A comparison between intravenous iron polymaltose complex (Ferrum Hausmann) and oral ferrous fumarate in the treatment of iron deficiency anaemia in pregnancy in pregnancy. European Journal of Haematology, 60, 119-124.

Thomas, W., Hinchliffe, R., Briggs, C., Macdougall, I., Littlewood, T., \& Cavill, I. (2013). Guidelines for the laboratory diagnosis of functional iron deficiency. British Journal of Haematology, 161(5), 639-648. doi: 10.1111/bjh.12311

Thurnham, D., McCabe, L., Haldar, S., Wierenga, F., Northrop-Clewes, C., \& McCabe, G. (2010). Adjusting plasma ferritin concentrations to remove the effects of subclinical inflammation in the assessment of iron deficiency: a meta-analysis. American Journal of Clinical Nutrition, 2010(92), 546-55. doi: 10.3945/ajen.2010.29284

Vandenbroucke, J., von Elm, E., Altman, D., Gotzsche, P., Mulrow, C., Pocock, S., ...Egger, M. (2007). Strengthening the Reporting of Observational Studies in Epidemiology (STROBE): Explanation and Elaboration. PLoS Med 4(10): e297. doi:10.1371/journal.pmed.0040297 
Victoria University of Wellington. (2014). Human Ethics Policy. Retrieved from http://www.victoria.ac.nz/documents/policy/research-policy/human-ethicspolicy.pdf

Waldie, K., Peterson, E., D'Souza, S., Underwood, L., Pryor, J., Atatoa-Carr, P., Grant, C., \& Morton, S., (2015). Depression symptoms during pregnancy: Evidence from Growing up in New Zealand. Journal of Affective Disorders, 186(Nov), 6673. doi: 10.1016/j.jad.2015.06.009.

Walsh, T., O’Broin, S., Cooley, S., Donnelly, J., Kennedy, J., Harrison, R., McMahon, C., \& Geary, M. (2011). Laboratory assessment of iron status in pregnancy. Clin Chem Lab Med, 49 (7), 1225-1230. doi: 10.1515/CCLM.2011.187

Wang, W., Knovich, M., Coffman, L., Torti, F., \& Torti, S. (2010). Serum ferritin: past, present and future. Boichim Biophys Acta, 1800(8), 760-769. doi: 10.1016/j.bbagen.2010.03.011

Wiegerinck, W., \& Mole, B. (2012). Insufficient evidence supporting iron supplementation in pregnancy. Ned Tijdscher Geneeskd, 156(2), A4293. Retrieved from http://www.ntrg.nl/artikeln/onvoldoende-bewijs-voorijzersuppletie-bij-anemishe-zwangeren

Van Wyck, D.B., Martens, M.G., Seid, M.H., Baker, J.B., \& Mangione, A. (2007). Intravenous ferric carboxymaltose compared with oral iron in the treatment of postpartum anaemia: a randomized controlled trial. The American College of Obstetricians and Gynaecologists, 10(2), 267-278. doi: 10.1097/01.AOG.0000275286.03283.18

World Health Organisation. (1968).Nutritional anaemias: report of a World Health Organisation scientific group. Geneva: World Health Organisation. Retrieved from http://www.apps.who.int/iris/bitstream/10665/40707/1WHO

World Health Organisation. (2000). The management of nutrition in major emergencies. Geneva: World Health Organisation, 2000, 1-289. Retrieved from http://www.apps.who.int/iris/handle/10665/42085

World Health Organisation. (2011). Serum ferritin concentrations for the assessment of iron status and iron deficiency in populations. Vitamin and Mineral Nutrition Information System. Geneva, World Health Organisation, 2011, 1-5. Retrieved from http://www.who.int/vmnis/indicators/serum ferritin

Zeng, L., Cheng, Y., Dang, S., Yan, H., Dibley, M., Chang, S., \& Kong, L., (2008). Impact of micronutrient supplementation during pregnancy on birth weight, duration of gestation, and perinatal mortality in rural western China: Double blind 
cluster randomised controlled trial. British Medical Journal, 2008(337), 1-11. doi: 10.1136/bmj.a.2001

Ziaei, S., Norrozi, M., Faghihzadeh, S., \& Jafarbegloo, E. (2007). A randomised placebo-controlled trial to determine the effect of iron supplementation on pregnancy outcome in pregnant women with haemoglobin $\geq 13.2 \mathrm{~g} / \mathrm{dl}$. International Journal of Obstetrics and Gynaecology, 2007(114), 684-688. doi: 10.1111/j.1471-0528.2007.01325.x 


\section{List of Appendices}

Appendix A: Victoria University of Wellington Ethics Approval

Appendix B: District Health Board Ethics Approval

Appendix C: Participant Information sheet

Appendix D: LMC midwives antenatal decision tree: Serum ferritin tested in the first trimester

Appendix E: LMC midwives antenatal decision tree: Serum ferritin not tested in the first trimester

Appendix F: LMC midwives postpartum decision tree 